\title{
Performance effects and complementarity of internal, cooperative and external R\&D
}

Citation for published version (APA):

Lokshin, B. (2005). Performance effects and complementarity of internal, cooperative and external R\&D. [Doctoral Thesis, Maastricht University]. Universitaire Press Maastricht.

https://doi.org/10.26481/dis.20050907bl

Document status and date:

Published: 01/01/2005

DOI:

10.26481/dis.20050907bl

Document Version:

Publisher's PDF, also known as Version of record

\section{Please check the document version of this publication:}

- A submitted manuscript is the version of the article upon submission and before peer-review. There can be important differences between the submitted version and the official published version of record.

People interested in the research are advised to contact the author for the final version of the publication, or visit the DOI to the publisher's website.

- The final author version and the galley proof are versions of the publication after peer review.

- The final published version features the final layout of the paper including the volume, issue and page numbers.

Link to publication

\footnotetext{
General rights rights.

- You may freely distribute the URL identifying the publication in the public portal. please follow below link for the End User Agreement:

www.umlib.nl/taverne-license

Take down policy

If you believe that this document breaches copyright please contact us at:

repository@maastrichtuniversity.nl

providing details and we will investigate your claim.
}

Copyright and moral rights for the publications made accessible in the public portal are retained by the authors and/or other copyright owners and it is a condition of accessing publications that users recognise and abide by the legal requirements associated with these

- Users may download and print one copy of any publication from the public portal for the purpose of private study or research.

- You may not further distribute the material or use it for any profit-making activity or commercial gain

If the publication is distributed under the terms of Article $25 \mathrm{fa}$ of the Dutch Copyright Act, indicated by the "Taverne" license above, 


\section{PERFORMANCE EFFECTS AND COMPLEMENTARITY OF INTERNAL, COOPERATIVE, AND EXTERNAL R\&D}


Performance effects and complementarity of internal, cooperative, and external R\&D

C B. B. Lokshin, Maastricht 2005

Universitaire Pers Maastricht

ISBN 9052784787

Niets uit deze uitgave mag worden verveelvoudig en/of openbaar gemaakt door middel van druk, fotokopie, microfilm, of welke andere wijze dan ook, zonder voorafgaande, schriftelijke toestemming van de houder van het auteursrecht. 


\title{
PERFORMANCE EFFECTS AND COMPLEMENTARITY OF INTERNAL, COOPERATIVE, AND EXTERNAL R\&D
}

\author{
PROEFSCHRIFT
}

TER VERKRIJGING VAN DE GRAAD VAN DOCTOR AAN DE UNIVERSITEIT MAASTRICHT,

OP GEZAG VAN DE RECTOR MAGNIFICUS, PROF. MR. G.P.M.F. MOLS VOLGENS HET BESLUIT VAN HET COLLEGE VAN DECANEN,

IN HET OPENBAAR TE VERDEDIGEN

OP WOENSDAG 7 SEPTEMBER 2005 OM 1.6.00 UUR DOOR

BORIS LOKSHIN

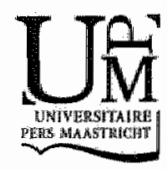


Promotors:

Prof. Dr. M. A. Carree

Prof. Dr. R. A. Belderbos (Katholieke Universiteit Leuven)

Beoordelingscommissie:

Prof. Dr. P. A. Molmen (voorzitter)

Prof. Dr. L.L.G. Soete

Prof. Dr. R. Veugelers (Katholieke Universiteit Leuven) 
To my parents 



\section{Table of Contents}

Acknowledgements $\quad$ xi

CHAPTER 1 Introduction

1.1 The context of the study $\quad 2$

1.2. Outline of the thesis $\quad 7$

$\begin{array}{ll}1.3 \text { Data and units of analysis } & 10\end{array}$

1.4 Publications and dissemination of research 11

CHAPTER 2 Heterogeneity in R\&D Cooperation Strategies 13

2.1 Introduction. 14

2.2 R\&D Cooperation: theoretical and empinical models $\quad 15$

2.3 Empirical model, data, and estimation method $\quad 19$

$\begin{array}{ll}2.4 \text { Empirical Results } & 28\end{array}$

2.5 Conclusion $\quad 35$

Appendix A Description of Variables 37

Appendix B.1 Individual probit results for the full sample 39

Appendix B.2 Individual probit results for the new cooperation sample 41

Appendix C Auxilliary regression $\quad 43$

Appendix D Correlations $\quad 44$

CHAPTER 3 Cooperative R\&D and Firm Performance 45

3.1 Introduction $\quad 46$

$\begin{array}{ll}3.2 \text { Previous Literature } & 47\end{array}$

3.3 Empirical model, data and descriptive statistics $\quad 50$

3.4 Empirical Results $\quad 58$

$\begin{array}{ll}3.5 \text { Conclusions } & 61\end{array}$

Appendix A Description of Variables 63

Appendix B Correlations 65

$\begin{array}{ll}\text { Appendix C Some selected previous studies } & 67\end{array}$

CHAPTER 4 Testing for complementarity and substitutability in case of multiple practices $\quad 69$

4.1 Introduction $\quad 70$

4.2 Complementarity and substitutability 71

$\begin{array}{ll}4.3 \text { The testing procedure } & 73\end{array}$

4.4 Empirical illustration $\quad 76$

4.5 Conclusion $\quad 80$ 
CHAPTER 5 Complementarity in R\&D cooperation strategies

5.1 Introduction

5.2 Literature review

5.3 Testing for Complementarity

5.4 Empirical model, Data, and Descriptive statistics

5.5 Empirical results

5.6 Conclusions

Appendix A Description of Variables

Appendix B Means and Standard Deviations of Variables

Appendix D Log-Likelihood values of the complementarity tests

CHAPTER 6 The productivity effects of internal and external R\&D:

Evidence from a dynamic panel data model $\quad 107$

6.1 Introduction

6.2 External and internal technology sourcing

6.3 Model construction and estimation techniques

6.4 Estimation results

6.5 Concluding remarks

Appendix 6A Results with R\&D cooperation

CHAPTER 7 Conclusions and limitations

7.2 Limitations and future research

References

Nederlandse samenvatting (Summary in Dutch) 


\section{List of Tables}

Table 2.1 Distribution of cooperation cases 21

Table 2.2 Descriptive statistics $\quad 22$

Table 2.3 Results of multivariate probit analysis of R\&D cooperation 28

Table 2.4 Multivariate probit results for new R\&D cooperation 33

Table 3.1 Distribution of firms across industries and R\&D cooperation strategies 56

Table 3.2 Descriptive statistics for different R\&D cooperation profilles $\quad 57$

Table 3.3 Regression results for productivity growth, 1996-1998 59

Table 4.1 Descriptive statistics $\quad 76$

Table 4.2 Unconstrained and constrained models, 3 practices 78

Table 4.3 Unconstrained OLS results 79

Table 4.4 Complementarity results obtained by interacting dummies $\quad 79$

Table 5.1 Distribution of firms across industries and R\&D cooperation strategies 93

Table 5.2 Contingency table: Distribution of cooperation cases 94

Table 5.3 Estimates of Equation 95

Table 5.4 Tests for complementarity and substitutability 99

Table 6.1 Variables used in estimation and descriptive statistics $\quad 115$

Table 6.2 Means across years $\quad 116$

Table 6.3 Means according to R\&D intensity quintiles $\quad 117$

Table 6.4 Distribution of firms across industries $\quad 118$

$\begin{array}{ll}\text { Table } 6.5 \text { Main results } & 120\end{array}$

\section{List of figures}

$\begin{array}{ll}\text { Figure 6.1 Plot value function } & 121\end{array}$

$\begin{array}{ll}\text { Figure 6.C1 Graphical sollution internal rate of return } & 128\end{array}$ 



\section{Acknowledgements}

This monograph is a result of the research carried out in the period August 2002 March 2005 at the Department of Economics and Business Administration of the University of Maastricht. I am grateful to a number of people whose help and encouragement were invaluable and instrumental in the work's progression and its fruitful completion.

First of all, I would like to thank my supervisors, René Belderbos and Martin Carree, for their guidance and support. Their first words of encouragement came during our get-to-know conversation in the Fall 200.1 at a dinner at $A u$ Coin des Bons Enfants. Contrary to what some may believe, not the superiority of European gastronomy, but our conversation back then convinced me to move from the United States to Maastricht and to take up the project, predicting that the research environment at the University of Maastricht would be pleasant and productive. Little did I know that by the time this book was completed René Belderbos would become the department chair at Katholieke Universiteit Leuven and Martin Carree the head of Organization \& Strategy department at Maastricht University. Their knowledge and experience helped me grow and their enthusiasm for the supervision, despite their consuming duties, made this experience lively. Iterations (always converging) in our discussions, without doubt, raised the quality of this work and were invaluable in discovering the errors in my papers. René Belderbos and Martin Carree are also co-authors of the two publications originating from the thesis and I am grateful to them for allowing me to include our joint work in this book.

Data availability and their quality largely determine the success of empirically based research. The cases when a researcher spends the first years of writing of a $\mathrm{Ph}$.D. dissertation on data collection/entry are not uncommon. I am gratefull to Bert Diederen of CEREM, CBS Heerlen, for sharing his knowledge of the CIS/Micronom database with me. Without his expertise the period between our first conversation and the journal acceptance of my first paper would be much longer. Other CBSers, namely, Bert Balk and George van Leeuwen, were always interested in our research output, providing an excellent forum in the form of the CEREM meetings, to share the ideas and papers. The essays presented in this thesis have also benefited from discussions and criticall comments of the participants of the various conferences and workshops where this research was presented.

Several other people helped me during the research years in various ways. Pierre Mohnen, Franz Palm, Luc Soete, Reinhilde Veugelers commented on my work at various stages and pointed to the relevant literature. Reinhilde Veugelers was also a co-author of the first empirical chapter in this book. I also wish to thank the colleagues at the department of Organization \& Strategy. Mieke van Zutphen often helped me find the way out of confusion about various regulations, internal procedures and accommodation after my arrival from the States. Kitty van Straaten, Adela Buttolo, and Eva Nelissen could always patiently answer my questions 
dealing with administration. Alex and Helen Grigorievs had set on the path to Ph.D. before me and have been always generous in sharing their experience, but also a beer once in a while.

Finally, I would like to thank my family for their enduring support and encouragement. My wife Helen who could always create a new home after each time we changed a continent; my mom and dad who always supported me unconditionally. Without them II would never have got this far.

Boris Lokshin

Maastricht, Summer 2005 


\section{CHAPTER 1}

\section{Introduction}

The rapid rise in the number of inter-firm R\&D partnerships in the last two decades $(\mathrm{OECD}, 2002,1992)$ has attracted considerable academic interest to this phenomenon. This trend is first and foremost caused by the significant increase in contracted-out and cooperative forms of $R \& D$ in the developed economies. According to the National. Science Foundation report (2002), these developments are reflected through the growth of contracted and cooperative R\&D outpacing the increase in of firms' purely internal $R \& D$ in the recent years. To explain this development it is useful to keep in mind that the process of production of knowledge is characterized by its relatively high fixed cost and risks associated with uncertain commercial profitability of innovations. This is why a cost-related motive such as sharing of resources has been posited to be an important rationale behind R\&D cooperation. However, albeit important, it is only one of the incentives that make R\&D collaboration attractive. There is growing evidence that firms no longer rely exclusively on their internal $R \& D$ activities. Such factors as increased demand on technological competence of firms, shortening product innovation cycles, and declining transaction costs of acquiring external $R \& D$ inputs have made cooperative $R \& D$ and contracted-out $R \& D$ more compelling for firms. Sharing of knowledge as a means to accelerate creation of new knowledge capital and to increase welfare has also become an important policy issue.

The economic significance of this phenomenon explains why ongoing academic research in this area is expanding, contributing to a live policy debate. In Europe promotion of innovation, and of joint R\&D research effort, is one of the dimensions of the policy for making the EU the most competitive knowledge-based economy in the world. The policy of 'developing a European area for innovation, research and development' is one of the cornerstones of the Lisbon agreement, considered to be critical for national competitiveness declared by Europe's heads of states in March 2000. The EU block as a whole currently lags behind the US and Japan on the share of national income spent on R\&D and scores lower than the US on seven out of eight Lisbon dimensions (Lisbon Review, 2004). The European Commission, in recognition of the challenges posed by the Lisbon agenda, has recently set out plans that call for enhancing collaboration among countries and facilitation of public-private research collaboration (European Commission, April 2005). Economists agree that these stimuli are vital if the European Union is to succeed in its transformation into a knowledge-based economy capable of delivering new high-technology innovations. At the same, time the economic issues around fostering of innovation and promoting knowledge-based economy are of interest for academic researchers who ponder over incentives that best reward inventors, answer questions of what is the optimal form of organization of research 
and development, which R\&D strategies are effective and lead to higher innovation rate and increased productivity, and how these strategies interact and complement each other.

This dissertation presents an analysis of internal, cooperative, and contractedout R\&D among innovating companies. It does so by providing an understanding of the determinants of collaborative R\&D and its effect on firm productivity and innovative performance. The study also brings out the dynamic links between $R \& D$ and performance, and examines complementarity between internal, external and cooperative R\&D strategies. The thesis intends to contribute to our understanding in the field of innovation by developing and applying advanced econometric techniques to a rich and previously less explored panel dataset of firms in the Netherlands. The data come from three waves of the Dutch Community Innovation Survey (CIS) and are collected at the bedrijf eenheid (establishment) level using the combination of census (large enterprises) and stratified sampling (small and medium size enterprises) techniques. The main issues examined in this thesis are introduced to the reader in the first section of the introduction chapter below. There are five self-contained empirical essays in this thesis. Common themes that unify the essays are innovation strategies and their contribution to productivity, and growth in manufacturing and service production.

The remainder of this introductory chapter is organized as follows. In section 1.1 we present a short overview of the literature that serves as context for this thesis. The following section, 1.2 provides an outline of the separate chapters of the thesis. and their main contributions. The chapters in this thesis are empirical in nature. Section 1.3 gives a short introduction to the data and unit of analysis used in them. It is followed by a summary of the publications, which form the basis for the chapters of this thesis and dissemination of research.

\subsection{The context of the study}

In the corresponding parts of this section we summarize the major streams of research and issues around which the essays of this thesis are written. We begin with the overview of the literature devoted to the determinants of innovation activities, a background for Chapter 2. The following subsection discusses some major developments in research that links innovation to firm performance and explains how Chapter 3 of this thesis aims to contribute to this literature. The final subsection discusses the developments in the literature on complementarity, which serves as motivation for Chapter 4, Chapter 5 and partly Chapter 6.

\section{Determinants of innovation activities}

Over the past three decades, a large body of empirical literature has developed on the determinants and effects of innovative activities. These developments have 
recently been surveyed, among other, by Cohen, 1995, Griliches, 1995, and Hall and van Reenen, 2000. A number of research traditions can be distinguished, which we briefly discuss in turn. Much attention has been paid to the Schumpeterian hypotheses examining the relationship between firm size, market structure and firm's R\&D investment (Cohen and Klepper, 1996; Levin and Reiss, 1984; Pakes and Schankerman, 1984). Overall, the results have suggested that there is no systematic relationship between firm size and R\&D intensity. Large firms do appear to be less productive in $\mathrm{R} \& \mathrm{D}$, but are able to sustain larger $\mathrm{R} \& \mathrm{D}$ expenditures because they expect higher, scaleable, returns to innovation (Cohen and Klepper, 1994). With respect to market power, the literature has suggested an inverted U. shaped relationship with too little or too much competition in the industry not conducive to innovation. Studies of R\&D investment have also specifically examined the Schmooklerian hypothesis of a major impact of potential demand and consumers' willingness to pay for innovations (e.g. Brouwer and Kleinknecht, 1999; Cohen and Klepper, 1996; Goto et al., 2002).

Another stream of research has focused on the role of internal finance as a facilitator of R\&D (Acs and Isberg, 1991; Bhagat and Welch, 1995; Himmelberg and Petersen, 1994). A related stream of research examined the effects of fiscal R\&D incentives and R\&D subsidies (Hines, 1994; Klette et al., 2000; and David et al., 2000 for a survey of studies on the impact of R\&D subsidies; and Hall and van Reenen, 2000 for a survey of studies on the role of fiscal incentives). Conflicting answers were given to the question whether public R\&D crowds out private R\&D. Many studies, especially at the aggregate level, found a positive effect of government funding and tax incentives on privately financed R\&D (e.g. Levy, 1990; Lichtenberg, 1987; Mamuneas and Nadiri, 1996; Robson, 1993). At the firm level, however, the results are more ambiguous with several recent studies arguing that public $R \& D$ crowds-out private $R \& D$, i.e. they are substitutes (Toivanen and Niininen, 2000; Wallsten, 2000) or, alternatively, complements for business R \&D (Busom, 2000; Holemans and Sleuwaegen, 1988; Guellec and van Pottelsberghe, 2003; Garcia-Quevedo, 2004 for surveys). More recent work on firm level R\&D investment has re-examined the impact on $R \& D$ investment of technological opportunity conditions and the extent to which results from innovative activities can be appropriated (Crépon et al., 1998; Levin and Reiss, 1984). Technological opportunity conditions depend on the importance of different sources of information, the science based nature of technology and the cumulativeness of knowledge. Appropriability depends on patent protection, and other, frequently more important, mechanisms to prevent diffusion of know-how, such as secrecy and lead time (Cockburn and Griliches, 1988; Cohen and Levin, 1989; Hanel and StPierre, 2002; Saviotti, 1998) that in turn, affects firm's strategic decisions such as timing of the commercialization of the product (Dechenaux et al., 2003) and engagement in cooperative R\&D (Cassiman and Veugelers, 2002; Panagopoulos, 2003). 
Another stream of research has examined R\&D cooperation between firms. A number of previous studies, primarily in the strategic management literature, have examined R\&D cooperation in the form of R\&D joint ventures and strategic R\&D alliances as a different mode of $R \& D$ organization. In general these studies have established a positive correlation between internal $R \& D$ and $R \& D$ cooperation (e.g. Duysters and Hagedoorn, 1996; Kleinknecht and Reijnen, 1992 and the survey in Hagedoorn et al., 2000). The management literature has typically analyzed cooperation within a transaction costs and resource-based framework (Tyler and Steensma, 1995). The transaction cost approach describes alliances as a hybrid form of organization combining aspects of hierarchical transactions within the firm and arm's-length transactions in the market place. Cooperation may reduce transaction costs through a better control and monitoring of technology transfer than on arm's length markets, while the inherent reciprocal relationship and "hostage" exchange between partners with complementary capabilities can minimize opportunism (e.g. Pisano, 1990; Hennart, 1988). The resource-based view of the firm suggests that the rationale for partnerships is the value-creation potential of pooling together firms' resource bases. Cooperation is viewed as a mechanism to maximize firm value through effectively combining the resources of the partners by exploiting complementarities (Das and Teng 2000; Hagedoorn, Link and Vonortas 2000; Kogut, 1988).

The industrial organization literature, on the other hand, has focused on the relationship between spillovers and $R \& D$ cooperation. The essays presented in this book take primarily the I.O. approach. The empirical literature on R\&D cooperation and alliance literature have developed largely independent from the theoretical, mainly industrial organization literature on strategic $R \& D$ investment, research joint ventures, and spillovers (e.g. Kamien and Zang, 2000, Kesteloot and Veugelers, 1995 and the survey in DeBondt, 1996). In summary, the IO literature suggests that spillovers (here we stress incoming or received spillovers) increase incentives to cooperate in particular if cooperation allows firms to enhance knowledge transfers among the collaborating partners. However, if incoming spillovers are associated with outgoing spillovers they have a more ambiguous effect on competitor collaboration as collaborating product market rivals benefit more from a firm's R\&D effort. These appropriability considerations have been found to be of much less importance for vertical (supplier, customer) and institutional collaboration.

The determinants of horizontal, vertical and university $R \& D$ cooperation are the focus of Chapter 2 of this thesis. It is partly motivated by an observation that vertical linkages (customers, suppliers) and R\&D cooperation with universities are as frequent as cooperation with competitors. Therefore, we model the simultaneous decision to engage in these four types of cooperation agreements. This chapter aims to build on the existing Industrial Organization (IO) literature that has previously extensively examined the incentives of R\&D cooperation among competing firms focusing on the role of R\&D spillovers and appropriability and theoretical contributions in the management literature that have stressed that R\&D 
collaboration stems from the search for complementary know-how between partner firms.

\section{R\&D, imnovation strategles and performance}

In a Schumpeterian framework, the impact of R\&D and innovation on firm growth and performance, and vice versa, plays a central role. Griliches (1995, pp.75-81) notes that there is a shortage of studies that reveal this inter-linkage. The impact of R\&D activities on performance has primarily been analyzed by treating R\&D investment as contributing to the firm's knowledge base, considering the latter a production factor that can potentially increase capital and labor productivity (see Mairesse and Sasenou; 1991; Branstetter, 2001; Crépon et al., 1998, Fors, 1996; Klette and Johanson, 1998; Klette, 1996; Lööf, 2002 and the overview in Griliches, 1995). An important issue in this literature is the productivity increase from knowledge spillovers, both intra- and inter-firm. Inter-firm or extermal transfers of technology have also been examined with specific reference to the role of multinational firms' manufacturing and R\&D activities in host countries (see Bertschek, 1995; Aitken et al., 1997; Globerman, 1979; Branstetter, 2000; and the review in Blomstrom and Kokko, 1998). A relatively large number of studies have focused on the determinants of R\&D internationalization decisions by firms and the management and organizational aspects of cross border R\&D networks (e.g* Belderbos, 2001; Kuemmerle, 1998). These findings relate to a larger body of literature on the degree of localization of spillovers and know-how (e.g. Audretsch and Feldman, 1996; Verspagen, 1999).

A number of important issues have not yet received due attention in the literature. Very few studies have attempted to estimate the impact of R\&D on performance measures other than productivity or have studied the dynamic links between innovation and performance (Cohen, 1995, p. 197). A major exception is Geroski et al. (1993) who estimate the impact on profits of the introduction of major innovations in UK firms over a period of 20 years and find significant direct and. indirect effects of innovations for innovators and user industries. In addition, onlly very few empirical studies examine all types of innovation strategies such as internal, external, R\&D cooperation in conjunction and have linked innovation strategies to firm performance. The papers presented in this thesis, especially Chapter 3, Chapter 5 and Chapter 6, aim to fill this gap. The performance effects of innovative strategies, and more particularly the degree to which forms of internal, external, and collaborative R\&D activities are complements or substitutes, are analyzed using the productivity approach linking combinations of R\&D modes to innovation output and performance. An advantage of the time dimension in the presented analysis is that it allows reducing the simultaneity bias, which has hampered previous research (e.g. Veugelers and Cassiman, 1999). In particullar, Chapter 3 examines in detail the effects of partner-specific cooperation strategies on firm performance. Several performance measures are examined: direct measures of 
innovation output such as the sales of innovative products as well as the effects of innovation on sales and productivity growth.

\section{Complementarity in innovation strategies}

Researchers in the fields of industrial organization and management have long been interested in investigating complementary relations between various organizational practices of a firm. To assess complementarity between innovation strategies, two approaches can be followed. One approach stems from the notion that if two innovative strategies are mutually reinforcing each others' productivity, they are more likely to be chosen simultaneously. Applying this adoption approach and controlling for observable firm differences, Arora and Gambardella (1990) find evidence for the US biotechnology sector of complementarity among different external sourcing strategies, such as cooperative agreements and acquisitions. Unfortunately, in the presence of unobserved heterogeneity a finding of positive correlation among different innovation activities is not sufficient to conclude that they are complementary (Athey and Stern, 1998). A methodologically more robust, a so called productivity approach, taken in Chapter 5 , is to examine directly the link with productivity or profitability: complementarity can be established when firms that are combining innovative strategies have a higher (innovative) performance as compared to firms relying on single innovation strategies. For example, Basant and Fikkert (1996) use this approach to examine the productivity effects of licensing and R\&D by Indian Firms. Other examples of studies of complementarity in the economics and management literature are the relationships between human resource practices and firm strategy (Tchniowski et al., 1997), firms" internal R\&D and external technology sourcing (Arora and Gambardella, 1994), different government innovation policies (Mohnen and Röller, 2005), information technology, workplace reorganization, and new product and service innovations (Bresnahan et al, 2002; Caroli and van Reenen, 2001), computerization, language and skills (ter Weel, 2002; Berman et al., 2003; Levy and Murnane, 1996) the adoption of different information technologies in emergency health care (Athey and Stern, 2002), and process and product innovation (Miravete and Pemias, 2004). To date, the only application to R\&D strategy of firms in a developed country is a recent working paper by Cassiman and Veugelers (2002). Using innovation data for Belgian manufacturing firms, they find that a combination of acquiring external know-how and internal $\mathrm{R} \& \mathrm{D}$ ensures the best innovative performance.

Chapter 5 contributes to this growing field by examining complementarity between four R\&D cooperation strategies. It examines whether different types of R\&D partnerships are complementary, i.e. whether forming a new alliance in $R \& D$ enhances the effectiveness of other existing R\&D collaborations. Such a synergy, or complementarity, is assumed to exist if the implementation of one practice or strategy increases the marginal return to other practices. To evaluate the complementarity effects, an appropriate testing framework, developed in Chapter 4, 
is applied that can be used for multiple practices when these practices are measured by discrete or continuous variables. All previous research ${ }^{1}$ on complementarity between multiple strategies has drawn conclusions on the basis of the effect of the interaction term between each possible pair of practices. Chapter 4 of the book shows that when more than two decision variables are present, the conclusions derived from pair wise interactions can be misleading. An important contribution of Chapter 4 of the thesis is that it develops a more robust testing procedure and then applies it in Chapter 5 .

A specific line of research has examined firms' choices between internal (inhouse) R\&D and external technology sourcing, such as procurement of licenses and outsourcing of contract research (Deolikar and Evenson; 1989; Braga and Willmore, 1991; Veugelers, 1997; Mackun and MacPherson, 1997; den Hertog and Thurik, 1993; Blonigen and Taylor, 2000). Most of this literature has concentrated on finding determinants of the exclusive choice of internal or external innovation strategies, ignoring the possible complementary relationship between internal and external R\&D. One contribution of Chapter 6 to this literature is in addressing this issue. Combining internal and external sourcing strategies can create synergies, since internal R\&D allows for more effective screening and utilization of external know-how (Arora and Gambardella, 1994; Cassiman and Veugelers, 2002). On the other hand, external sourcing of technology licenses may reduce the marginal productivity of own $R \& D$, indicating that internal and external innovations are substitutes in the context of firms based in developing countries (Basant and Fikkert 1996). The last part of the thesis is devoted to the study of internal vs. external $R \& D$ technology acquisition. No matter how extensive the R\&D cooperation might be, an innovative firm is likely to benefit from it if it has sufficient absorptive capacity. Previous research (e.g. Cohen and Levinthal, 1989; Griffith et al, 2004) has stressed two functions performed by own R\&D: as an active stimulus for innovation and productivity growth and its role as absorptive capacity. Chapter 6 examines these roles played by internal R\&D but also looks at the interaction between internal and external knowledge sources. The analysis in this chapter is based on a dynamic panel data model, which utilizes some newly developed econometric techniques.

\subsection{Outline of the thesis}

The main body of the thesis consists of five empirical essays, followed by a short conclusion. This section provides a short overview of the empirical chapters.

Chapter 2 explores heterogeneities in the determinants of innovating firms' decisions to engage in $R \& D$ cooperation, differentiating between four types of cooperation partners: competitors, suppliers, customers, and universities and

\footnotetext{
'One notable exception is Mohnen and Röller, 2005.
} 
research institutes (institutional cooperation). The contribution of this chapter compared to previous work in this area is three-fold. First, while most previous studies have not been able to disaggregate R\&D cooperation over different types of partners, we explicitly differentiate between the determinants of different types of cooperation. Second, while most previous studies have investigated different R\&D partnerships in separate models, we apply a system method of estimation (MVP) for limited dependent variables to reflect that firms consider simultaneously the decisions to cooperate with various partners. Third, previous studies only had a cross-section data at their disposal, and hence have grappled with the problem of a simultaneous relationship between $R \& D$ cooperation on the one hand, and major determinants R\&D intensity and spillovers on the other. Using panel data from Dutch Community Innovation Survey (CIS) surveys in 1996 and 1998, the chapter links lagged determining variables from 1996 to R\&D cooperation activities from CIS 1998. In this way the simultaneity bias between cooperation and its determinants is reduced, in particular between R\&D intensity and spillovers. In the second part of the analysis we further check the robustness of results by estimating a model limiting the estimation sample to firms initiating new R\&D cooperation in the 1996-1998 period. For this specific sub-sample, the problem of simultaneity can be assumed to be absent. Chapter 2 shows that there is substantial merit in disaggregating R\&D cooperation by type of partner and that there are substantial differences in the motives and determinants of the different types of cooperation.

In Chapter 3 we turn to the analysis of the key question whether R\&D cooperation has an impact on firm (innovation) performance. Similar to the analysis in Chapter 2 , we consider the impact of the four major types of partner-specific cooperation strategies: cooperation with competitors, suppliers, customers, and universities and research institutes. We consider two performance measures: labor productivity and productivity in innovative, i.e. new to the market sales. Using data on a large sample of Dutch innovating firms in two waves of the Community Innovation Survey (1996, 1998), linked to production statistics, we examine the impact of R\&D cooperation in 1996 on subsequent productivity growth in 1996-1998. The results confirm a major heterogeneity in the rationales and goals of $R \& D$ cooperation.

Chapter 4 is different from the other chapters in the dissertation in that its contribution is in a new testing method for complementarity, research on which has become recently more frequent in the innovation field. In the first place, the chapter is motivated by the lack of appropriate econometric tools necessary for the complemetarity analysis between multiple organizational practices/innovation strategies, measured dichotomously. Such analysis is performed in Chapter 5 . The chapter is more technical in nature with the objective to build necessary tools that are used in a subsequent part of the dissertation. It discusses a number of recent empirical studies of firm-level productivity that have been concerned with 
establishing potential complementarity between multiple organizational design practices. Complementarity is understood in this context to exist if the implementation of one practice increases the marginal or incremental return to other practices. Thus, a joint implementation of several practices may result in economies of scope. By the same token the implementation of one practice can decrease the marginal or incremental return to other practices. This is the case of substitutability (sub-additivity). We note that the previous research has drawn conclusions on the basis of the effect of the interaction term between each possible pair of practices. In this chapter, we show that this approach may lead to misleading results in case more than two practices are considered. The chapter proceeds with developing a proper testing procedure for complementarity and substitutability in case there are multiple organizational practices that affect output. We also discuss how the testing framework can easilly be applied to test for supermodularity.

Chapter 5 takes its motivation from industrial organization and alliance literature emphasizing the complexity of rationales behind cooperative strategies. However, despite the growing literature on R\&D cooperation in both the fields of management and industrial economics, surprisingly little evidence has emerged on the interaction of different cooperation strategies in innovation. Having built the necessary econometric framework in the previous section of the thesis, Chapter 5 assesses the performance effects of such simultaneous engagement in R\&D cooperation with different partners and tests whether these different types of R\&D cooperation are complements in improving productivity. The results suggest that the joint adoption of cooperation strategies could be either beneficial or detrimental to firm performance, depending on the specific combination of strategies and firm size. Customer cooperation helps to increase market acceptance and diffusion of product innovations and so enhances the impact of competitor and university cooperation. On the other hand, smaller firms in particular also face diseconomies in pursuing multiple R\&D cooperation strategies, which may stem from higher costs and complexity of simultaneously managing multiple partnerships with different innovation objectives.

The analysis presented in Chapters 2,3 and 5 serves hopefully as an intuitive and tractable approach to understanding firm-level productivity and heterogeneity in various types of $R \& D$ cooperation strategies. It also provides sufficient argument for the thesis that empirical work examining contribution of several organizational practices to firm performance should also consider complementarities between these practices. Due to the nature of the CIS data, namely that the key variables are measured as binary variables, the preceding analysis could not examine the economies of scale, alongside with the economies of scope of innovation strategies. At the same time, while the use of two waves of surveys was a step forward compared to the bulk of previous research that used cross-sectional data, it could not properly address two important issues: the first is an issue of persistency of 
productivily differences among firms, i.e. some firms being persistently more productive than others and/or persistent in R\&D effort for a long period of time; a second issue is heterogeneity. While the models in chapters $2,3,5$ tried to take persistency into account through a partial adjustment mechanism, it is the panel data analysis that allows properly addressing both issues.

The design of Chapter 6 was to address the abovementioned issues ${ }^{2}$ by applying a robust panel-data model to examine the complementarity between intemal and external R\&D. The thesis" last empirical chapter examines the impact of internal and extemal R\&D on labor productivity in a 6-year panel of 372 innovating firms. Applying a dynamic linear panel data model we find positive impacts of both types of R\&D and a negative interaction between them in a linear model. Estimation of a non-linear model revals complementarity (supermodularity) in combining internal and external R\&D (the expenditure on outsourced R\&D), which appears consistent with the frequent joint adoption of internal and external R\&D strategies. The positive effect is only evident when substantial internal R\&D is present. This finding supports the dual role played by the internal R\&D. On the one hand, it acts as absorptive capacity facilitating acquisition of extemal knowledge. On the other hand, it acts as productivity accelerator.

\subsection{Data and units of analysis}

The empirical analysis in this thesis utilizes a series of large micro-level datasets on innovative activity in Dutch firms in combination with micro data from Dutch production statistics. The unit of analysis in all the empirical chapters of this thesis is the bedrijf eenheid (establishment). These data are available at Statistics Netherlands through its CEREM project. Innovation data are drawn from a two yearly survey among manufacturing and service industry establishments in the Netherlands, set up in accordance with the guidelines from the European Union's Community Innovation Survey (CIS). The first CIS survey in the Netherlands (CIS1) was conducted in 1992 and concerns innovative activity in the years $1990-$ 1992 , covering some 2,500 business units. Because it has a relatively small number of overlapping observations with the subsequent surveys, we do not use it in this research. The second survey (CIS2) covers the years 1994-1996 and contains responses from 10,500 business units with more than 10 employees. CIS-2.5 concerns the years 1996-98. In the course of this PhD project the next wave, CIS-3, (covering the years 1998-2000) became available making possible panel-data analysis. Both CIS 2.5 and CIS 3 contain responses of up to 14,000 business units.

\footnotetext{
"It should be immediately noted, that while if would have been desirable to estimate all of the models presented in this book based on the panel data. Unfortunately, this was not feasible at the time Chapters 2 and 3 were being completed. Access to the later years of R\&D data and a third wave of CIS was made available after the first chapters had been already finalized.
} 
The business units were code-linked over time and a substantial number of business units respond in CIS2, CIS2.5 and CIS3. The business unit data in the CIS surveys are code-linked with business unit level data in the production statistics. In most cases, business units are independent firms, but in other cases they are subsidiaries of larger domestic or foreign groups. Where the wider group-level influences are important they can be taken into account through information in the CIS survey concerning group affiliation and intra group R\&D relationships. In case various establishments are part of one and the same group, the research strategy was to identify such cross establishment linkages in order to correct for group-specific factors impacting the innovation process in the various establishments.

\subsection{Publications and dissemination of research}

Chapters 2 through Chapter 6 of this thesis are based on previously written articles and papers. These papers or earlier versions thereof have been presented at various international conferences such as $30^{\text {th }}$ annual E.A.R.I.E. conference, 2003 in Helsinki (Chapter 2), ZEW workshop on "The Empirical Economics of Innovation and Patenting" in Mannheim (Chapter 2); International Network on Innovation Research ( $4^{\text {th }}$ INIR) workshop, Université Libre de Bruxelles (Chapter 2);31 ${ }^{\text {st }}$ E.A.R.I.E. conference in 2004 in Berlin (Chapter 3); DRUID conference on "Industrial Dynamics, Innovation and Development" in Copenhagen (Chapter 3); Workshop on the "Economics and Management of Science and Technology", University of Leuven (Chapter 3); The $3^{\text {rd }}$ Seminar on "Research with Microdata in the Netherlands", Statistics Netherlands in Voorburg (Chapter 4). The earlier versions of the papers have benefited from the comments of the participants of these conferences/workshops. In particular, II am grateful for helpful comments of Bronwyn Hall, Jacques Mairesse, Pierre Mohnen, Stephen Martin, Franz Palm, Reinhilde Veugelers and anonymous referees of International Joumal of Industrial Organization, and Research Policy. The papers presented in this thesis have either appeared or have been submitted to international, refereed journals. The chapters can be read independently of each other. Below is an overview of the chapters and the corresponding articles and papers.

Heterogeneity in R\&D cooperation strategies, 2004, Intemational Journal of Industrial Organization, 22(8/9), 1237-64 (with R. Belderbos, M. Carree, B. Diederen, R. Veugelers)

Cooperative R\&D and firm performance, 2004, Research Policy 33(10): 1477-92 (with R. Belderbos, M. Carree)

Testing for complementarity and substitutability in case of multiple practices. Meteor working papers series $\$ 04 / 002$, University of Maastricht.

Complementarity in R\&D cooperation strategies. Mefeor working papers series, University of Maastricht. 
Chapter 1

The productivity effects of internal and external R\&D: Evidence from a dynamie panel data model. Meteor working paper series, University of Maastricht 


\section{CHAPTER 2}

\section{Heterogeneity in R\&D Cooperation Strategies*}

We explore heterogeneities in the determinants of innovating firms' decisions to engage in R\&D cooperation, differentiating between four types of cooperation partners: competitors, suppliers, customers, and universities and research institutes (institutional cooperation). We use two matched waves of the Dutch Community Innovation Survey (in 1996 and 1998) and apply system probit estimation. We find that determinants of R\&D cooperation differ significantly across cooperation types. The positive impact of firm size, R\&D intensity, and incoming source-specific spillovers is weaker for competitor cooperation, reflecting greater appropriability concerns. Institutional spillovers are more generic in nature and positively impact all cooperation types. The results appear robust to potential simultaneity bias.

Acknowledgement: The empirical part of this research uses micro-level data provided by CEREM/Statistics Netherlands, drawing on the MICRONOOM data integration project at Statistics Netherlands supervised by Bert Diederen. The views expressed in this chapter are those of the author and do not necessarily reflect the policies of Statistics Netherlands. The comments received from two anonymous referees, Stephen Martin, and from the participants at the ZEW Workshop on "Empirical Innovation and Patenting" in Mannheim, the 30th annual EARIE Conference in Helsinki and the INIR Workshop on "The Economics of Knowledge Spillovers" in Brussels, all in 2003 are gratefully acknowledged.

*This chapter is based on the article: Heterogeneity in R\&D cooperation strategies, 2004, International Joumal of Industrial Organization, 22(8/9):1237-64 (with R. Belderbos, M. Carree, B. Diederen, and R. Veugelers) 


\subsection{Introduction}

The growing role of R\&D collaboration in firms" innovative activities (Hagedoorn, 2002) has spurred research into the determinants of R\&D cooperation and the effects of cooperative R\&D. Two major strands of theoretical literature can be distinguished. The Industrial Organization (IO) literature has extensively examined the incentives and welfare effects of $R \& D$ cooperation among competing firms, focusing on the role of $R \& D$ investments and R\&D spillovers. Theoretical contributions in the management literature have stressed that $R \& D$ collaboration aims at minimizing transaction costs and exploiting complementary know-how between partner firms (e.g. Kogut, 1988; Das and Teng 2000). Empirical work on R\&D cooperation has utilized micro-level survey data from the European Community Innovation Surveys (CIS), and has focused mainly on the impact of firm size and R\&D intensity as determinants of cooperation (Becker and Dietz, 2002; Kleinknecht and Reijnen, 1992; Leiponen, 2001; Kaiser, 2002; Veugelers, 1997).

Most of the existing literature does not distinguish R\&D cooperation by type of partner (e.g. competitors, suppliers, clients, universities) but instead aggregates over R\&D cooperation types, with some notable recent exceptions. Kaiser (2002) distinguishes between vertical cooperation (cooperation with suppliers and customers) and a mix of other $R \& D$ partnerships in analyzing cooperative $R \& D$ by German service firms. Cassiman and Veugelers (2002), using CIS-I data on Belgian firms in 1994, distinguished between university-firm cooperation and cooperation with vertically related partners, but did not consider cooperation with competitors. Fritsch and Lukas (2001) differentiate cooperation by type of partner to focus on the impact of firm size and R\&D intensity on the propensity to cooperate among German manufacturing firms. Tether (2002) distinguishes suppliers, customers, competitors, universities and consultants in his sample of UK CIS-II firms. Leiponen (2001) considers cooperation with competitors, customers, suppliers and universities using 1997 CIS data for Finnish manufacturing firms. These studies have in common that they only had cross-section data at their disposal and hence have grappled with the problem of a simultaneous relationship between R\&D cooperation and R\&D intensity and spillovers. Another feature of these studies is that they have treated the different cooperation strategies as independent, not taking into account possible correlations between the strategies that could be due to complementarities.

In this chapter we consider heterogeneity in R\&D cooperation by exploring differences in the determinants of innovating firms' decisions to establish different types of cooperation: with competitors (horizontal), with suppliers or customers (vertical), and with universities and research institutes ('institutional' cooperation). We take into account a broad set of possible explanatory variables, but we concentrate particularly on the impact of different types of spillovers, a central focus in the industrial organization literature. Furthermore, while previous studies 
have investigated the propensity to establish different types of R\&D partnerships in separate models, we allow for possible correlations between $R \& D$ cooperation strategies, by applying a system method of estimation for dichotomous variables. In addition, we are able to limit simultaneity bias by employing lagged explanatory variables utilizing two waves of Dutch CIS surveys in 1996 and 1998. We further check the robustness of the results to potential simultaneity bias by estimating a model limiting the analysis to firms that had no R\&D cooperation in 1996, examining the determinants of the propensity to establish new cooperation agreements in 1998.

The remainder of this chapter is organized as follows. The next section provides a brief overview of the theoretical and empirical literature on R\&D cooperation. Section 2.3 explains the empirical model used and describes the dataset. Section 2.4 presents the results and Section 2.5 concludes.

\subsection{R\&D Cooperation: theoretical and empirical models}

\section{Theoretical Models}

Models that seek to answer the questions why and what kinds of firms seek to perform joint research activities are grounded in several theoretical approaches. We will first review the Industrial Organization (IO) literature, after which we briefly discuss relevant literature in the domains of management and technology (policy).

The IO literature has focused on the relationship between two kinds of spillovers and R\&D cooperation. On the one hand, there are measures of the importance of external information flows for the firm's innovation process. These are incoming spillovers. On the other hand, firms attempt to appropriate the benefits of their innovations by controlling information flows out of the company. These are outgoing spillovers. Spillovers can refer to both involuntary leakage and voluntary transfers of knowledge between market participants. When spillovers are considered to be at least partly voluntary, firms that are partners in R\&D cooperation can improve on incoming knowledge transfer through information sharing (Kamien et al., 1992; Katsoulacos and Ulph, 1998). In most theoretical models of R\&D cooperation, incoming and outgoing spillovers are treated as symmetric and exogenous to the firm. When anticipated, voluntary or involuntary transfers of know-how complicate cooperative R\&D strategies in a non-trivial way (e.g. Spence, 1984; Katz, 1986; d'Aspremont and Jacquemin, 1988; De Bondt and Veugelers, 1991; Kamien et al., 1992; Suzumura, 1992; Vonortas, 1994; De Bondt, 1996; Leahy and Neary, 1997 and Katsoulacos and Ulph, 1998). A finding in most models is that spillovers increase the relative profitability of $R \& D$ cooperation once spillovers are sufficiently high, i.e. beyond a critical level (De Bondt and Veugelers, 1991). On the other hand, models considering free riding problems in joint ventures have found that higher spillovers also increase the incentives to cheat by partner 
firms and the profits from free riding by outsiders to the cooperative agreement (Kesteloot and Veugelers, 1994; Eaton and Eswaran, 1997). These results emphasize a dual role of spillovers: outgoing spillovers may jeopardize the cooperative agreement while incoming spillovers increase the attractiveness of cooperation.

More recent 10 models take into account that firms can attempt to manage spillovers, trying to minimize outgoing spillovers while at the same time maximizing incoming spillovers (Cassiman et al. 2002; Martin 1999; Amir et al. 2003). Firms can increase the effectiveness of incoming spillovers by investing in "absorptive capacity". Cohen and Levinthal (1989) show that external knowledge is more effective for the innovation process when the firm engages in own R\&D. Increased absorptive capacity through investments in internal $R \& D$ efforts thus increases the effectiveness of incoming information. In addition, the choice of research approach by the firm influences the appropriability conditions it faces and the extent of incoming spillovers it enjoys. Kamien and Zang (2000) derive a model in which firms that cooperatively choose their $R \& D$ expenditures, seek to maximize information flows (their incoming spillovers) by choosing broader research directions for the research joint venture.

IO research on R\&D cooperation has paid little attention to the different types of potential partners. It has typically considered horizontal cooperation, i.e. between competing firms, stressing the importance of the degree of product market competition. When firms are not direct competitors but market independent or complementary goods, cooperation is associated with higher R\&D investment levels independent of any critical level of spillovers (De Bondt et al, 1992; Röller et al, 1997). In such a setting where firms are less direct competitors, joint R\&D and possible cheating have no detrimental effect in terms of strengthening the product market position of the rival. A similar logic holds for inter-industry cooperation with furms in unrelated markets (Steurs, 1995) and vertical cooperation with suppliers (Atallah, 2002), although in the latter type of cooperation commercially sensitive information may also leak out to competitors through common suppliers or customers.

The management literature typically analyzes cooperation from a transaction costs and resource-based framework (Tyler and Steensma, 1995). The transaction cost approach describes alliances as a hybrid form of organization combining aspects of hierarchical transactions within the firm and arm"s-length transactions in the market place. Cooperation may reduce transaction costs through a better control and monitoring of technology transfer than on arm's length markets, while the
inherent reciprocal relationship and "hostage" exchange between partners with
complementary capabilities can minimize opportunism 1988). The resource-based view of the firm suggests that the rationale for Cooperation is viewed as a mechanism to maximize firm value through effectively 
combining the resources of the partners by exploiting complementarities (Kogut, 1988; Das and Teng 2000; Hagedoorn, Link and Vonortas, 2000).

The management literature further provides helpful insights to pinpoint different motives and problems for R\&D cooperation with different types of partners. The importance of lead customers in helping to define innovations and, therefore, to reduce the risk associated with their market introduction, has already been long recognized (von Hippel, 1988; Schmookler, 1966). This provides a major motive for cooperation with customers in the development of particularly novel or complex new products (Tether, 2002). The goal of vertical cooperation with suppliers has been linked more to cost reduction, related to the tendency of firms to focus on core competences, outsource activities to suppliers and/or develop close collaborative arrangements with suppliers to reduce costs. ${ }^{3}$

Recent work on industry - science collaboration has shown that cooperation between universities and industry has intensified (e.g. Hall, Link \& Scott, 2000). Firms look for public science as one of the external sources for rapid and privileged access to new knowledge and to increase the firms' engineers understanding of scientific developments. Science is more important as source of information for innovation in those science-based technology fields where new breakthrough innovations can be achieved and transferred to applied research and translated into new products and processes (e.g. Klevorick et al., 1995). In particular when coupled with the available public funding opportunities, cooperation arrangements with academia are increasingly seen as an inexpensive source of specialist knowledge. Furthermore, the more generic nature of research projects with universities and research institutes involves fewer appropriation issues as compared to the more commercially sensitive content when cooperating in later development stages with customers/suppliers and -a fortiori- competitors (Cassiman and Veugelers, 2002).

In summary, the IO literature suggests that spillovers increase incentives to cooperate in particular if cooperation allows firms to enhance knowledge transfers among the collaborating partners. However, if incoming spillovers are associated with outgoing spillovers they have a more ambiguous effect on competitor collaboration as collaborating product market rivals benefit more from a firm's R\&D effort. These appropriability considerations are much less important for vertical (supplier, customer) and institutional collaboration. Firms that increase their absorptive capacity through larger R\&D investments are more likely to benefit from cooperation. In case of competitor cooperation, higher R\&D investments lead to a greater pool of know-how on which the partner firms can potentially free-ride. The management literature indicates that different $R \& D$ partnerships may be engaged in for different purposes, with customer cooperation more focused on bringing to market adapted or improved products, supplier cooperation more focused on cost reduction, and university cooperation focused on new generic technologies and product families in sectors with greater technological opportunities.

3 See also Atallah (2002). Suzuki (1993) finds that collaboration with suppliers within Japanese vertical business groups has a significant impact on cost reduction. 


\section{Empirical Research}

There is an expanding empirical literature on the determinants of R\&D cooperation. Given the difficulties in empirically assessing the profitability of R\&D cooperation, most studies indrectly focus on explaining the frequency of occurrence of R\&D cooperation to assess which characteristics are more beneficial to R\&D cooperation. Product complementarities among partners are found to positively affect the likelihood of R\&D cooperation (Röller et al., 1997). Sakakibara (1997) finds that access to complementary knowledge is one of the most important objectives of establishing government sponsored research cooperation in Japan. This is in line with Narula's (2002) finding that access to complementary technology has the highest importance among motives for R\&D cooperation for European ICT firms. Tyler and Steensma (1995) find that the ability to share cost and risks is important for the success of R\&D cooperation. Fritsch and Lukas (2001), Röller et al. (1997) and Colombo and Garrone (1996) show a positive impact of firm size and R\&D intensity of firms on R\&D cooperation. This is reminiscent of the absorptive capacity idea that stresses the need to have in-house (technological) knowledge to optimally benefit from R\&D cooperation ${ }^{5}$. Similarly, Kleinknecht and Reijnen (1992) find that having an own R\&D department increases the probability of co-operation. Another line of empirical research has specifically taken into account the simultaneous relationship between $R \& D$ cooperation and inhouse R\&D activities. These studies have generally confirmed that, controlling for this simultaneity, internal R\&D investments still have a positive impact on the probability or intensity of cooperation (Colombo and Garrone, 1996; Veugelers, 1997; Cassiman and Veugelers, 2002; Becker and Dietz, 2004).

The relationship between R\&D spillovers and R\&D cooperation, as well as the potentially different determinants of alternative types of cooperation, has remained largely unexplored in empirical work. Empirical work on R\&D cooperation distinguishing between the types of cooperation partner has often singled out specific types of partnerships, not taking into account the simultaneity among different types of cooperation. Cassiman and Veugelers (2002) analyzed the impact of spillovers on cooperation but could only distinguish between research institutes and vertically related partmers. They found that higher incoming public spillovers (knowledge available from public sources) positively affect the probability of cooperating with research institutes and universities. Greater appropriability of results of the innovation process (lower outgoing spillovers) increased the probability of cooperating with customers or suppliers, but was unrelated to cooperative agreements with research institutes. Kaiser (2002) applied a nested logit

\footnotetext{
4. See e.g. Monjon and Waelbroeck (2003) for a cross section analysis of the impact of different types of R\&D cooperation on firm innovativeness.

This parallels the argument in Vaugelers (1997) for including a permanent R\&D variable as
tacilitator of appropriation of external knowledge.
} 
framework to analyze firms' R\&D cooperation in the German service sector, distinguishing between the decision whether or not to cooperate and the decision which type of cooperation to choose. Here a distinction could only be made between vertical cooperation and a mixed category of university and competitor cooperation. The cooperation model had weak explanatory power and neither measures of spillovers nor variables proxying the research base of the firm were found to have a statistically significant impact.

Tether (2002), using UK CIS data, investigated the patterns of cooperation between innovating firms and different potential collaboration partners in a series of independent logistic regressions. He found firm size to be most influential in cooperation with suppliers and universities, but less so for cooperation with customers. Engagement in own R\&D had a clear positive effect on all types of cooperation. Leiponen (2001) used a classification into four types of cooperation: competitors, suppliers, customers, and universities. The probit results for cooperation suggested that R\&D intensity, firm size, and membership of a larger group generally had positive impacts on the four types of cooperation. The results also showed higher probabilities of cooperation with universities (customers) in industries where spillovers from universities (customers) wete important, but generally lower probabilities in industries where suppliers were an important source of incoming spillovers ${ }^{6}$. The latter result is consistent with the notion that in 'supplier dominated' industries (Pavitt, 1984), firms are more dependent on technological development coming from their suppliers and are less likely to engage in major product innovations, focusing on incremental process improvements requiring little formal collaboration. The analysis did not include firm-specific data on the importance of incoming spillovers.

\subsection{Empirical model, data, and estimation method}

This paper contributes to the growing empirical literature on R\&D cooperation by estimating a multivariate probit model that jointly determines the decision to engage in four types of R\&D cooperation: competitor, customer, supplier and (researcl1) institutional $R \& D$ partnerships. While the nested logit approach used in previous work (Kaiser, 2002a) does not account for the fact that firms can engage simultaneously in multiple cooperation agreements, the multivariate probit specification allows for systematic correlations between choices for the different cooperation types. Such correlations may be due to complementarities (positive correlation) or substitutability (negative correlation) between different cooperation types, e.g. the benefit of horizontal cooperation may be larger if the firm also cooperates with universities or research institutes. Positive correlation also arises if

\footnotetext{
${ }^{6}$ Fontana et al. (2004) find that in addition to size and R\&D intensity, firm openness to the external environment (measured as reliance on publications for acquiring knowledge) affects the probability, but not the level, of cooperation with universities.
} 
there are unobservable firm-specific characteristics that affect several cooperation decisions but that are not easily captured by measurable proxies, such as the stock of tacit knowledge. The multivariate probit model takes these correlations into account, although it is not able to distinguish between the two sources of correlation. If correlation exists, the estimates of separate (probit) equations of the cooperation decisions are inefficient.

Our panel dataset is constnucted from two consecutive CIS surveys performed by Statistics Netherlands in 1996 and 1998, which allows us to take past values of independent variables (in 1996) to explain the existence of $R \& D$ cooperation in 1997-98. This setup reduces simultaneity bias inherent to cross section analysis in a single year. According to the theoretical IO literature, the two main explanatory variables that are most likely to be simultaneously determined with the cooperation decision are incoming spillovers and R\&D intensity: R\&D investments may increase if cooperation makes own R\&D activities more effective, and incoming spillovers are likely to increase through cooperation if only because of information sharing among partners. In our model setup using two year lagged variables such bias will be reduced, but it will not be completely eliminated. If $R \& D$ partnerships last longer than 2-3 years, the R\&D intensity and the importance of incoming spillovers in 1996 are still partly affected by those R\&D partnerships that were formed in or before 1996 and still in existence in 1998. In order to further reduce such potential simultaneity bias we follow two routes. First, we correct the spillover measures for systematic impacts of past or existing cooperation. The 1996 spillover measures are also affected by purposeful informational exchanges in past R\&D partnerships. We adjust the spillover measure by regressing the 1996 spillover variable on the corresponding cooperation variables in 1996 and a set of industry dummies. The residuals of these equations are then included as spillovers that are not due to past cooperation. Secondly, we examine the determinants of cooperation among a sub-sample of firms lacking any cooperative agreements in 1996. This model of new cooperation allows us to test for the robustness of the impact of 1996 R\&D intensity and incoming spillovers on the possible establishment of new R\&D partnerships in the 1997-1998 period. Although this approach reduces the potential simultaneity between R\&D (cooperation) and spillovers to a minimum, ${ }^{7}$ its results need to be interpreted with care. Restricting the sample to firms without any type of
R\&D cooperation in 1996 among the set of innovating firms in 1996 excludes
persistently cooperating firms - those firms that arits persistently cooperating firms - those firms that are most likely to engage in R\&D partnerships. This selection itself creates a sample selection bias and reduces the number of observations considerably, which is likely to bias standard errors upwards. However, if tests on this lower tail of firms inclined to cooperate replicate

\footnotetext{
The new cooperation model eliminates the potential reverse causality effect from R\&D cooperation to spillowers and R\&D, but it does not completely do away with unobserved between the profitability of cooperation an not cooperating in 1996, there may be a correlation characteristics.
} 
the results using the complete sample, we take this as a strong indication of the robustness of the results.

\section{Data}

The dataset used in this chapter contains data at the establishment leve: (in this chapter referred to as "firms") from the CIS surveys in the Netherlands in 1996 and 1998. To create a panel data set, the 6315 innovating firms in the 1998 CIS survey are matched with the information on these firms in the 1996 survey: 2353 firms could be linked to the 1996 survey and were classified as innovating firms in that survey. "Due to missing values for some of the 1996 explanatory variables the number of observations used in the final sample is 2149 . The distribution of cases for the four equations by the dependent variable is presented in Table 2. 1. There were 627 firms with R\&D cooperation of some type among the 2149 innovating firms in 1998. Vertical cooperation is most prominent: supplier only (68), customer only (64), combined (71) or both combined with institutional cooperation (66). A total of 72 firms have cooperative agreements of all four types. The model restricting the sample to firms with newly formed cooperative agreements or no $\mathbb{R} \& D$ cooperation at all uses a smaller sample of 1484 firms, in which the number of firms with cooperation in 1998 is substantially reduced to 269.

\section{Table 2.1 Distribution of cooperation cases}

\section{Cooperation type}

\begin{tabular}{lll}
\hline & $(1)$ & $(2)$ \\
None & 1542 & 1215 \\
Institutional only & 39 & 19 \\
Supplier only & 68 & 38 \\
Supplier and institutional & 42 & 17 \\
Customers only & 64 & 32 \\
Customers and institutional & 27 & 4 \\
Customers and suppliers & 71 & 35 \\
Customers, suppliers and institutional & 66 & 20 \\
Horizontal only & 43 & 26 \\
Horizontal and institutional & 31 & 13 \\
Horizontal and suppliers & 8 & 5 \\
Horizontal, suppliers, institutional & 17 & 4 \\
& & \\
s Information on explanatory variables is only available in the survey if firms are classified as \\
innovating firms. Since we did not correct for a possible sample selection bias on innovating firms, \\
the results need to be interpreted as applicable to innovation active firms only.
\end{tabular}
sample new cooperation sample

Number of cases in full Number of cases in 


\begin{tabular}{lll}
\hline Horizontal and customers & 8 & 4 \\
Horizontal, customers, institutional & 20 & 5 \\
Horizontal, customers, suppliers & 31 & 17 \\
All four & 72 & 30 \\
Total & 2149 & 1.484 \\
\hline
\end{tabular}

\section{Dependent and Independent Variables}

The dependent variables of the model are four dummy variables equal to one if the firm was engaged in 1998 in an active R\&D partnership with competitors, suppliers, clients, or research institutes and/or universities (institutional cooperation), respectively. The model includes a range of explanatory variables supported by our review of theoretical work and previous empirical models, but remains rather explorative given the lack of straightforward theoretical predictions available. Since it is our interest to explore the varying determinants of R\&D cooperation between the types, we include each explanatory variable in all four equations to test whether some variable impacts cooperation of one type but not another. The descriptive statistics for the samples are presented in Table 2.2. A detailed description of the variables is provided in Appendix A and a correlation table in Appendix D.

Table 2.2 Descriptive statistics

\begin{tabular}{|c|c|c|c|c|c|c|}
\hline & $\begin{array}{l}\text { Sample } \\
\text { mean } \\
n=2149\end{array}$ & $\begin{array}{l}\text { Mean } \\
\text { non- } \\
\text { coop. } \\
\text { firms } \\
n=1542\end{array}$ & $\begin{array}{l}\text { Mean } \\
\text { coop. } \\
\text { firms } \\
m=607\end{array}$ & $\begin{array}{l}\text { Sample } \\
\text { mean } \\
n=1484\end{array}$ & $\begin{array}{l}\text { Meam } \\
\text { non- } \\
\text { coop. } \\
\text { firms } \\
n=1215\end{array}$ & $\begin{array}{l}\text { Semple } \\
\text { Mean } \\
\text { coop } \\
n=269\end{array}$ \\
\hline & \multicolumn{3}{|c|}{ Full Sample } & \multicolumn{3}{|c|}{ New Cooperation Sample } \\
\hline & (1) & (2) & (3) & (4) & $(5)$ & (6) \\
\hline $\begin{array}{l}\text { Competitor } \\
\text { incoming spillovers }\end{array}$ & 1.108 & 1.071 & 1.203 & 1.025 & 1.022 & 1.037 \\
\hline $\begin{array}{l}\text { Customer } \\
\text { incoming spillovers }\end{array}$ & 1.358 & 1.316 & 1.247 & 1.244 & 1.239 & 1.268 \\
\hline $\begin{array}{l}\text { Supplier } \\
\text { incoming spillovers }\end{array}$ & 1.179 & 1.152 & 1.247 & 1.135 & 1.117 & 1.219 \\
\hline $\begin{array}{l}\text { Instifutiona! } \\
\text { incoming spillovers }\end{array}$ & 0.444 & 0.361 & 0.655 & $0.34 \rrbracket$ & 0.314 & 0.462 \\
\hline $\begin{array}{l}\text { Public incoming } \\
\text { spillovers }\end{array}$ & 0.631 & 0.584 & 0.760 & 0.556 & 0.544 & 0.611 \\
\hline $\begin{array}{l}\text { Industry } \\
\text { outgoing spillovers }\end{array}$ & 0.711 & 0.704 & 0.729 & 0.705 & 0.703 & 0.714 \\
\hline
\end{tabular}




\begin{tabular}{|c|c|c|c|c|c|c|}
\hline R\&D intensity & 0.029 & 0.025 & 0.039 & 0.024 & 0.023 & 0.028 \\
\hline R\&D intensity & 0.004 & 0.003 & 0.005 & 0.003 & 0.003 & 0.003 \\
\hline \multicolumn{7}{|l|}{ Squared } \\
\hline Firm size & 4.459 & 4.307 & 4.841 & 4.273 & 4.203 & 4.569 \\
\hline $\begin{array}{l}\text { Industry average } \\
\text { innovative firm size }\end{array}$ & 0.080 & 0.077 & 0.088 & 0.076 & 0.075 & 0.079 \\
\hline $\begin{array}{l}\text { Organizational } \\
\text { capability constraint }\end{array}$ & 0.042 & 0.032 & 0.067 & 0.033 & 0.030 & 0.050 \\
\hline Cost constraint & 0.061 & 0.054 & 0.080 & 0.047 & 0.048 & 0.045 \\
\hline Rüsk constraint & 0.101 & 0.081 & 0.151 & 0.075 & 0.069 & 0.100 \\
\hline $\begin{array}{l}\text { Speed of } \\
\text { techno logical change }\end{array}$ & 0.501 & 0.491 & 0.526 & 0.495 & 0.493 & 0.506 \\
\hline Service dummy & 0.350 & 0.359 & 0.328 & 0.351 & 0.344 & 0.383 \\
\hline $\begin{array}{l}\text { Internal } \\
\text { knowledge flows }\end{array}$ & 0.539 & 0.564 & 0.474 & 0.576 & 0.592 & 0.505 \\
\hline $\begin{array}{l}\text { Part of a domestic } \\
\text { group }\end{array}$ & 0.471 & 0.446 & 0.537 & 0.438 & 0.431 & 0.468 \\
\hline Foreign & 0.280 & 0.274 & 0.294 & 0.275 & 0.273 & 0.283 \\
\hline Multinational & & & & & & \\
\hline R\&D subsidy & 0.434 & 0.377 & 0.578 & 0.356 & 0.342 & 0.416 \\
\hline
\end{tabular}

We include firm-specific and type-specific direct measures of the importance of incoming spillovers. ${ }^{9}$ The firms are asked in the CIS survey to rate the importance of various external sources of information for the firm's innovation activities. We include the scores of importance of information from competitors, suppliers, customers, and the average of scores of information from universities and research institutions (institutional incoming spillovers). Our prediction is that R\&D cooperation of a given type is more likely if incoming spillovers coming from the potential partners are more important. As noted supra, we estimate the impact of exogenous spillovers, i.e. not due to purposeful informational exchanges that arise through past cooperation. The adjusted spillovers are the residuals obtained from auxiliary regressions of the spillover variables in 1994-1996 on the corresponding cooperation variable and the set of industry dummies. ${ }^{10}$ In addition, we control for other incoming spillovers that may affect cooperation decisions, by including a measure of the importance of spillovers stemming from public sources (public

\footnotetext{
${ }^{9}$ Several alternative indirect measures of spillovers have been used in previous empirical work, e.g., based on uncentered correlation (Jaffe 1988, Adams 1990), Euclidean distance (Inkmann and Pohlmeier, 1995), and geographic distance. According to a comparative study of various spillover measures by Kaiser (2002b) both uncentered correlation and direct measures (used in our model) appear to capture spillovers quite accurately.

10 The auxiliary results of the spillover variables in 1996 on the corresponding cooperation variable and the set of industry dummies are presented in appendix $C$.
} 
incoming spillovers): the average of scores of the importance of patents, databases, trade literature and fairs."

A shortcoming of the Dutch version of the CIS questionnaire is the lack of a question to construct a measure of firm-specific outgoing spillovers or appropriability. Instead we proxy outgoing spillovers through an industry level variable, taking the average of horizontal spillovers of firms in the same industry (c.f. Leiponen, 2001). The variable industry outgoing spillovers is constructed at the 2-digit industry level and measures the mean of average scores of information obtained from competitors and patents reported by all competing firms in the industry. If firms in the industry report that they obtain important information from competitors and through published patents (filed among others by competitors), appropriability conditions in the industry are weak and this may negatively affect the propensity to cooperate. Industry outgoing spillovers is expected to impact horizontal cooperation negatively since it measures spillovers to same-industry competitors.

We include $R \& D$ intensity and $R \& D$ intensity squared, allowing for a nonlinear impact of R\&D (measured as the number of R\&D personnel over total personnel) as explanatory variables. Increasing levels of R\&D intensity up to a point will be closely correlated with absorptive capacity. Further increases may be less effective in expanding absorptive capacity due to diminishing scale economies or may be associated with the conduct of idiosyncratic in-house R\&D efforts. Hence, we expect a concave relationship, with the marginal effect of $R \& D$ intensity declining. Following previous theoretical and empirical work, we also expect the relationship between $R \& D$ intensity and $R \& D$ cooperation to differ depending on the type of cooperation partner. In case of horizontal cooperation, the positive relationship is predicted to be weaker than in case of vertical or institutional cooperation. A large R\&D base is likely to be associated with stronger proprietary knowledge and greater risks for the firm of leakage of information in cooperation with competitors. This risk is less important in case of cooperation with research institutes and suppliers and customers.

In line with the existing literature, we also include frm size (the logarithm of the number of the firm"s employees) as an explanatory variable. We expect that the larger the firm, ceteris paribus, the more likely it is that it engages in R\&D cooperation. For any given level of R\&D intensity, larger firms perform more R\&D and are more likely to possess the necessary absorptive capacity to benefit from R\&D cooperation. Larger firms are also more likely to be engaged in multiple technologies that may require various $\mathrm{R} \& \mathrm{D}$ partnerships. The largest absorptive

\footnotetext{
"The four spillower sources included in the model identify directly the source of the information in line with theoretical models and identify most relevant potential sources of information, regardless of the channel of information transfer. The public spillover measure, on the other hand, identifies the chawnel of the spillover (databases, trade fairs, palents) rather than the source and is likely to overlap with the direct measures (if information from competitors is important, it may reach the firm through patents or trade shows). Inclusion nevertheless controls for spillovers that may affect cooperation but are not covered by the direct source specific measures.
} 
capacity and R\&D intensity is likely to be required to absorb scientific knowledge stemming from universities (Leiponen, 2001).

The propensity to engage in cooperation is also affected by the presence or absence of partner firms with complementary resources in R\&D, and the ease with which suitable partners can be located. Both are likely to be related to the presence of large innovating firms in the industry. We aim to control for this influence in case of horizontal cooperation by including the variable industry average innovative firm size (mean of turnover of all innovating firms in the 2-digit industry). We expect a positive impact, but only on horizontal cooperation. ${ }^{12}$

We include three firm-specific measures that aim to capture factors hampering the innovation process of the firm, potentially pushing the firm to search for cooperation partners. This follows the perspective of the management literature on R\&D alliances on the various motivations for partnerships. Cost constraint captures bottlenecks caused by lack of financial resources or high costs of new innovation projects. Risk constraint captures bottlenecks caused by financial uncertainty (profitability) or uncertain market conditions. Organizational capability constraint is an average of ranked scores of the bottlenecks that relate to the firm's shortage of (R\&D) personnel, lack of knowledge, and organizational rigidity that cause the delay or abandonment of new innovation projects or the failure to start these. These constraints are expected to provide an incentive for firms to cooperate to reduce the costs, risks, and organizational constraints of $R \& D$.

In case of rapid technological developments it is likely that firms want to be active in multiple technological trajectories which buys them options to expand in the technology directions that eventually prevails (e.g. Tyler and. Steensma, 1995). Such rapid technological developments are most likely to be a feature of "science based' industries characterized by strong technological opportunities and relying on scientific developments in scientific institutions (Leiponen, 2001; Klevrorick et al, 1995; Pavitt, 1984). To proxy for the speed of techrological change we take the ratio of the number of firms in the 2 -digit industry that reported that they had introduced products new to the industry to the number of firms that did not introduce new products, weighted by firm size. We expect that firms operating in industries characterized by rapid introduction of completely new products have a higher incentive to engage in cooperation, but primarily with research institutions. One problem with this measure is that the question on new products may not adequately pick up technological change in the services sector. To get an unbiased impact of speed of technological change we include a service dummy. If service sectors are more technologically active than the speed of technological change proxy suggests, the service dummy will have a positive sign correcting for this bias

\footnotetext{
${ }^{12}$ The average size of innovative firms in the industry is correlated with market concentration, such that its impact may also pick up an effect of industry concentration on cooperation (see e.g. Katsoulacos and Ulph (1998) on the potential anti-competitive effects of research joint-ventures). However, including a $\mathrm{C} 4$ concentration ratio in the model in addition to the innovative firm size variable did not change the latter"s significance while the impact of the $C 4$ wariable was not significantly different from zero for any of the cooperation types.
} 
in the variable. Naturally, the service dummy in addition will pick up any systematic differences in cooperation between manufacturing and service sectors beyond this bias. ${ }^{13}$

We also control for the relative importance of information used in the innovation process coming from other establishments that are part of the same firm group. Internal knowledge flows is the ratio of the score on the importance of information from other firms within the group to the importance of external spillovers (sum of scores of all external sources of information). We expect a negative impact on cooperation, as firms that rely more on internally generated know-how, perhaps because of unique innowation processes or technologies, are less likely to see benefit in cooperation with external partners. Table 1 indeed shows that the mean of the internal knowledge flow variable is lower for cooperating firms than for non-cooperating firms, while the means for the incoming spillover variables are higher for cooperating firms.

We include a dummy for firms that are part of a domestic group. It takes the value 1 if an establishment is part of a larger firm grouping. Firms that are part of a larger group may draw on group financial and technological resources that make them more attractive as cooperation partners, but at the same time such firms may have fewer incentives to cooperate with outside partners. ${ }^{\text {If }}$ In addition, we include a durnmy variable multinational firm, taking the value 1 if the headquarters of the group to which the firm belongs is located outside the Netherlands. ${ }^{15}$

Finally, we control for the possible role of R\&D subsidies, by including a dummy taking the value one if the firm stated that it received an $R \& D$ subsidy. On the one hand, R\&D subsidies can moderate financial bottlenecks for the firm's R\&D activities and hence reduce the need to cooperate to share costs. On the other hand, given that a variety of R\&D national and European subsidy schemes are aimed particularly at promoting R\&D cooperation, the availability of R\&D

${ }^{3}$ One may expect more differences between sectors in the propensity to cooperate due to the diwergent technological trajectories (e.g. Pavitt, 1984; Leiponen, 2001). We ran seperate models for manufacturing and services firms only but found remarkably little differences in explanatory factors. To check the consistency of the estimation results further, we estimated an alternative model including a full set of industry dummies. Since performing this test within the multivariate probit framework (a four-equation model with 17 dummies) is exceedingly burdensome computationally, we could only run tests for the individual probit equations. In three out of four cases (the exception was supplier cooperation), the LR test did not reject the industry variable institutional cooperats were $17.6,27.6,20.1$ and 12.2 for conpetitor, supplier, customer and supplier spillovers, the spillover. and more informative industry variable model

it Note that the internall spillover variale

towards intra-group rather than external $R$ already corrects for a potential greater inclination is A sizeable proportion

dependent wariable includes a limited the establishments is owned by foreign multinationals. The models limiting the analysis of R\&D cooperation intemational R\&D partnerships. We also ran the stronger negative impact of the multing cooperation to domestic cooperation. As expected, we found a results. 
subsidies may make the difference in motivating firms to establish R\&D partnerships. These schemes often target pre-competitive and basic R\&D cooperation (e.g. with universities) but are less often aimed at $R \& D$ partnerships with competing firms. However, we cannot measure the availability of subsidy schemes but only the actual receipt of subsidies by the firms. If indeed R\&D subsidies are conditional on cooperation, there will be a strong positive correlation between subsidies and cooperation but this is due to a simultaneous relationship between the two rather than a causal effect of subsidies. By comparing results of the full model with results of the new cooperation model we will be able to further examine the different effects of subsidies.

\section{Model and estimation method}

Our model consists of four binary choice equations. These choices are for horizontal (competitors), customer, supplier and institutional (universities, research centers) cooperation, respectively. We have four binary dependent variables $y_{1}, y_{2}, y_{3}$ and $y_{4}$ where

$$
y_{i, k}=\left\{\begin{array}{l}
1 \text { if } x_{i, k} \beta_{k}+\omega_{i, k}>0 \\
0 \text { otherwise }
\end{array} \quad, \mathrm{k}=1, \ldots, 4 ; \quad \mathrm{i}=1, \ldots, \mathrm{N}\right.
$$

and $\left(\omega_{1} \omega_{2} \omega_{3} \omega_{4}\right) \sim N(0, \Sigma)$ where $\Sigma$ is the covariance matrix of the error terms. The error terms are likely to be correlated if only because of omitted variables in these choice processes. If one does not take this into account, for example with four separate probit equations, inefficient estimators result. To capture the possible interdependence of yes-or-no decisions we employ a multivariate limited dependent variable (multivariate probit) model. The computation of the maximum likelihood function based on a multivariate normal distribution requires multidimensional integration. Simulation methods have been proposed (see Train, 2002, chapter 5) to approximate such a function. The GHK simulator (Geweke et al. 1997; Hajivassiliou et al. 1996) has been a particularly popular choice ${ }^{16}$. We will follow the GHK simulator approach and choose a simulated maximum likelihood estimator that also offers possibilities of cross-equation tests and restrictions in parameters. ${ }^{17}$

\footnotetext{
16 Another possibility is to apply GMM along the lines of the estimator proposed by Bertschek and Lechner (1998). This estimator is shown to have good small sample properties and to have limited efficiency loss compared to maximum likelihood. Greene (2004) using the same data as Berschek and Lechner (1998), shows that maximum likelihood estimates using the GHK simulator are very close to GMM estimates.

${ }^{17}$ The results are obtained with a Stata routine due to Cappellari and Jenkins (2003) and are based on 200 random draws. Hajivassiliou and Ruud (1994) prove that under regularity conditions the simulated maximum likelihood estimator is consistent when both the number of draws and
} 


\subsection{Empirical Results}

Table 2.3 reports the results of the multivariate probit model for the complete sample of 2149 observations. First of all, we note that the correlation coefficients of the error terms in the multivariate probit are positive, ranging from 0.636 to 0.834 , and highly significant. ${ }^{18}$ This supports the notion of interdependence between the different cooperation decisions, which may be due to complementarity in R\&D cooperation strategies but also to omitted firm-specific factors affecting all types of cooperation. A second finding is that the estimated coefficients differ substantially across the equations, indicating the appropriateness of differentiating between cooperation types. In order to formally test this, we estimated a constrained specification with all slope coefficients forced to be equal. The likelihood ratio test statistic was 411.57 (76 degrees of freedom), decisively rejecting the null hypothesis of equal slope coefficients. This result strongly indicates the heterogeneity in cooperation strategies and, consequently, the unsuitability of aggregating them into one cooperation wariable (cf. Fritsch and Lukas, 2001; Janz et al., 2002).

Table 2.3 Results of Multivariate probit analysis of R\&D cooperation

\begin{tabular}{|c|c|c|c|c|}
\hline & $\begin{array}{l}\text { Competitor } \\
\text { Coop }\end{array}$ & $\begin{array}{l}\text { Customer } \\
\text { Coop }\end{array}$ & $\begin{array}{l}\text { Supplier } \\
\text { Coop }\end{array}$ & $\begin{array}{l}\text { Inst. } \\
\text { Coop }\end{array}$ \\
\hline & (1) & (2) & (3) & (4) \\
\hline res. Competitor incoming & 0.079 & -0.032 & 0.032 & 0.007 \\
\hline spillovers & $(0.047)^{*}$ & $(0.042)$ & $(0.042)$ & $(0.046)$ \\
\hline res. Customer incoming & 0.015 & 0.209 & 0.007 & -0.000 \\
\hline spillovers & $(0.044)$ & $(0.039)^{*}$ & $(0.039)$ & $(0.043)$ \\
\hline res. Supplier incoming & 0.057 & 0.030 & 0.239 & -0.051 \\
\hline spillovers & $(0.046)$ & $(0.041)$ & $(0.040) *$ & $(0.045)$ \\
\hline res. Institutional incoming & 0.367 & 0.223 & $0.2 \rrbracket$ & 0.722 \\
\hline spillovers & $(0.070)^{* * * *}$ & $(0.064) * * *$ & $(0.065)^{* *}$ & $(0.065)$ \\
\hline Public inconing spillovers & 0.010 & 0.000 & -0.013 & 0.104 \\
\hline & $(0.076)$ & $(0.069)$ & $(0.069)$ & $(0.073)$ \\
\hline Industiry outgoing spillo vers & -0.476 & 0.402 & -0.007 & -0.199 \\
\hline
\end{tabular}

observations goes to infinity. Gourjeroux and Monfort (1996) show that it has the same limiting distribution as the (infeasible) maximum likelihood estimator if in addition the ratio of the square root of the number of observations over the number of draws approaches zero.
For comparison Appendix B.1 


\begin{tabular}{|c|c|c|c|c|}
\hline & $(0.305)$ & $(0,285)$ & $(0.281)$ & $(0.301)$ \\
\hline \multirow[t]{2}{*}{ R\&D intensity } & 2.117 & 4.179 & 3.219 & 4.588 \\
\hline & $(1.649)$ & $(1.530) *$ & $(1.606)^{*}$ & $(1.599)^{*}$ \\
\hline \multirow[t]{2}{*}{ R\&D intensity squared } & -3.860 & -12.440 & -11.729 & -11.714 \\
\hline & $(5.108)$ & $(5.159)^{* * *}$ & $(5.669)^{*}$ & $(5.229)^{* *}$ \\
\hline \multirow[t]{2}{*}{ Firm size } & 0.145 & 0.1137 & 0.153 & 0.215 \\
\hline & $(0.031)^{* * *}$ & $(0.029)^{* * * *}$ & $(0.029)^{*}$ & 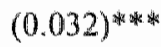 \\
\hline \multirow{2}{*}{$\begin{array}{l}\text { Industry average innovative } \\
\text { from size }\end{array}$} & 1.070 & 0.299 & 0.372 & 0.778 \\
\hline & $(0.394)^{* 2.4 k}$ & $(0.409)$ & $(0.387)$ & $(0.420)^{*}$ \\
\hline \multirow{2}{*}{$\begin{array}{l}\text { Organizational capability } \\
\text { constraint }\end{array}$} & -0.1 .63 & 0.103 & 0.730 & 0.428 \\
\hline & $(0.259)$ & $(0.222)$ & $(0.214)^{*}$ & $(0.228)^{*}$ \\
\hline \multirow[t]{2}{*}{ Cost constraint } & 0.171 & 0.247 & -0.525 & 0.683 \\
\hline & $(0.341)$ & $(0.304)$ & $(0.3] 4)^{*}$ & $(0.324)^{* \sin ^{2}}$ \\
\hline \multirow[t]{2}{*}{ Risk constraint } & 0.351 & 0.188 & 0.328 & -0.060 \\
\hline & $(0.153)^{* * *}$ & $(0.139)$ & $(0.138)^{* * *}$ & $(0.150)$ \\
\hline \multirow[t]{2}{*}{ Speed of technological change } & 0.547 & 0.605 & 0.169 & 1.067 \\
\hline & $(0.242)^{* * *}$ & $(0.227)^{* * *}$ & $(0.224)$ & $(0.251)^{\text {* * }}$ \\
\hline \multirow[t]{2}{*}{ Service dummy } & 0.238 & 0.187 & 0.095 & 0.031 \\
\hline & 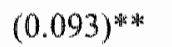 & $(0.086)^{\text {* }}$ & $(0.086)$ & $(0.094)$ \\
\hline \multirow[t]{2}{*}{ Internal knowledge flows } & -0.023 & -0.031 & -0.156 & -0.109 \\
\hline & $(0.070)$ & $(0.066)$ & $(0.071)^{* * * *}$ & $(0.077)$ \\
\hline \multirow[t]{2}{*}{ Part of a domestic group } & -0.034 & 0.144 & 0.192 & 0.048 \\
\hline & $(0.080)$ & $(0.072)^{* * *}$ & $(0.072)^{*}$ & $(0.078)$ \\
\hline \multirow[t]{2}{*}{ Foreign multinational } & -0.231 & -0.033 & 0.030 & -0.084 \\
\hline & $(0.092)^{* * *}$ & $(0.079)$ & $(0.078)$ & $(0.086)$ \\
\hline \multirow[t]{2}{*}{ R\&D subsidy } & 0.021 & 0.174 & 0.220 & 0.236 \\
\hline & $(0.087)$ & $(0.078)^{* *}$ & $(0.078)^{\left(* *_{*}^{*} k_{2}\right.}$ & $(0.083)^{* * * * * * 1 *}$ \\
\hline \multirow[t]{2}{*}{ Constant } & -2.090 & -2.584 & -2.049 & -2.949 \\
\hline & 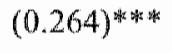 & 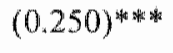 & $(0.240)^{\text {th }}$ & 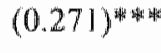 \\
\hline \multicolumn{5}{|l|}{ Comelations } \\
\hline & Rhol & Rho2 & Rho3 & \\
\hline \multirow[t]{2}{*}{ Rho/2 } & 0.649 & & & \\
\hline & $(0.035)^{2}$ & & & \\
\hline \multirow[t]{2}{*}{ Rho/3 } & 0.636 & 0.834 & & \\
\hline & $(0.036)^{*}$ & 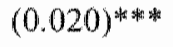 & & \\
\hline \multirow[t]{2}{*}{ Rho/4 } & 0.744 & 0.735 & 0.784 & \\
\hline & $(0.03 \llbracket)^{-5}$ & $(0.029)^{*}$ & $(0.026)^{* 3 *}$ & \\
\hline Observations & 2149 & & & \\
\hline $\mathrm{Ll}$ & -2536.12 & & & \\
\hline Wald chi2 (76) & 521.67 & & & \\
\hline $\mathrm{LLO}_{0}(10)^{\mathrm{a}}$ & -2843.826 & & & \\
\hline LR chi2 $(76)^{b}$ & 615.41 & & & \\
\hline
\end{tabular}


Likelihood ratio test of tho $21=$ tho $31=$ rho $41=$ rho $32=$ rho $42=$ rho $43=0$.

Chi-square $(6)=1234$, Prob $>$ chi-square $=0.0000$.

Standard errors in parentheses * significant at 10\%; significant at $5 \%$; significant at $1 \%$

"Denotes log-likelihood value (df) of the "naive" model, containing only the intercepts

"LR test is between the full model and the "narve" model

The hypothesis that source-specific incoming spillowers positively affect the probability of cooperation is confirmed. All spillover variables have significantly positive impacts on the respective cooperation type. The results suggest that firms tend to gravitate to the cooperation type that has the potentially highest value in terms of incoming knowledge. Customer and supplier incoming spillovers are significant the 5 percent level, while competitor incoming spillovers is significant at the 10\% level (two-sided), but clearly smaller in impact. This finding is consistent with the theoretical literature on R\&D cooperation which predict a weaker relationship between spillover levels and cooperation for competing firms compared with vertically related or unrelated firms (e.g. Attala, 2002). This result holds when incoming and outgoing spillovers are not separately identified. We may measure this weaker impact on competitor cooperation because the model may not sufficiently correct for outgoing spillovers at the firm level. ${ }^{19}$ Institutional incoming spillovers have a positive and strongly sigmificant effect in all four cooperation equations, and, as expected, the largest impact on institutional cooperation. The impact on vertical (both customer and supplier) cooperation and horizontal cooperation suggests that institutional incoming spillovers are more generic in nature, improving the general effectiveness of the firm"s $R \& D$ activities and stimulating vertical and horizontal cooperation as well. This is consistent with the notion that for firms for which science is more important as a source of knowledge, there exist greater technological opportunities, enhancing the effectiveness of various innovation strategies (Klevorick et al, 1995; Leiponen, 2001). Also, the importance of this type of incoming spillovers may refiect that the firms are engaged in basic R\&D, such that information sharing within R\&D cooperation is more effective (Katsoulacos and Ulph, 1998).

Industry outgoing spillovers has the expected negative impact on horizontal cooperation, but it just fails to reach conventional two-sided significance levels. ${ }^{20}$ With the source-specific spillovers included, there is no additional impact discernable of incoming public spillovers, perhaps because these measure partly the

\footnotetext{
19. The outgoing spillovers variable is measured at the industry level and hence not fully representative for the specific appropriability conditions for individual firms within the industry. An alternative explanation may be that firms rating horizontal incoming spillovers as important are more likely to be technology followers rather than leaders and are as such less attractive $\mathbb{R} \& D$
partners.
}

${ }^{201}$ The coefficient does reach significance in the univariate probit model reported in Appendix B.1. 
channel through which spillovers of various sources reach the firm and do not constitute new sources of information.

The effect of $R \& D$ intensity on the probability of cooperation is positive and concave as expected, with the linear term positive and the quadratic term negative, but there are differences between cooperation types. A robust concave relationship is estimated for supplier, customer, and institutional cooperation, with the maximum impact reached at rather high levels between 0.137 and 0.196 (percentage of R\&D employees over total employees). For competitor cooperation both terms are insignificant with the coefficients substantially smaller than in the other cooperation equations. On the other hand, the F-test on removing both R\&D intensity terms from the horizontal cooperation equation is rejected and a specification in which the quadratic term is dropped renders a significantly positive coefficient on the linear term (not reported here). Overall these findings suggest a positive but weaker impact of R\&D intensity on competitor cooperation. This is consistent with the notion that R\&D-intensive firms in horizontal partnerships also face greater risks of leakage of their proprietary knowledge, which may outweigh the potential benefits of knowledge transfers due to cooperation.

Firm size is positive and significant in each of the equations, with the coefficient highest in case of institutional cooperation. Larger firms are more likely to have the critical size and absorptive capacity required to engage in R\&D cooperation, and this effect is strongest for cooperation with universities. The industry average innovative firm size variable is positive and significant in the horizontal cooperation equation as hypothesized, and also marginally (10 percent) in the institutional cooperation equation. The availability of large innovating potential partmers (nearby) appears to stimulate horizontal cooperative R\&D. ${ }^{21}$

The organizational capability constraint is significantly positive in the supplier and institutional. cooperation equations. The risk constraint variable is significant and positive for both the competitor and supplier cooperation decisions, while the cost constraint variable has a positive and significant impact on institutional cooperation but a negative impact on supplier cooperation. Overall, the results confirm that the various types of constraints induce R\&D cooperation strategies, while commercial risk sharing and access to complementary knowledge when faced with internal resource constraints appear to be the most consistent motivation for firms to seek R\&D partners. The various constraints do not affect customer cooperation, perhaps because the goal of this type of cooperation is often to improve market acceptance or design features of new products, rather than to alleviate internal constraints.

The speed of technological change variable is found to have a positive and significant effect for the horizontal, customer and institutional cooperation

\footnotetext{
${ }^{21}$ Since the Netherlands is a small country, the majority of potential partners is in geographical proximity: The large majority of firms is located in a circle of less than $100 \mathrm{~km}$ around Utrecht. Perhaps in industries in which the average innovative firm size is larger, there is also a greater probability of $R \& D$ consortia involving large firms and universities.
} 
decisions, but not for supplier cooperation. Firms in industries with shorter product life eycles and rapid technological developments are more inclined to cooperate with rivals or/and customers or to cooperate in generic technologies with research institutes and universities. The largest impact is estimated for institutional cooperation, consistent with the notion that for firms facing rapid technological developments and greater technological opportunities, collaboration with universities and research institutes is essential for innovative success. The speed of technological change variable may have been less adequately measured for the service industries and, therefore, we incorporated a service dummy expecting a positive impact if this dummy corrects for under-reported speed of technological change. The service dummy has the expected positive effect in the customer and competitor cooperation equations.

The effect of the internal knowledge flow variable is negative as expected in each of the four equations, but is only significant in the supplier equation. Firms that are part of a group are more likely to cooperate with suppliers and customers, but not with competitors or research institutions. The dummy for a multinational firm is negative and significant in the competitor cooperation equation: affiliates of multinationals are less likely to cooperate with local rivals, but are not less inclined to engage in vertical or institutional types of cooperation. Finally, the $R \& D$ subsidy variable has a positive and significant impact on vertical (both customers and suppliers) and institutional cooperation, which may suggest that subsidies promote pro-competitive R\&D partnerships.

\section{New R\&D Cooperation}

The multivariate probit results obtained on the sub-sample of firms not (yet) cooperating in 1996 are presented in Table $2.4{ }^{22}$ The results are broadly in line with results for the complete sample. The standard errors are generally somewhat larger, which is likely to be due to a smaller sample (1488 observations) and the exclusion of consistently cooperating firms resulting in a much smaller percentage of cooperating firms. The source specific spillovers remain significant in their respective cooperation equations, while only the 'generic' effect of institutional spillovers on supplier cooperation appears less robust. The results for R\&D intensity are by and large replicated, with the exception that the quadratic term for customer cooperation falls just below conventional significance levels. Overall, the findings indicate the robustness of results in the presence of potential simultaneity

\footnotetext{
${ }^{22}$ For comparison, the results from the four binary probits on this sample are reported in Appendix
B.2.
} 
Table 2.4 Multivariate probit results for new $R \& D$ cooperation

\begin{tabular}{|c|c|c|c|c|}
\hline & $\begin{array}{l}\text { Competitor } \\
\text { Coop }\end{array}$ & $\begin{array}{l}\text { Customer } \\
\text { Coop }\end{array}$ & $\begin{array}{l}\text { Supplier } \\
\text { Coop }\end{array}$ & $\begin{array}{l}\text { Inst. } \\
\text { Coop }\end{array}$ \\
\hline & (1) & (2) & (3) & (4) \\
\hline res. Competitor incoming & 0.105 & -0.033 & 0.024 & 0.015 \\
\hline spillovers & $(0.062) *$ & $(0.057)$ & $(0.055)$ & $(0.064)$ \\
\hline res. Customer incoming & 0.031 & 0.181 & 0.012 & -0.032 \\
\hline spillovers & $(0.058)$ & $(0.052) * * *$ & $(0.050)$ & $(0.058)$ \\
\hline res. Supplier incoming & -0.033 & -0.018 & 0.212 & 0.009 \\
\hline spillovers & $(0.061)$ & $(0.056)$ & $(0.053)^{* * * * * *}$ & $(0.062)$ \\
\hline res. Institutional incoming & 0.266 & 0.186 & 0.128 & 0.671 \\
\hline spillovers & $(0.100) * *$ & $(0.090)^{* *}$ & $(0.089)$ & $(0.088)^{* * * * 3}$ \\
\hline \multirow[t]{2}{*}{ Public incoming spillovers } & -0.192 & -0.131 & -0.040 & -0.116 \\
\hline & $(0.117)$ & $(0.099)$ & $(0.095)$ & $(0.110)$ \\
\hline Industry outgoing & -0.039 & 0.457 & 0.154 & 0.132 \\
\hline spilllovers & $(0.428)$ & $(0.414)$ & $(0.404)$ & $(0.431)$ \\
\hline \multirow[t]{2}{*}{ R\&D intensity } & 2.471 & 3.874 & 5.865 & 7.299 \\
\hline & $(2.736)$ & $(2.247)^{*}$ & $(2.492)^{* * k}$ & $(2.882)^{* * 1}$ \\
\hline \multirow[t]{2}{*}{ R\&D intensity squared } & -8.693 & -10.665 & -21.333 & -29.678 \\
\hline & $(9.920)$ & $(7.684)$ & $(10.376)^{* * *}$ & $(1.2 .981)^{* * *}$ \\
\hline \multirow[t]{2}{*}{ Firm size } & 0.104 & 0.180 & 0.174 & 0.195 \\
\hline & $(0.046)^{* * *}$ & $(0.043)^{* * *}$ & $(0,042)^{* * * *}$ & $(0.049)^{* \text { *水* }}$ \\
\hline \multirow{2}{*}{$\begin{array}{l}\text { Industry average innovative } \\
\text { firm size }\end{array}$} & 0.913 & -0.694 & -0.718 & 0.495 \\
\hline & $(0.546)^{*}$ & $(0.695)$ & $(0.669)$ & $(0.661)$ \\
\hline \multirow{2}{*}{$\begin{array}{l}\text { Organizational capability } \\
\text { constraint }\end{array}$} & -0.591 & -0.010 & 0.802 & 0.570 \\
\hline & $(0.430)$ & $(0.325)$ & 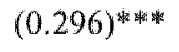 & $(0.325)^{\text {Hex }}$ \\
\hline \multirow[t]{2}{*}{ Cost constraint } & -0.405 & -0.501 & -0.819 & -0.723 \\
\hline & $(0.572)$ & $(0.500)$ & $(0.502)$ & $(0.569)$ \\
\hline \multirow[t]{2}{*}{ Risk constraint } & 0.400 & 0.194 & 0.253 & -0.136 \\
\hline & $(0.236)^{*}$ & $(0.216)$ & $(0.201)$ & $(0.244)$ \\
\hline \multirow{2}{*}{$\begin{array}{l}\text { Speed of technological } \\
\text { change }\end{array}$} & 0.044 & 0.548 & 0.213 & 1.213 \\
\hline & $(0.336)$ & $(0.307)$ & $(0.296)$ & $(0.351)^{* * * * *}$ \\
\hline \multirow[t]{2}{*}{ Service dummy } & 0.179 & 0.283 & 0.279 & 0.113 \\
\hline & $(0.125)$ & $(0.114)^{* * *}$ & $(0.111)^{* * *}$ & $(0.129)$ \\
\hline \multirow[t]{2}{*}{ Internal knowledge flows } & -0.052 & -0.080 & -0.211 & -0.355 \\
\hline & $(0.091)$ & $(0.087)$ & $(0.096)^{* * *}$ & 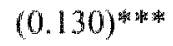 \\
\hline \multirow[t]{2}{*}{ Part of a domestic group } & -0.202 & 0.086 & 0.138 & -0.032 \\
\hline & $(0.108)^{*}$ & $(0.097)$ & $(0.095)$ & $(0.107)$ \\
\hline \multirow[t]{2}{*}{ Foreign multinational } & -0.233 & -0.071 & -0.091 & 0.074 \\
\hline & $(0.127)^{*}$ & $(0.107)$ & $(0.105)$ & $(0.118)$ \\
\hline
\end{tabular}




$\begin{array}{lllll}\text { R\&D subsidy } & -0.184 & 0.057 & 0.016 & -0.051 \\ & (0.123) & (0.106) & (0.105) & (0.118) \\ \text { Constant } & -1.789 & -2.745 & -2.303 & -3.010 \\ & (0.346)^{* * *} & (0.336)^{* * *} & (0.320)^{* * *} & (0.376)^{* * *}\end{array}$

Cowrelations

Rhol Rho2 Rho3

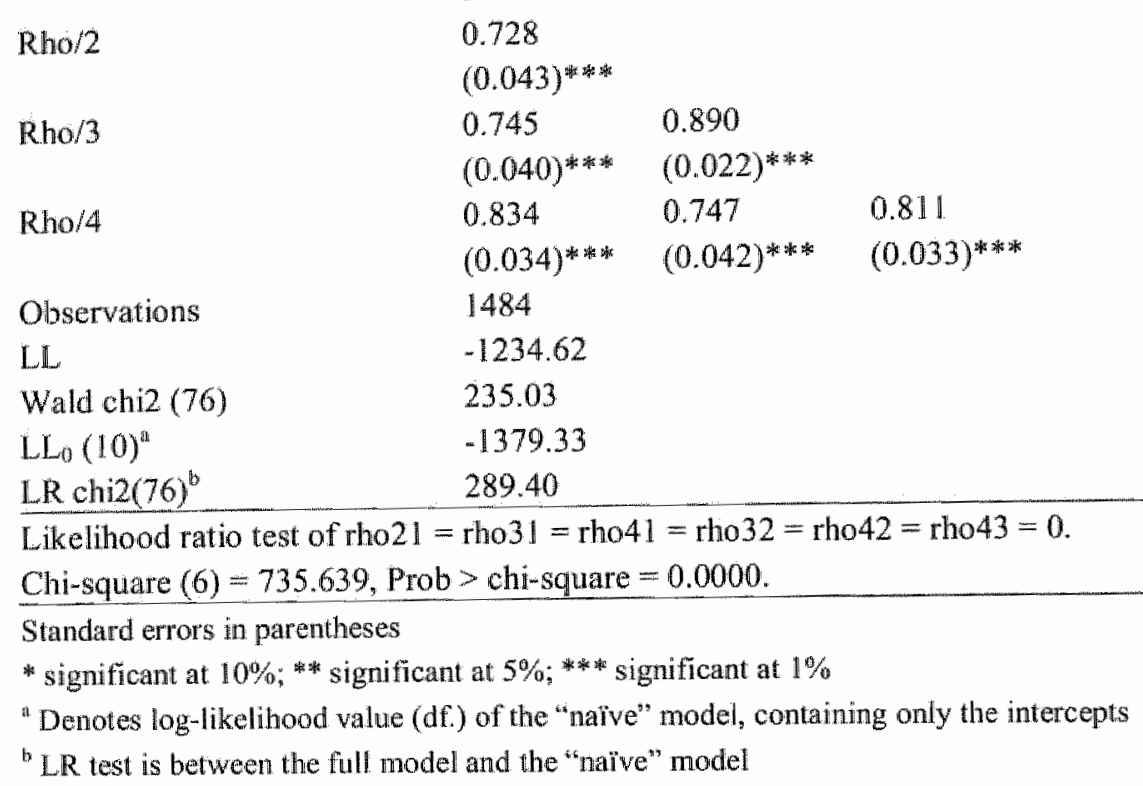

A number of differences are also worth noting in the new cooperation equations. Firms that rate internal knowledge flows as relatively important appear less likely to form new supplier and research institutional links, an effect that was not identified significantly in the full sample model. The average size of innovative firm maintains its expected positive impact on competitor cooperation, while the positive impact on institutional cooperation disappears. The speed of technological change variable looses its significance in the competitor cooperation equation but remains robust in the institutional and customer cooperation equations. Group nembership now loses its positive effect on cooperation and instead has a significantly negative impact on competitor cooperation. The greatest change in the results compared those for the full sample model occurs for the RdD subsidy dummy, as expected. For the new cooperation sample, the coefficient of the R\&D subsidy dummy no longer includes the effects of R\&D subsidies that were granted conditional on R\&D cooperation. Hence the results cannot be affected by simultaneity between subsidies and cooperation but reflect the effect of existing R\&D subsidies on new R\&D cooperation. While the estimated effect in the full 
model was significantly positive in supplier, customer, and institutional cooperation, these effects are now insignificant. The results suggest that the positive impact found for the full sample may indeed be biased upward by simultaneity between cooperation and subsidies. ${ }^{23}$

\subsection{Conclusion}

This chapter has explored the heterogeneity in the determinants of firms decisions to engage in vertical (suppliers, customers), horizontal (competitors) and research institutional (universities and research labs) R\&D cooperation. We took into account a broad set of determinants but paid particular attention to the effects of different types of spillovers, a central focus in the industrial organization literature on R\&D cooperation. We limited potential problems of simultaneity bias between cooperation and its determinants (notably R\&D intensity and incoming spillovers) by utilizing a two-period dataset on innovating firms, which allowed us to employ lagged variables. In addition, we considered a sample of firms that had not cooperated in the first period, further minimizing potential simultaneity problems. We used a multivariate probit model to reflect that firms consider simultaneously the decisions to cooperate with various partners. We found significantly positive correlations between the equations, which might indicate that the various cooperation decisions tend to be viewed by the firms as complementary rather than substitutes, but could also be due unobserved firm heterogeneity.

Our results confirmed that incoming source-specific spillovers are an important determinant of R\&D cooperation: cooperation with a type or partner is significantly more likely if incoming spillovers from that type of partner are more important for the firms" innovation process. We found a smaller impact of competitor spillovers on horizontal cooperation, consistent with stylized results from theoretical industrial organization models of R\&D cooperation, where spillover levels have a less unambiguously positive impact on R\&D cooperation with competing firms than on cooperation with vertically or unrelated firms. Another finding was that incoming spillovers from universities and research institutes stimulate cooperation of all types, suggesting that this knowledge is more generic in nature and improves the technological opportunities and general effectiveness of the firm's R\&D activities and R\&D cooperation strategies.

\footnotetext{
${ }^{23}$ Such bias may be caused by a positive impact of R\&D subsidies in 1996 effectively allocated to joint R\&D projects set up around that time but still in existence in 1998. The individual probit result for the impact of $R \& D$ subsidies on horizontal cooperation, as reported in Appendix B.2, is even found to be significantly negative. This could point to an alternative impact of subsidies in alleviating financial constraints: R\&D subsidies moderate financial bottlenecks for the film's R\&D activities and hence reduce the need to cooperate. Non-cooperating firms that have received subsidies would be more likely to find it optimal to rely on internal R\&D efforts instead of sharing funds and research results with competitors.
} 
R\&D intensity has a positive impact on vertical and institutional cooperation, with a decreasing marginal impact for highly $R \& D$ intensive firms. A weaker positive impact was found for horizontal R\&D cooperation with competing firms, consistent with the notion that firms in horizontal partnerships also face greater risks of leakage of proprietary knowledge. Firm size has a positive impact on all four types of cooperation, as larger firms are more likely to have the critical size and absorptive capacity required to engage in R\&D cooperation. The largest firms were more likely to cooperate with universities and research institutes, suggesting that small and medium sized firms often do not have the critical size to cooperate effectively with science institutions. Risk and organizational constraints in the firm's innovation process generally had a positive impact on R\&D cooperation, with the most robust results for the commercial risk factor being on horizontal cooperation and for organizational constraints on supplier and institutional cooperation. R\&D cooperation with institutions, customers, and competitors were found to be more likely in case of a greater speed of technological change in terms of new product introductions in the industry. Foreign multinationals were found to have a lower propensity to engage in horizontal cooperation, but were not less inclined to cooperate vertically or with universities and research institutes. The estimated impact of $R \& D$ subsidies proved to be sample sensitive: received subsidies had a positive effect on R\&D cooperation in the full sample model, but not in the model for new cooperation, suggesting that the positive impact is not generic but stems from those subsidies that are granted conditional on cooperation.

The results show that there is merit in disaggregating R\&D cooperation by type of partner and that there are substantial differences in the motives and determinants of the different types of cooperation. Further empirical work in this area would greatly benefit from an extension of theoretical models to other types of R\&D partnerships than horizontal cooperation. High on the agenda of future empirical work is analysis of potential complementarities between cooperation types, i.e. the choice of multiple R\&D partnerships, and the effects of these on innovative performance. 


\section{Appendix A Description of Variables}

\begin{tabular}{|c|c|}
\hline Variable name & Definition \\
\hline $\begin{array}{l}\text { Competitor incoming } \\
\text { spillovers* }\end{array}$ & $\begin{array}{l}\text { Importance of competitors as source of knowledge for the } \\
\text { firm's innovation process. }\end{array}$ \\
\hline $\begin{array}{l}\text { Customer incoming } \\
\text { spillovers* }\end{array}$ & $\begin{array}{l}\text { Importance of customers as source of knowledge for the } \\
\text { firm's innovation process. }\end{array}$ \\
\hline $\begin{array}{l}\text { Supplier incoming } \\
\text { spillovers* }\end{array}$ & $\begin{array}{l}\text { Importance of suppliers as source of knowledge for the } \\
\text { firm's innovation process. }\end{array}$ \\
\hline $\begin{array}{l}\text { Institutional incoming } \\
\text { spillovers* }\end{array}$ & $\begin{array}{l}\text { Average of importance of universities, innovation centers, } \\
\text { and research institutions as source of knowledge for the } \\
\text { firm's innovation process. }\end{array}$ \\
\hline Public incoming spillover & $\begin{array}{l}\text { Average of inportance of patents, databases, trade } \\
\text { literature and fairs as source of knowledge for the firm's } \\
\text { innovation process. }\end{array}$ \\
\hline $\begin{array}{l}\text { Industry outgoing } \\
\text { spillovers }\end{array}$ & $\begin{array}{l}\text { Mean of scores of importance of information received from } \\
\text { competitors and patents for all firms operating in the ( } 2 \\
\text { digit) industry. }\end{array}$ \\
\hline R\&D intensity & R\&D employees/total employees \\
\hline R\&D intensity squared & R\&D employees/total employees squared \\
\hline Firm size & Logarithm of number of employees \\
\hline $\begin{array}{l}\text { Industry average } \\
\text { inmowative firm size }\end{array}$ & $\begin{array}{l}\text { Mean of sales by all innovating firms operating in the } 2 \text { - } \\
\text { digit industry. }\end{array}$ \\
\hline $\begin{array}{l}\text { Organizational capability } \\
\text { constraint }\end{array}$ & $\begin{array}{l}\text { A verage of scores on the following responses: } \\
\text { innovation project } \\
\text { not started due to short of staff } \\
\text { not started due short of knowledge } \\
\text { not started due to rigid organization }\end{array}$ \\
\hline Risk constraint & $\begin{array}{l}\text { Average of scores on the following responses: } \\
\text { innovation project } \\
\text { not started due to economic risks } \\
\text { not started due to uncertain markets. }\end{array}$ \\
\hline
\end{tabular}




\section{Chapter 2}

Cost onstrint

Speed of technological

change

Service dummy

Internal knowledge flows

Part of a domestic group

Foreign multinational

R\&D subsidy
Average of scores on the following responses:

innovation project

not started or delayed or abandoned due to short of

financing

not started or delayed or abandoned due to high costs

Sum of sales of firms in the 2-digit industry that stated that they had introduced products new to the industry, divided by sum of sales of all firms in the industry.

1. if business unit belongs to the services sector, else 0

Importance of other group firms as source of knowledge for the firm's innovation process, divided by the total of importance scores of all external sources of knowledge

1. if the firm is part of a domestic corporate group, else 0

1 if headquarters of the firm is located outside the Netherlands, else 0

1 if firm received subsidy for innovation activities, else 0

Nore: all independent variables are derived from the 1996 CIS survey

* In the full sample analysis, the source-specific incoming spillovers are substituted by the error terms of regressions of the 1996 spillovers on the 1994-1996 cooperation dummies and the set of indus try dummies. 
Appendix B.I Individual probit results for the full sample

\begin{tabular}{|c|c|c|c|c|}
\hline & $\begin{array}{l}\text { Competitor } \\
\text { Coop }\end{array}$ & $\begin{array}{l}\text { Customer } \\
\text { Coop }\end{array}$ & $\begin{array}{l}\text { Supplier } \\
\text { Coop }\end{array}$ & $\begin{array}{l}\text { Inst. } \\
\text { Coop }\end{array}$ \\
\hline & (1) & (2) & (3) & (4) \\
\hline res. Competitor & 0.085 & -0.022 & 0.038 & 0.020 \\
\hline incoming spillovers & $(0.048)^{*}$ & $(0.043)$ & $(0.043)$ & $(0.048)$ \\
\hline res. Customer & 0.022 & 0.224 & 0.021 & 0.016 \\
\hline incoming spillovers & $(0.045)$ & $(0.040)^{* * *}$ & $(0.039)$ & $(0.045)$ \\
\hline res. Supplier & -0.055 & 0.044 & 0.248 & -0.053 \\
\hline incoming spillovers & $(0.047)$ & $(0.042)$ & $(0.041)^{2 * 3}$ & $(0.047)$ \\
\hline res. Institutional & 0.375 & 0.227 & 0.221 & 0.722 \\
\hline incoming spillovers & $(0.069)^{* * * *}$ & $(0.063)^{* * * *}$ & $(0.063)^{* * * * *}$ & $(0.066)^{* * * *}$ \\
\hline Public incoming & -0.001 & 0.007 & -0.004 & 0.091 \\
\hline spillovers & $(0.077)$ & $(0.069)$ & $(0.069)$ & $(0.075)$ \\
\hline Industry outgoing & -0.557 & 0.395 & 0.105 & -0.203 \\
\hline spillover & $(0.312)^{*}$ & $(0.292)$ & $(0.286)$ & $(0.309)$ \\
\hline \multirow[t]{2}{*}{ R\&D intensity } & 2.184 & 4.370 & 3.421 & 4.684 \\
\hline & (1.684) & $(1.578)^{* * * * * * ⿰ ㇇ ⿰ 亅 ⿱ 丿 丶 丶 ~}$ & $(1.690)^{* * *}$ & $(1.656)^{\prime}$ 冰冰 \\
\hline R\&D intensity & -4.182 & -13.289 & -12.479 & -12.016 \\
\hline squared & $(5.286)$ & $(5.465)^{* * *}$ & $(6.294)^{* 1 * k}$ & $(5.488)^{* *}$ \\
\hline \multirow[t]{2}{*}{ Firm size } & 0.139 & 0.138 & 0.157 & 0.240 \\
\hline & $(0.032)^{* * * * *}$ & 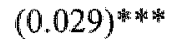 & 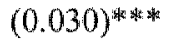 & $(0.033)^{\text {***** }}$ \\
\hline Industry average & 1.004 & 0.329 & 0.323 & 0.796 \\
\hline innovative firm size & $(0.395)^{* * *}$ & $(0.411)$ & $(0.394)$ & $(0.417)^{*}$ \\
\hline Organizational & -0.169 & 0.008 & 0.732 & 0.412 \\
\hline capability constraint & $(0.270)$ & $(0.236)$ & $(0.224)^{* 2 * 2 *}$ & $(0.242)^{*}$ \\
\hline \multirow[t]{2}{*}{ Cost constraint } & 0.164 & 0.347 & -0.427 & 0.794 \\
\hline & $(0.350)$ & $(0.308)$ & $(0.323)$ & $(0.334)^{\text {吸隶 }}$ \\
\hline \multirow[t]{2}{*}{ Risk constraint } & 0.371 & 0.207 & 0.302 & -0.050 \\
\hline & $(0.156)^{* *}$ & $(0.142)$ & $(0.143)^{\text {w2* }}$ & $(0.158)$ \\
\hline Speed of & 0.621 & 0.612 & 0.147 & 1.115 \\
\hline technological change & $(0.246)^{* * *}$ & $(0.231)^{* * *}$ & $(0.230)$ & $(0.265)^{2}$ \\
\hline \multirow[t]{2}{*}{ Service dummy } & 0.217 & 0.166 & 0.067 & -0.033 \\
\hline & $(0.094)^{* *}$ & $(0.088)^{*}$ & $(0.088)$ & $(0.097)$ \\
\hline Internal & -0.013 & -0.027 & -0.127 & -0.103 \\
\hline knowledgeflows & $(0.069)$ & $(0.065)$ & $(0.071)^{*}$ & $(0.080)$ \\
\hline Part of a & -0.053 & 0.156 & 0.190 & 0.058 \\
\hline domesticgroup & $(0.082)$ & $(0.073)^{* * *}$ & $(0.073)^{* * * * *}$ & $(0.081)$ \\
\hline Foreign & -0.241 & -0.064 & 0.011 & -0.137 \\
\hline multinational & $(0.095) *$ & $(0.080)$ & $(0.079)$ & $(0.090)$ \\
\hline \multirow[t]{2}{*}{ R\&D subsidy } & -0.008 & 0.153 & 0.177 & 0.201 \\
\hline & $(0.089)$ & $(0.079)^{*}$ & 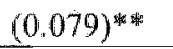 & $(0.086)^{4 * *}$ \\
\hline
\end{tabular}


Chapter 2

\begin{tabular}{lllll}
\hline Constant & -2.004 & -2.585 & -2.119 & -3.044 \\
& $(0.271)^{* * *}$ & $(0.255)^{*}$ & $(0.246)^{* * *}$ & $(0.287)^{* * *}$ \\
Observations & 2149 & 2149 & 2149 & 2149 \\
LL & -673.26 & -876.62 & -892.62 & -710.62 \\
Chi2 & 115.88 & 185.95 & 204.52 & 366.34 \\
\hline
\end{tabular}

Standard errors in parentheses

* significant at 10\% significant at 5\%; significant at $1 \%$ 
Appendix B.2 Individual probit results for the new cooperation sample

\begin{tabular}{|c|c|c|c|c|}
\hline & $\begin{array}{l}\text { Competitor } \\
\text { Coop }\end{array}$ & $\begin{array}{l}\text { Customer } \\
\text { Coop }\end{array}$ & $\begin{array}{l}\text { Supplier } \\
\text { Coop }\end{array}$ & $\begin{array}{l}\text { Inst. } \\
\text { Coop }\end{array}$ \\
\hline & (I) & $(2)$ & (3) & (4) \\
\hline res. Competitor incoming & 0.102 & -0.026 & 0.022 & 0.019 \\
\hline spillovers & $(0.064)$ & $(0.059)$ & $(0.057)$ & $(0.069)$ \\
\hline res. Customer incoming & 0.044 & 0.209 & 0.046 & 0.002 \\
\hline spillovers & $(0.059)$ & $(0.054)^{* * * *}$ & $(0.052)$ & $(0.064)$ \\
\hline res. Supplier incoming & -0.047 & -0.018 & 0.223 & -0.010 \\
\hline spillovers & $(0.064)$ & $(0.059)$ & $(0.055)^{* * *}$ & $(0.068)$ \\
\hline res. Institutional incoming & 0.319 & 0.232 & 0.178 & 0.694 \\
\hline spillovers & $(0.097)^{* * * *}$ & $(0.089)^{* * *}$ & $(0.088)^{* * *}$ & 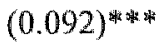 \\
\hline \multirow[t]{2}{*}{ Public incoming spillovers } & -0.194 & -0.1 .27 & -0.014 & -0.171 \\
\hline & $(0.119)$ & $(0.103)$ & $(0.099)$ & $(0.119)$ \\
\hline \multirow[t]{2}{*}{ Industry outgoing spillovers } & -0.099 & 0.403 & 0.207 & 0.023 \\
\hline & $(0.443)$ & $(0.438)$ & $(0.420)$ & $(0.459)$ \\
\hline \multirow[t]{2}{*}{ R\&D intensity } & 3.430 & 4.115 & 6.790 & 7.827 \\
\hline & $(2.803)$ & $(2.316)^{*}$ & $(2.910)^{* *}$ & $(3.085)^{* *}$ \\
\hline \multirow[t]{2}{*}{ R\&D intensity squared } & -11.218 & -11.973 & -28.871 & -31.620 \\
\hline & $(10.358)$ & $(8.070)$ & $(14.954)^{*}$ & $(14.419)^{* * * 3}$ \\
\hline \multirow[t]{2}{*}{$\mathbb{F}$ irm size } & 0.113 & 0.179 & 0.190 & 0.223 \\
\hline & $(0.048)^{* * *}$ & $(0.044)^{* * *}$ & $(0.043)^{* * * *}$ & $(0.052)^{* * *}$ \\
\hline \multirow{2}{*}{$\begin{array}{l}\text { Industry average innovative } \\
\text { firm size }\end{array}$} & 0.821 & -0.513 & -0.490 & 0.774 \\
\hline & $(0.552)$ & $(0.720)$ & $(0.651)$ & $(0.643)$ \\
\hline \multirow{2}{*}{$\begin{array}{l}\text { Organizational capability } \\
\text { constraint }\end{array}$} & -0.730 & -0.022 & 0.785 & 0.544 \\
\hline & $(0.497)$ & $(0.357)$ & $(0.306)^{* * *}$ & $(0.369)$ \\
\hline \multirow[t]{2}{*}{ Cost constraint } & -0.262 & -0.291 & -0.585 & -0.468 \\
\hline & $(0.580)$ & $(0.505)$ & $(0.509)$ & $(0.608)$ \\
\hline \multirow[t]{2}{*}{ Risk constraint } & 0.454 & 0.228 & 0.233 & -0.156 \\
\hline & $(0.246)^{*}$ & $(0.225)$ & $(0.215)$ & $(0.275)$ \\
\hline \multirow{2}{*}{$\begin{array}{l}\text { Speed of technological } \\
\text { change }\end{array}$} & 0.127 & 0.578 & 0.172 & 1.381 \\
\hline & $(0.350)$ & $(0.323)^{*}$ & $(0.3 \llbracket 2)$ & 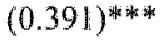 \\
\hline \multirow[t]{2}{*}{ Service dummy } & 0.140 & 0.235 & 0.230 & 0.044 \\
\hline & $(0.130)$ & $(0.118)^{* * *}$ & $(0.115)^{* * *}$ & $(0.140)$ \\
\hline \multirow[t]{2}{*}{ Internal knowledge flows } & -0.029 & -0.052 & -0.151 & -0.332 \\
\hline & $(0.088)$ & $(0.085)$ & $(0.095)$ & $(0.162)^{\text {*.* }}$ \\
\hline \multirow[t]{2}{*}{ Part of a domestic group } & -0.207 & 0.113 & 0.154 & 0.018 \\
\hline & $(0.113)^{*}$ & $(0.101)$ & $(0.098)$ & $(0.117)$ \\
\hline \multirow[t]{2}{*}{ Foreign multinational } & -0.217 & -0.106 & -0.086 & 0.079 \\
\hline & $(0.132)$ & $(0.112)$ & $(0.108)$ & $(0.125)$ \\
\hline \multirow[t]{2}{*}{ R\&D subsidy } & -0.288 & -0.008 & -0.054 & -0.150 \\
\hline & $(0.130)^{* * *}$ & $(0.109)$ & $(0.109)$ & $(0.126)$ \\
\hline
\end{tabular}


Chapter 2

\begin{tabular}{lllll}
\hline Constant & -1.807 & -2.740 & -2.443 & -3.169 \\
& $(0.359)^{* * *}$ & $(0.349)^{*}$ & $(0.333) *$ & $(0.414)^{*} *$ \\
Observations & 1484 & 1484 & 1484 & 1484 \\
Ll & -353.19 & -444.86 & -473.67 & -330.73 \\
Chi2 & 47.04 & 68.95 & 92.61 & 132.69 \\
\hline
\end{tabular}

Standard errors in parentheses

* significant at $10 \%$; significant at $5 \%$ * significant at $1 \%$ 
Appendix C Auxiliary regression to remove the effect of past cooperation on incoming spillowers

\begin{tabular}{lllll}
\hline & $\begin{array}{l}\text { Competitor } \\
\text { spillovers }\end{array}$ & $\begin{array}{l}\text { Customer } \\
\text { spillovers }\end{array}$ & $\begin{array}{l}\text { Supplier } \\
\text { spillovers }\end{array}$ & $\begin{array}{l}\text { Institutional } \\
\text { spillovers }\end{array}$ \\
\cline { 2 - 5 } $\begin{array}{l}\text { Competitor } \\
\text { cooperation }\end{array}$ & $\begin{array}{l}0.169^{* * *} * \\
(0.060)\end{array}$ & & & \\
$\begin{array}{l}\text { Customer } \\
\text { cooperation }\end{array}$ & & $0.391^{* * *}$ & & \\
$\begin{array}{l}\text { Supplier } \\
\text { cooperation }\end{array}$ & & $(0.053)$ & & $0.204^{* * *}$ \\
Institutional & & & $(0.048)$ & \\
cooperation & & & & $0.393^{* * * *}$ \\
Industry dummies & Yes & Yes & Yes & $(0.033)$ \\
$\mathrm{R}^{2}$ & 0.02 & 0.07 & 0.03 & Yes \\
\hline
\end{tabular}




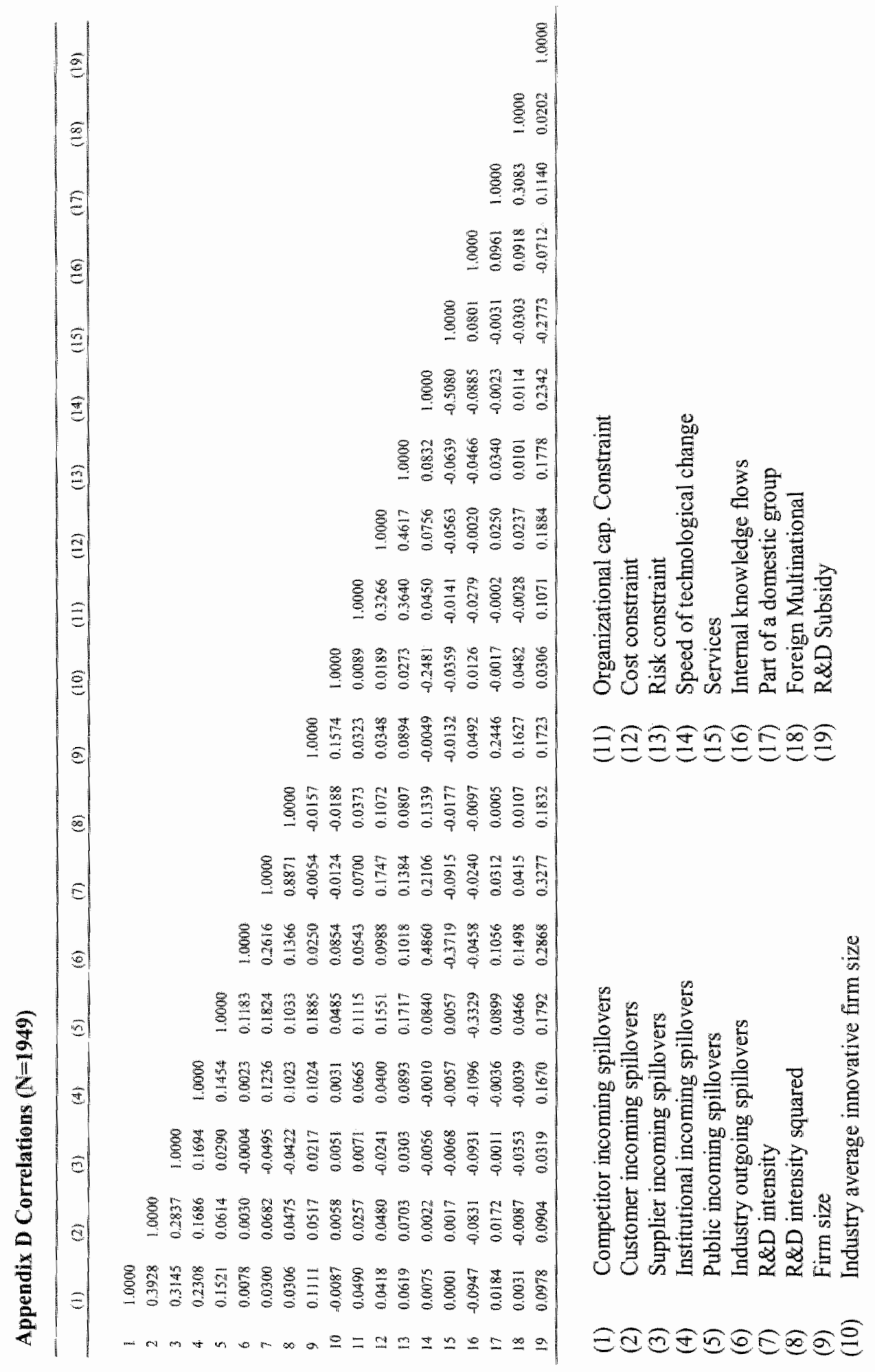




\section{CHAPTER 3}

\section{Cooperative R\&D and Firm Performance*}

We analyze the impact of R\&D cooperation on firm performance differentiating between four types of R\&D partners (competitors, suppliers, customers, and universities \& research institutes), and considering two performance measures: labor productivity and productivity in innovative (new to the market) sales. Using data on a large sample of Dutch innovating firms in two waves of the Community Innovation Survey $(1996,1998)$, we examine the impact of R\&D cooperation in 1996 on subsequent productivity growth in 1996-1998. The results confirm a major heterogeneity in the rationales and goals of $R \& D$ cooperation. Competitor and supplier cooperation focus on incremental innovations, improving the productivity performance of firms. University cooperation and again competitor cooperation are instrumental in creating innovations generating sales of products that are novel to the market, improving the growth performance of firms. Furthermore, customers and universities are important sources of knowledge for firms pursuing radical innovations, which facilitate growth in innovative sales in the absence of formal R\&D cooperation.

Acknowledgement: This paper benefited from helpful comments by two anonymous referees and participants at the DRUID conference on "Industrial Dynamics, Innovation and Development", Copenhagen, June 14-16, 2004, and the INIR workshop on the "Economics and Management of Science and Technology", Katholieke Universiteit Leuven, 24-25 May 2004. The empirical analysis for this paper has been performed at CEREM/Statistics Netherlands. We thank Bert Diederen of CEREM for his assistance; the views expressed in this paper are those of the author and do not necessarily reflect the policies of Statistics Netherlands.

* This chapter is based on the article: Cooperative R\&D and firm performance, 2004, Research Policy 33(10): 1477-92 (with R. Belderbos, M. Carree) 


\subsection{Introduction}

The observed substantial increase in R\&D alliances in the late $1980 \mathrm{~s}$ and throughout the 1990s, in particular in sectors such as biotechnology and information technology (Hagedoorn, 2002; Tyler and Steensma, 1995) has provoked a substantial academic and policy interest in the phenomenon. A large body of literature in the management domain has been produced that discusses various motives that incite firms to collaborate on R\&D (Contractor and Lorange, 2002; Nooteboom, 1999). In parallel, a stream of literature in industrial organization theory has taken a game theoretical perspective to focus on the relationships between R\&D cooperation, R\&D investment, and inter-firm knowledge flows (termed "knowledge spillovers"). The latter literature has been most concerned with the potential impact of R\&D cooperation and knowledge spillovers on R\&D investment levels, and has largely been restricted to the analysis of cooperation with direct competitors. By and large, the findings suggest that the presence of (potential) effective knowledge spillovers between firms provides incentives for R\&D cooperation, which in turn leads to higher $R \& D$ investment levels.

A number of empirical studies have explored the determinants of $R \& D$ cooperation (e.g. Kleinknecht and Reinen, 1992; Fritsch and Lucas, 2001; Tether, 2002; Belderbos et al. 2003). A major finding of recent contributions is that the goals and, hence, the determinants of $R \& D$ partnerships differ depending on the type of R\&D and cooperation partner. Fritsch and Lucas (2001) find for German manufacturing firms that innovative effort directed at process improvement is more likely to involve cooperation with suppliers, whereas product innovations are associated with customer cooperation. Tether (2002), using UK data on innovating firms, finds that $R \& D$ cooperation is mostly the domain of firms pursuing radical innovations rather than incremental innovations. Distinguishing more specifically between partnerships with competitors, suppliers, customers, and universities \& research institutes, Belderbos et al. (2003) find substantial heterogeneity in the determinants to establish R\&D collaborations with different partners. Cooperation with a type of partner generally is more likely to be chosen if that type of partner is considered an important source of knowledge for the innovation process, while knowledge sourced from universities and research institutes positively impacts all types of cooperation. R\&D cooperation with universities is more likely to be chosen by R\&D intensive firms in sectors that exhibit faster technological and product development.

Surprisingly, the key question whether cooperative R\&D has the expected positive impact on firms' (innovation) performance has remained largely unexplored in both the industrial organization as well as in the management literature (e.g. Tether, 2002; Das and Teng, 2000). A number of papers have included a cooperation variable in empirical models explaining differences in firms" innovation output (Janz et al., 2003; Van Leeuwen and Klomp, 2001; Klomp and van Leeuwen, 2001; Lööf and Heshmati, 2002; Monjon and Waelbroeck, 2003; 
Criscuolo and Haskell, 2003), but most of these studies have been primarily concerned with the impact of R\&D investments on performance and did not examine systematically differences in impacts across cooperation types. Management studies have restricted analysis to particular performance indicators in specific industries, e.g. the effect of alliances on high tech start-up firm performance in the biotech industry (Baum et al. 2002), or the effect of learning in alliances on market share performance in the global automotive industry (Dussauge et al., 2002).

The contribution of this paper is to examine in detail the effects of different types of R\&D cooperation on firm performance. We consider the impact of the four major types of partner-specific cooperation strategies: cooperation with competitors, suppliers, customers, and research institutes and \& universities. We analyze the effects of these $R \& D$ partnerships on two alternative performance measures for a large sample of Dutch firms active in manufacturing and service industries: growth of value added per employee (labor productivity), and growth of sales per employee from products new to the market (which we term 'innovative sales productivity'). The analysis controls for the potential impact of incoming knowledge flows that are not due to R\&D partnerships, as well as for the effect of the firms' own R\&D expenditures. Using data on a large sample of innovating firms in two waves of the biannual Dutch Community Innovation Survey $(1996,1998)$ linked to production statistics, the analysis allows for an appropriate time lag with which the impact of R\&D cooperation (1996) feeds through in productivity growth (1996-1998).

The remainder of the chapter is organized as follows: section two provides an overview of the previous theoretical and empirical literature discussing the impact of R\&D (cooperation) and knowledge spillovers on firm performance. Section three describes the empirical model and data. Section four discusses the empirical results and section five concludes.

\subsection{Previous Literature}

In this section we will briefly review the theoretical and empirical literature on R\&D cooperation, knowledge spillovers and productivity. A first stream of relevant literature relates to theoretical $R \& D$ cooperation models in the industrial organization tradition. This literature has focused on the role of knowledge spillovers between (potential) R\&D cooperation partners. In the absence of cooperation, knowledge spillovers to competing firms are considered involuntary, as they increase the knowledge stock of competing firms and may weaken the firm's relative market position. The existence of such involuntary spillovers reduces the effectiveness of the firms' $R \& D$ efforts as they cannot appropriate all of the returns, and this results in lower $R \& D$ investment levels. $R \& D$ cooperation enables firms to internalize the knowledge spillovers and eliminate the disincentive effect of spillovers on R\&D (e.g. Amir, 2000; De Bondt, 1996; Kamien et al., 1992; Suzumura, 1992; Leahy and Neary, 1997). Most of these studies make the rather 
implausible assumption that the lewel of knowledge spillovers is given and unaffected by the cooperation itse]f. A number of recent papers have enriched the analysis by taking into account that cooperation allows firms to increase knowledge transfers voluntarily among the cooperating partners (Katsoulacos and Ulph, 1998). Firms have incentives to manage the flow of spillovers to and from competitors by attempting to maximize incoming spillovers through R\&D collaboration while at the same time minimizing outgoing spillovers through investments in knowledge protection (Cassiman et al. 2002; Martin 1999, Amir et al. 2003). A limitation of this line of theoretical research is that it has been strictly focusing on R\&D cooperation with competing firms, and has paid little attention to $R \& D$ collaboration with universities, or with firms that are not direct competitors. An exception is Atallah (2002), who finds that collaboration with 'vertical' partners (client firms or supplier firms) is already induced by small levels of knowledge spillovers, as pooling of R\&D with vertical partners has no direct effect on competition in output markets.

The literature in the management and technology policy domain has examined broader motivations for $R \& D$ cooperation than internalizing involuntary knowledge spillovers and has paid more attention to the voluntary nature of knowledge exchange in R\&D alliances. Explanations for collaborative R\&D that have been extensively discussed revolve around factors such as sharing risks and costs in the face of uncertain technological developments (Das and Teng, 2002; Tyler and Steensma, 1995), shortening innovation cycles (Pisano, 1990), the pursuit of efficiency gains such as economies of scope and scale or synergistic effects through efficient pooling of the firms' resources (Kogut, 1988; Das and Teng, 2000), learning through monitoring technology and market developments (Hamel, 1991; Roberts and Berry, 1985), dealing with regulations and industry standards, and responding to government subsidy policies (Benfratello and Sembenelli, 2003; Nakamura, 2003). Although it has been noted more generally that a substantial share of alliances fail (Harrigan, 1986), R\&D alliances may be a source of competitive advantage and have long lasting effects on firm performance. Teece (1980) argues that organizational practices affect firms' performance and can explain sustained performance differences within industries due to slow diffusion of best practices and difficulties in imitating complex organizational capabilities. It has also been suggested that different types of collaboration may serve different purposes, where the two main goals of innovative effort are cost reduction and market expansion. Collaboration with customers is important to reduce the risk associated with the market introduction of innovations, as has been recognized since Von Hippel (1988). In particular when products are novel and complex and hence require adaptations in use by customers, collaboration may be essential to ensure market expansion (Tether, 2002). In contrast, cooperation with suppliers is often related to the tendency to focus on core business through outsourcing, whille closely collaborating with suppliers to guarantee input quality improvements aimed at further cost reductions. Cooperation with universities and research institutes is 
generally more aimed at innowations that may open up entire new markets or market segments (Tether, 2002; Monjon and Waelbroeck, 2003).

A number of empirical studies have found a positive impact of engaging in $R \& D$ cooperation on innovation performance i.e. sales of innovative products (e.g. Klomp and van Leeuwen, 2001; Janz et al., 2003; van Leeuwen, 2002; Lööf and Heshmati, 2002; Criscuolo and Haskell, 2003, Faems et al., 2004), patenting (Vanhaverbeke et al., 2002), and sales growth (Cincera et al., forthcoming). Some of these papers have also examined the effect of different cooperation types, but have produced ambiguous results. Appendix $\mathrm{C}$ summarizes the selected studies. Faems et al. (2004) used cross-section data from Belgian CIS sturvey in 1992 and found a positive association between university cooperation and the share in firm sales of innovative products new to the market, while an aggregate measure of other cooperation types was positively associated with the share in firm sales of innovative products new to the firm (but not new to the market). Monjon and Waelbroeck (2003) regressed innovative sales levels of firms in a French CIS survey on a range of collaboration and incoming knowledge spillover variables and found a mixture of negative and positive impacts of R\&D cooperation and spillovers. Cincera et al. (forthcoming) distinguished between overseas and domestic R\&D collaboration by Belgian firms and found a positive impact on productivity of the latter but a counter-intuitive negative impact of the former. Löof and Heshmati (2002) included a selected group of cooperation types in an innovation output equation for Swedish firms and found that cooperation with competitors and universities affected innovation output levels positively, but cooperation with customers negatively. As the above studies use cross-sectional data drawn from a single survey, the ambiguous results may be partly attributed to the difficulties in allowing for an appropriate lag with which cooperative R\&D impacts innovative output and performance. At the same time, if there are unobserved firm characteristics that impact at the same time firms' incentives to cooperate and their innovative output, a positive correlation between cooperation and innovation may be spurious rather than causal (Van Leeuwen and Klomp, 2001).

There is a large body of empirical literature examining the sources of productivity growth and in particular the role of inter-firm knowledge spillovers (e.g. Adams and Jaffe, 1996; Branstetter, 2001; Coe and Helpman, 1995; Basant and Flikkert, 1996). These studies have generally confirmed that knowledge spillovers that may arise from interaction with other firms through international trade, foreign direct investments, and input-output linkages, have a positive impact on productivity growth. Similarly, empirical studies have documented the positive impact of own R\&D on productivity at the firm level (e.g. Griliches and Mairesse, 1984; Lichtenberg and Siegel, 1991; Hall and Mairesse, 1995). A related literature has been concerned with the role of foreign multinational enterprises (MNEs) in productivity performance (Griffith, 1999; Harris and Robinson, 2003). In these studies MNEs are generally found to be more productive than their local industry 
competitors, which is attributed to MNEs efficient exploitation of firm-specific assets allowing for multi-plant economies of scale (e.g. Pfaffermayr, 1999) and the transfer of accumulated tacit and specialized knowledge on production (Aitkin and Harrison, 1999).

In summary, the literature suggests that an analysis of different types of cooperation strategies should take into account the different possible aims of (collaborative) R\&D efforts. Labor productivity increases may be more reflective of incremental innovations and affected by collaborative $R \& D$ aimed at cost reductions, while sales expansion through innovative products is more likely to be related to basic R\&D efforts and client collaboration. We explore this by examining empirically the effect of cooperation on two different types of productivity performance: labor productivity growth and the growth in sales of innovative products that are new to the market per employee ("innovative sales productivity"). Furthermore, we follow the suggestion in the literature that analysis of the performance effects of R\&D cooperation should control for the positive impact of incoming knowledge spillovers, as well as R\&D expenditures, while the existence of multinational group linkages should also be taken into account. Since the analysis couples two waves of the Community Innovation. Survey, the analysis can allow for an appropriate time lag between R\&D and innovative performance, while the potential bias of unobserved firm characteristics is reduced by including lagged productivity levels as an explanatory variable.

\subsection{Empirical model, data and descriptive statistics}

The goal of the empirical analysis is to determine whether different types of R\&D collaboration affect a firm's growth in labor productivity and innovative sales productivity. To examine this effect the analysis should control for the effect of own R\&D efforts as well as the impact of incoming knowledge flows that are not due to cooperation. Our specification in equation (3.1) has as dependent variable the growth in productivity from $1996(\mathrm{t})$ to $1998(\mathrm{t}+1)$. We include explanatory variables measured in the preceding period as well as the lagged level of productivity (in 1996). In the absence of the possibility of including fixed firm effects, this specification has the major advantage that it partly adjusts for unobserved firm attributes that are relatively constant over time. ${ }^{24}$ We estimate the following growth in productivity equation:

\footnotetext{
2.4 A second advantage is that it allows for the effects of the exogenous variables to be interpreted in line with Granger-causation. The Granger approach to the question of whether $x^{*}$ causes $y$ is to see lagged values of $x$ can improve the statistical values of $y$ and then to consider whether adding caused by $x$ if the coefficients on the lagged values of an. The variable is said to be Grangercurrent model is restricted to a single lag in both $x$ and $y$
} 
$\Delta \log \left(\right.$ prodv $_{i}=\alpha+\beta X_{i}+\delta r d$ int $_{i}+\zeta_{1}$ Comp $_{-}$coop $_{i}+$

$\zeta_{2}$ Cust_coop ${ }_{i}+\zeta_{3} S_{u t p p_{-}} \mathrm{coop}_{i}+\zeta_{4} \mathrm{Uni}_{-} \mathrm{coop}_{i}+$

$\gamma_{1}$ Comp_spil $_{i}+\gamma_{2}$ Cust $_{-} s p i l_{i}+\gamma_{3} S_{u p p}$ spil $_{i}+\gamma_{4}$ Univ $_{-} s p i l_{i}+$

$\theta \log (\operatorname{prod} v)_{i}+\varepsilon_{i}$

where all left hand side variables are measured at time $t$ and where $\Delta \log (\operatorname{prod})_{i}=\log \left(\operatorname{prod}_{i, t+1}\right)-\log \left(\operatorname{prod}_{i, 1}\right)$, is the growth in productivity measured as either value added per employee or sales generated by new to the market products per employee, respectively. Labor productivity growth will be most affected by cost reducing innovation, while innovative sales productivity growth is more affected by demand expansion oriented innovation. Differences in the impact of cooperative $R \& D$ on the two performance measures can demonstrate the variety in purposes of different collaborative strategies. The model includes four dummies for cooperation types with the different possible partners: competitors, customers, suppliers, and universities \& research institutes (henceforward for convenience labeled 'universities'). ${ }^{25}$ The same potential partners are identified by the firms as potential sources of incoming knowledge spillovers, which are expected to have an additional impact on productivity growth. The model also includes the firm's innovation expenditure as percentage of sales (innovation intensity). The $\log$ (Prodv) variable is the firm's productivity level in 1996. Since highly productive firms that are at the frontier of productivity are less likely to be able to achieve strong growth rates in productivity than firms that are followers, we expect $\theta$ to fall within the interval $[-1,0] .{ }^{26}$ If $\theta$ is zero, the productivity frontier effect is absent and there is no gradual convergence between leading firms and productivity laggards. If $\theta$ is -1 , than a productivity lead in one period is fully neutralized in the next and past productivity has no impact on future productivity levels. ${ }^{27}$ The $X$-vector consists of other firm-level control variables, such as size, dummies variables controlling for foreign and domestic group membership, dummies for the stated objectives of innovation (cost reducing versus product improving), and dummies for the industry of the firm at the two-digit level.

One worry is that our specification does not allow separating the effect of the incoming spillovers from the effect of cooperation: cooperation can have a direct effect on productivity but will at the same time increase the reported incoming

25. We do not include cooperation with consultants in the empirical analysis because of its heterogeneous character and doubts whether linkages with consultants are genuine R\&D efforts.

${ }^{26}$ Since the model includes a full set of industry dummies, this variable can also be interpreted as the effect of the productivity level of the firm relative to the industry mean in 1996.

${ }_{27}$ To see this one can simply rewrite the relevant part of (1) as

$\log \left(\operatorname{prod} v_{i+1}\right)=\ldots . .\left(1+\theta_{i}\right)(\operatorname{prod} v)_{i}$ 
spillovers from the collaboration partner firm/institution. Since we are interested in estimating the full impact of formal cooperation, we have to separate spillovers due to purposeful informational exchanges that arise in formal cooperative arrangements from spillovers that are not due to such cooperation (e.g. arising from market contacts with suppliers and customers). We want to adjust the spillover variables from the influence of formal cooperation such that the estimated coefficients for $R \& D$ cooperation measure the full impact of $R \& D$ collaboration on productivity growth. This adjusted measure can be obtained by taking the residuals obtained from regressing the full spillover variable by partner on the corresponding cooperation variable (we added a set of industry dummies).

$$
\begin{aligned}
& \text { Comp_spil }=\lambda_{\text {hor }} \text { Comp_coop }+Z_{i}+\eta_{i}^{\text {comp }} \\
& \text { Cust_spil } l_{i}=\lambda_{\text {chss }} \text { Cust_coop } p_{i}+Z_{i}+\eta_{i}^{\text {cust }} \\
& S u p p_{-} \text {spil }_{i}=\lambda_{\text {sup } p} S u p p_{-} \operatorname{coop}_{i}+Z_{i}+\eta_{i}^{\text {sup } p} \\
& \text { Univ_spil }{ }_{i}=\lambda_{\text {ings }} \text { Univ_coop }{ }_{i}+Z_{i}+\eta_{i}^{\text {univ }}
\end{aligned}
$$

The estimated residuals from these equations $\hat{\eta}_{i}^{\text {simp }}$ through $\hat{\eta}_{i}^{\text {atin }}$ are then included in place of the spillover variables Comp_spil through Univ spil $_{i}$ in our specification. The residuals are no longer systematically related to firms' $R \& D$ collaborations and are not due to purposeful exchanges in R\&D partnerships. ${ }^{28}$

\section{Data and Variables}

The empirical analysis uses the data from two consecutive Community Innovation Surveys (CIS) conducted in 1996 and 1998 in the Netherlands, as well as information from the production statistics database in the same years. It has been only recently that researchers have been able to utilize consecutive CIS surveys merged with production statistics. ${ }^{29}$ An additional advantage of the Dutch CIS surveys is that they have been held every other year rather than in four-year intervals as has been customary in other EU countries. This allows us to more

\footnotetext{
${ }^{25}$ Whereas the four knowledge spillover variables included in the model identify the source of the spillower, there are a number of other types of incoming spillovers in the CIS survey that identify the channes of the spillover (databases, trade fairs, patents). There is a clear and arguably substuntial overlap in these measures (e.g. if information from competitors is important, it may reach the firms through patents or trade shows) making it problematic to include all types of spillovers available in the survey. We did include a composite measure of all the other spillover ratings by the firms in the empirical model, but this variable proved insignificant with no impact on the estimates of the four source-specific spillover measures. The source-specific spillovers are apparenty able to capture the lion's share of the impact of incoming knowledge on productivity
growth. growth
} 
accurately examine performance changes over a suitable period (two years). The CIS surveys, conducted by Statistics Netherlands (CBS) contains information concerning $R \& D$ and innovation activities of the firm, including innovation expenditures, innovation in partnership data and sources of knowledge used in the innovation process. The production statistics database includes information on output, employment, and value added. The CIS and production statistics surveys are sent to all large firms and to a random sample of smaller firms in the Netherlands. To create a two-year data set, 6327 innovating firms in 1998 are matched with information on these firms in 1996 survey: 2353 firms could be linked to the 1996 survey and were classified as innovating firms in that survey. We then linked these firms via a unique id number to the production statistics data. The data are at the establishment level and include manufacturing as well as service firms. Due to the missing values for some of the explanatory variables the complete sample includes 2056 firms.

The labor productivity growth variable is the growth in net value added per employee (drawn from the production statistics) between 1996 and 1998. The alternative performance measure 'innovation sales productivity growth' is the growth in the value of sales per employee of product and services that are new to the market, between 1996 and 1998. This variable is drawn from the CIS surveys, in which firms are asked to indicate what percentage of sales has been due products or services introduced in the passed two years that were new to the industry, not just novel to the firm. Firms that increase the performance on this variable are likely to be more productive in the pursuit of more substantial rather than incremental innovations. These in turn are a prerequisite for further firm growth (Klomp and Van Leeuwen, 2001).

The cooperation variables are taken from the 1996 CIS survey and are dummy variables taking the value one if the firm indicated that it was or had been engaged during 1994-1996 in active R\&D cooperation with competitors, suppliers, customers, and universities or research institutes, respectively. Hence we posit that cooperative R\&D projects in 1994-1996 have their main impact on productivity growth in the two-year period 1996-1998. This is a relatively plausible assumption, given that $R \& D$ efforts require some time to translate into innovative output and productivity advances. But it is not ruled out that some cooperative projects may have a faster impact on productivity. If this is the case, then early R\&D projects (e.g. those started in or before 1994) may already have had their impact on 1996 productivity levels and show no further impact in 1996-1998, in which case the empirical results will underestimate the impact of cooperation. In order to address this empirically, we also test for the impact of an alternative cooperation measure: whether a firm is a 'consistent' R\&D collaborator: i.e. whether the firm is cooperating with the respective type of partner both in 1996 and 1998. If cooperative projects have a relatively quick impact on productivity, the persistent cooperation variables may show more robust results. 
Incoming knowledge spillovers are direct measures of the importance of different sources of incoming knowledge for the firms" innovation process. The CIS survey asks each firm to rate on a Likert scale (1-5) the importance of various external sources of information in terms of the "effectiveness in the firms" innovation process" in the past two years. Given this wording of the question (firms are asked to identify incoming knowledge that have already been effectively used in the innovation process), the answers are more likely to indicate the contribution of such spillovers to current innovation output than future innovation output. Hence, effective spillovers in 1994-1996 (the 1996 CIS survey) are likely to have their main impact on the 1996 productivity level rather than on subsequent productivity growth in 1996-1998. Therefore, we do not include the 1996 spillover measure but instead the spillower measure from the 1998 survey (effective spillovers during 1996-1998) in our model explaining 1996-1998 productivity growth. As discussed above, we do not use the scores as explanatory variables but adjust the spillover measures for the impact of cooperation. We regress the 1998 spillover rating by source on 1996 cooperation and a set of industry dummies, and take the residuals of these equations as a measure of spillovers that are not due to purposeful exchanges in formal R\&D partnerships.

We also include an $R \& D$ input measure in line with the previous literature that documented a positive relationship between research intensity and productivity. Our R\&D measure is total innovation expenditures as percentage of sales. Such expenditures include, in addition to internal $R \& D$, expenditures on extramural $R \& D$ contracts paid to other firms and research centers, and expenditures on technology licenses, among others. Hence, the variable also controls for the impact of external technology acquisition. Innovation intensity is taken from the 1996 survey to allow for a 2-year lag with which innovation investments impact productivity.

Further control variables include a set of 2-digit industry dummies (we distinguish 19 industries) and firm size (the logarithm of the number of employees). We also allow for differences in productivity growth performance between independent firms and firms that are part of a domestic group or a foreign MNE, Group firms may show higher growth rates if they can draw on technology and organizational expertise from headquarters and other groups firms. The Dutch industrial structure is characterized by the presence of several large multinational corporations, such as Akzo-Nobel, DSM, Philips, Shell and Unilever, which are dominating the Dutch technological infrastructure and responsible for a large share of business R\&D. These large companies function as the core of firm networks with comparable research intensities (i.e. Cowan and Jonard 2001; Verspagen, 1999).

Finally, we include demand-pull and cost-push variables in the model as controls. The demand-pull variable is a sum of scores on the importance of objectives of innovation relating to demand factors. Cost-push is the sum of scores on importance of objectives relating to cost reduction. If cost-reduction is a major motivation for innovations efforts, it may be more likely that R\&D translates 
directly into improved labor productivity. Demand expansion orientation is most likely to impact innovative sales productivity.

\section{Descriptive Statistics}

The distribution of cases by industry and descriptive statistics is presented in Table 3.1. There are 630 firms with $R \& D$ cooperation of any type among the innovating firms in the combined sample. Supplier cooperation is the most frequent, with 375 firms indicating to be engaged in this type of collaboration, followed by customer cooperation (353 firms), university cooperation (280) and competitor cooperation (226). Some 1426 firms reported to have none of these four links. The comparison across industries indicates that the propensity to cooperate is not dissimilar between services and manufacturing industries. Cooperation is comparatively more frequent in (petro) chemicals, metallurgy, and business services. Science-based industries such as electronics and chemicals, but also the food and metallurgy industries, report a higher share of university cooperation compared to the other types of cooperation.

Table 3.2 provides a contingency table displaying the means of the variables used in the model by type of cooperation. This information provides some preliminary evidence that there exist significant differences along several key parameters between firms having an R\&D cooperation link and the noncollaborating firms. Collaborating firms report substantially greater incoming spillovers of all four kinds compared to non-cooperating firms (the F-tests in columns 6-7 show that these differences are significant). With the exception of competitor spillovers, source specific spillovers are greatest for firms that cooperate with the source, as expected (F-tests again shows that these differences overall are significant). The most dramatic difference is in university spillovers: firms that engage in $R \& D$ collaborations with universities or research institutes report to receive spillovers more than twice the magnitude as spillovers benefiting noncollaborating firms. These figures indicate that the importance for the firms' innovation process of knowledge coming from a specific source is a reason to engage in cooperation (Belderbos et al, 2003), but they are also indicative of subsequent purposeful increases in knowledge transfers within the collaborative agreement. Table 3.2 also shows cooperating firms to be larger and more R\&D intensive, to be more often part of a domestic or foreign group, and to report a greater emphasis on both cost reducing and demand expanding innovation. 


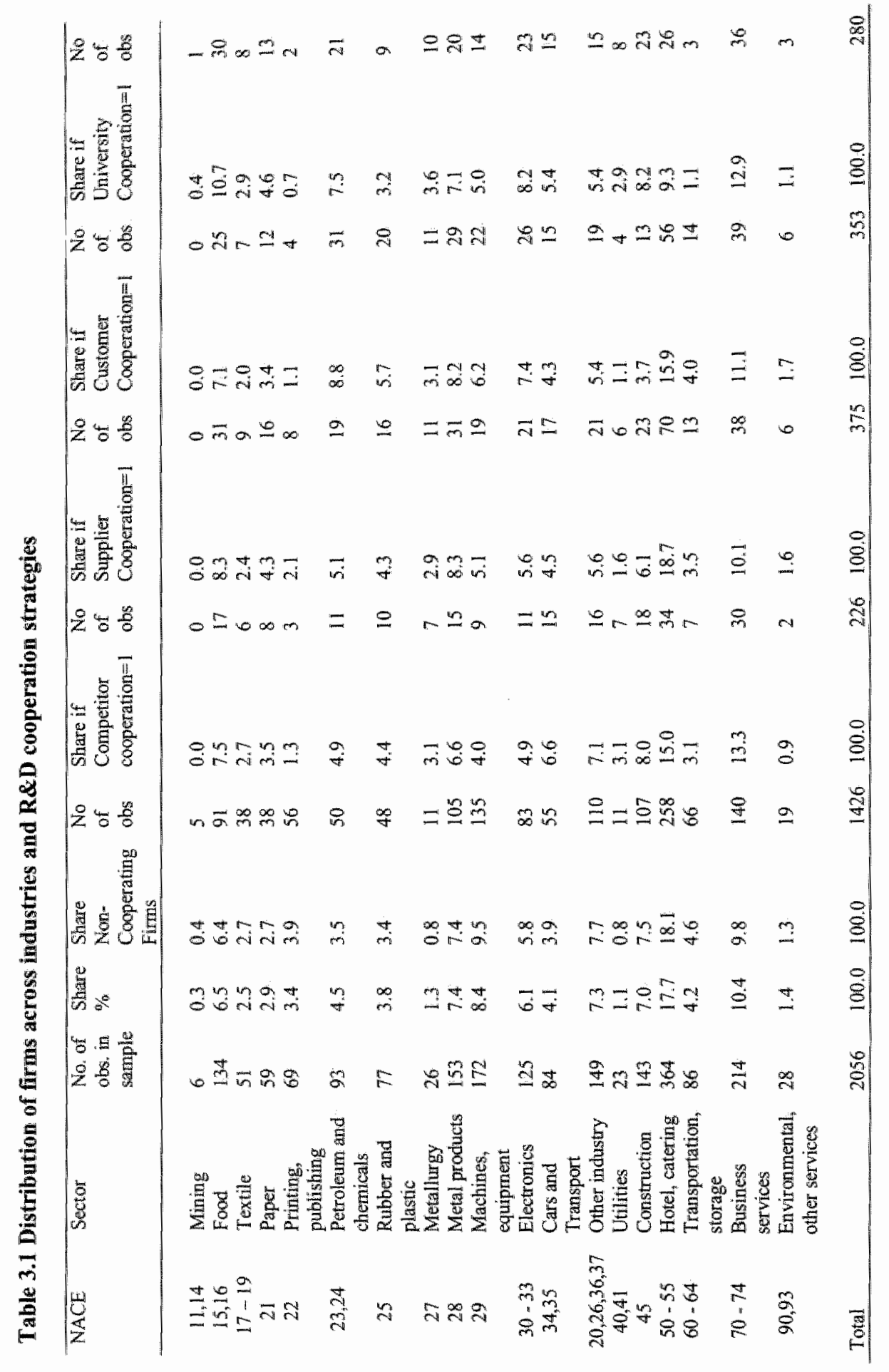


Table 3.2 Descriptive statistics for different R\&D cooperation profiles

\begin{tabular}{|c|c|c|c|c|c|c|c|}
\hline & No coop & $\begin{array}{l}\text { Competitor } \\
\text { Coop } \\
=1\end{array}$ & $\begin{array}{l}\text { Supplier } \\
\text { Coop } \\
=1\end{array}$ & $\begin{array}{l}\text { Customer } \\
\text { Coop } \\
=1\end{array}$ & $\begin{array}{l}\text { University } \\
\text { Coop } \\
=1\end{array}$ & $\begin{array}{l}\text { Mean } \\
\text { Test } 1 \\
\text { F-value }\end{array}$ & $\begin{array}{l}\text { Mean }^{2} \\
\text { Test } 2 \\
\text { F-Yalue }\end{array}$ \\
\hline & (1) & (2) & (3) & (4) & (5) & (6) & (7) \\
\hline $\begin{array}{l}\text { Competitor } \\
\text { spillovers } \\
\text { Supplier spillovers }\end{array}$ & 0.978 & 1.128 & 1.157 & 1.108 & 1.179 & 3.54 & $5.46^{* * *}$ \\
\hline Customer spillovers & 1.081 & $1.03 \mathrm{~L}$ & 1.245 & 1.133 & 1.089 & $13.63^{*}$ & $9.84 * * *$ \\
\hline University spillovers & 1.203 & 1.372 & 1.456 & 1.595 & 1.514 & $45.10^{* * *}$ & $44.50^{* * *}$ \\
\hline & 0.340 & 0.546 & 0.550 & 0.562 & 0.779 & $156.45 * * *$ & 156.49 \\
\hline
\end{tabular}

Fürm size

\begin{tabular}{|c|c|c|c|c|c|}
\hline Innovation intensity & 161 & 374 & 465 & 325 & 568 \\
\hline & 0.027 & 0.038 & 0.034 & 0.041 & 0.051 \\
\hline \multirow{3}{*}{\multicolumn{6}{|c|}{$\begin{array}{l}\text { Foreign } \\
\text { multinational } \\
\text { Domestic group }\end{array}$}} \\
\hline & & & & & \\
\hline & & & & & \\
\hline & 0.250 & 0.332 & 0.315 & 0.306 & 0.307 \\
\hline Cost Push & 1.906 & 2438 & 2.333 & 2.354 & 2.564 \\
\hline Demand Pull & 3.694 & 4.372 & 4.315 & 4.462 & 4.450 \\
\hline $\begin{array}{l}\text { Log (value added } \\
\text { per employee) }\end{array}$ & 4.459 & 4.667 & 4.627 & 4.641 & 4.670 \\
\hline 98 & & & & & \\
\hline $\begin{array}{l}\text { Log (imnovative } \\
\text { sales per employee) } \\
98\end{array}$ & 1.389 & 1.714 & 1.919 & 2.059 & 2.013 \\
\hline $\begin{array}{l}\text { Observations } \\
\text { (new sales sample) }\end{array}$ & $\begin{array}{r}1426 \\
(939) \\
\end{array}$ & $\begin{array}{l}226 \\
(154)\end{array}$ & $\begin{array}{l}375 \\
(248)\end{array}$ & $\begin{array}{l}353 \\
(238) \\
\end{array}$ & $\begin{array}{l}280 \\
(212) \\
\end{array}$ \\
\hline
\end{tabular}

* significant at $5 \%$; * * significant at $1 \%$

1. The test is the comparison of the received incoming spillovers between the groups of firms that reported engagement in competitor (supplier, customer, unversity) cooperation vis-àvis the firms that reported no such engagement.

2. The test is the comparison of the received incoming spillovers between the groups of firms that reported engagement in competitor (supplier, customer, university) cooperation vis-ávis the firms that reported no cooperation links at all. 
Finally, collaborating firms in Table 3.2 show higher labor productivity levels and higher innovative sales per employee, with the latter highest for firms cooperating with customers and universities. However, these simple mean comparisons cannot be taken as evidence of the impact of cooperation strategies on. productivity, as this requires controlling for initial productivity levels, industry differences, and the joint impact of the other variables in a multivariate analysis. The results of this analysis, estimates of equations (3.1)-(3.5), are discussed below.

\subsection{Empirical Results}

Table 3.3 reports the results of all variants of equation (3.1) with the spillover measures instrumented by the error term of equations (3.2)-(3.5). ${ }^{31}$ The auxiliary regressions (3.2)-(3.5) of the full spillover measures on the corresponding cooperation dummies in the previous period (not reported here) showed that cooperation is indeed a highly significant explanatory factor of the corresponding spillovers. For both dependent variables, labor productivity growth and innovative sales productivity growth, we first estimate an equation with aggregated measures of cooperation and spillovers, to make comparisons possible with earlier results. Results from the aggregated specification for labor productivity growth (model 1) strongly confirm the contribution of $R \& D$ cooperation to productivity growth. The cooperation variable is highly significant and positive. Taking the exponent of the coefficient minus one gives the proportional increase in productivity compared with non-cooperating firms, which amounts to a substantial 13 percent difference in productivity. In addition to the aggregate cooperation measure, the aggregate spillover measure and innovation intensity are positive and significant. Productivity growth is also higher for affiliates of foreign multinational firms and (marginally) higher for domestic group firms, while firm size and the direction of innovative efforts (demand enhancing or cost saving) have no appreciable impact. The lagged productivity variable is highly significant and negative, indicating that productivity leaders are less able to show further productivity growth. The estimated coefficient indicates that a firms with a 1 percent higher productivity level in 1996 are only able to maintain $48(1-52)$ percent of this lead in current productivity. ${ }^{32}$

\footnotetext{
3 We also estimated the models with a robust regression technique to correct for possible heteroscedasticity, but found only trivial differences in standard errors compared with the least
squares estimation.

The estimate of 48 percent appears quite small and maybe should be interpreted with care. Other productivity term in production function equations.
} 
Table 3.3 Regression results for productivity growth, 1996-1998

\begin{tabular}{|c|c|c|c|c|c|c|}
\hline & \multicolumn{3}{|c|}{$\begin{array}{l}\text { Growth value added per employee } \\
\text { (growth labor productivity) }\end{array}$} & \multicolumn{3}{|c|}{$\begin{array}{l}\text { Growth new to the market salles pen } \\
\text { employee (growth innovative sales } \\
\text { productivity) }\end{array}$} \\
\hline & (1) & $(2)$ & $(3)^{+}$ & (4) & (5) & $(6)^{4}$ \\
\hline R\&D & $0.0593 * *$ & & & $0.1823^{*}$ & & \\
\hline Cooperation & $(0.0225)$ & & & $(0.1055)$ & & \\
\hline Competitor & & $0,0747 * *$ & $0.1122^{*}$ & & $=0.1611$ & $0.4922^{*}$ \\
\hline Cooperation & & $(0.0364)$ & $(0.0604)$ & & $(0.1698)$ & $(0.2757)$ \\
\hline Supplier & & 0.0208 & $0.1079 * *$ & & -0.0119 & -0.0978 \\
\hline Cooperation & & $(0.0308)$ & $(0.0444)$ & & $(0.1469)$ & $(0.1941)$ \\
\hline Customer & & -0.0110 & -0.0268 & & 0.0780 & 0.2477 \\
\hline Cooperation & & $(0.0320)$ & $(0.0456)$ & & $(0.1479)$ & $(0.1940)$ \\
\hline University & & 0.0214 & 0.0676 & & $0.3239 * *$ & $0.5066^{*}$ \\
\hline Cooperation & & $(0.0351)$ & $(0.0472)$ & & $(0.1614)$ & $(0.2003)$ \\
\hline Incoming & $0.0080 * * *$ & & & $0.0521 * * *$ & & \\
\hline spillovers & $(0.0022)$ & & & $(0.0101)$ & & \\
\hline Competitor & & 0.0138 & 0.0064 & & -0.0507 & -0.0482 \\
\hline spillovers & & $(0.0125)$ & $(0.0078)$ & & $(0.0571)$ & $(0.0567)$ \\
\hline Supplier & & 0.0135 & -0.0024 & & -0.0254 & -0.0301 \\
\hline spillovers & & $0.0120)$ & $(0.0076)$ & & $(0.0562)$ & $(0,0563)$ \\
\hline Customer & & 0.0034 & -0.0012 & & $0.1706^{* * * *}$ & $0.1726 *$ * * * * \\
\hline spillovers & & $(0.0115)$ & $(0.0072)$ & & $(0.0523)$ & $(0.0521)$ \\
\hline University & & 0.0310 & $0.0069^{*}$ & & 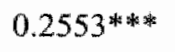 & 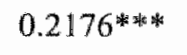 \\
\hline spillovers & & $(0.0195)$ & $(0.0040)$ & & $(0.0849)$ & $(0.0846)$ \\
\hline \multirow[t]{2}{*}{ Firm size } & 0.0127 & 0.0148 & 0.0133 & $0.0889 *$ & $0.1127 * *$ & $0.0814^{*}$ \\
\hline & $(0.0092)$ & $(0.0093)$ & $(0.0092)$ & $(0.0480)$ & $(0.0483)$ & $(0.0477)$ \\
\hline Innovation & 0.0054 & $0.0055^{* * * * * * * ⿲ 二 丨 匕 ~}$ & $0.0055^{* *}$ & 0.0612 & 0.1025 & 0.0007 \\
\hline intensity & $(0.0009)$ & $(0.0009)$ & $(0.0009)$ & $(0.6149)$ & $(0.6207)$ & $(0.6185)$ \\
\hline Foreign & $0.1332 * *$ & $0.1420^{* * * *}$ & $0.1363^{* * *}$ & 0.1712 & $0.2164^{*}$ & $0.2346^{*}$ \\
\hline multinational & $(0.0278)$ & $(0.0280)$ & $(0.0280)$ & $(0.1296)$ & $(0.1313)$ & $(0.1302)$ \\
\hline Domestic & $0.0431^{*}$ & $0.0472^{* *}$ & 0.0426 & -0.1499 & -0.1283 & -0.1576 \\
\hline group & $(0.0237)$ & $(0.0238)$ & $(0.0238)$ & $(0.1099)$ & $(0.1102)$ & $(0.1096)$ \\
\hline Cost push & 0.0072 & 0.0067 & 0.0073 & $-0.0672 *$ & $-0.0602 *$ & $-0.0586^{* * * 3 *}$ \\
\hline inno vation & $(0.0061)$ & $(0.0061)$ & $(0.0062)$ & 0.0277 & $(0.0278)$ & $(0.0277)$ \\
\hline Demand pull & 0.0038 & 0.0052 & 0.0053 & $0.0590^{*}$ & $0.0587 *$ & $0.0607^{*}$ \\
\hline innovation & $(0.0069)$ & $(0.0070)$ & $(0.0072)$ & $(0.0340)$ & $(0.0343)$ & $(0.0340)$ \\
\hline $\log$ (productivity) & $-.5252^{* * *}$ & $-5218 * * *$ & $-.5245^{* * *}$ & 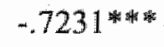 & $-.7163^{*} * *$ & 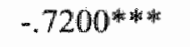 \\
\hline 1996 & $(0.0155)$ & $(0.0155)$ & $(0.0155)$ & $(0.0270)$ & $(0.0272)$ & $(0.0270)$ \\
\hline Industry dummies & Yes & Yes & Yes & Yes & Yes & Yes \\
\hline $\mathrm{R}^{2}$ & 0.39 & 0.39 & 0.39 & 0.37 & 0.37 & 0.37 \\
\hline Number of obs. & 2056 & 2056 & 2056 & 1360 & 1360 & 1360 \\
\hline
\end{tabular}


Standard crrors in parentheses significatit at $10 \%$ * significant at $5 \%$; ** significant at $1 \%$ + Cooperation wariables in columns (2) and (5) take the value one if an establishment indicated that it was engaged in a particular strategy in the 1996 survey (within the period 1994-1996). Cooperation variables in columns (3) and (6) take the value one if firms engaged in "persistent cooperation": they reported the specific type of cooperation in the two consecutive surveys, 1994 1996 and 1996-1998.

If spillovers and cooperation are differentiated by type of partner and source in model 2, only competitor cooperation is found to have an independent positive impact on labor productivity growth. If the cooperation dummy takes the value one only for persistent collaborators (firms that are cooperating with the respective partners both in 1996 and 1998) both competitor and supplier cooperation are found to have positive and significant impacts (model 3). In model 2, the individual source-specific spillovers are not significant, but in model 3, university spillovers do have a marginally significant and positive impact on labor productivity growth.

Models 4-6 present the results with the growth in firms" productivity in generating sales of innovative products new to the market per employee as the dependent variable. In the aggregate specification (model 4), again cooperation and spillovers are significant contributors to this type of productivity growth, but in the differentiated equations (models 5 and 6 ) we see different impacts of the different cooperation types. Now it is university cooperation that has a significant impact on productivity growth and competitor cooperation gets a marginally significant impact for persistent collaborators (model 6). In addition, clear contributions are confirmed by spillovers (not due to cooperation) from universities and from customers. Surprisingly, innovation intensity has no significant impact here, but larger firms are more successful in obtaining this type of productivity growth. Affiliates of foreign multinationals again are able to record systematically higher productivity growth (albeit only marginally significant), but domestic group membership has no effect. The cost and demand orientation of innovative efforts matter strongly for productivity growth in the expected direction. A demand orientation is more likely to translate into growth in new product sales, but a cost orientation has a negative impact. Firms that devote more R\&D efforts to cost reduction are not able to devote a much attention to market expansion and perform less in this type of productivity growth. Lagged productivity has a significantly negative impact with a coefficient of 0.72 , indicating that firms with a 1 percent higher productivity level in 1996 are only able to maintain 0.28 percent of this lead in current productivity. This indicates that a past leading performance in innovative sales productivity is more difficult to sustain than a lead in labor productivity.

Overall, the results show that $R \& D$ cooperation, innovation intensity, and incoming spillovers all have independent impacts on productivity growth (with the exception of innovation intensity in the innovative sales equations). The results
diverge once spillovers and cooperation are differentiated by source and partner. 
The direction of this divergence corresponds to our priors concerning the purposes of different types of collaboration. R\&D cooperation with suppliers appears more of an incremental nature focused on reducing input costs and labor productivity. Cooperation with universities is more focused on innovations aimed at creating novel products, improving innovative sales productivity. Competitor collaboration is the only type of collaboration that has multiple purposes and impacts, effective in generating both labor productivity increases (e.g. through cost sharing in R\&D) and innovative sales productivity increases (e.g. enabling the start of innovation projects through risk sharing and improving sales through the establishment of technological standards). Customer cooperation, in contrast, is not found to have any discernable impact on productivity growth: perhaps because the information on customer demands and technological requirements is already effectively captured by incoming spillovers from customers through market transactions, and does not require formal collaborative $R \& D$ agreements. The role of universities in firms' productivity performance also stands out, as it is the only source of knowledge that both provides effective public spillovers (not due to collaboration) and improves firms' innovative sales productivity through formal R\&D cooperation.

\subsection{Conclusions}

Despite a growing literature on $R \& D$ cooperation in both the fields of management and industrial economics, surprisingly little evidence has emerged on the performance effect of $R \& D$ collaboration. This chapter analyses the impact of R\&D cooperation on firm performance jointly with the impact of R\&D expenditures and the effect of incoming knowledge spillovers that are not due to formal collaborative agreements. We differentiate between the type of R\&D partner (competitors, suppliers, customers, and universities \& research institutes) and consider two performance measures: labor productivity and productivity in innovative sales new to the market. Using data on a large sample of Dutch innovating firms in two waves of the Community Innovation Survey $(1.996,1998)$, we examine the impact of R\&D collaboration on productivity growth in 1996-1998. We find that supplier and competitor cooperation have a significant impact on labor productivity growth, while cooperation with universities \& research institutes and again competitor cooperation positively affects growth in sales per employee of products and services new to the market. New product sales are furthermore stimulated by incoming knowledge spillovers (not due to collaboration) from customers and universities \& research institutes. The results are sensitive to the lag with which innovation strategies are allowed to impact productivity growth. Generally, allowing for a more variable lag structure by examining the impact of cooperation strategies that are sustained over a 2-4 year period demonstrated a more robust impact of cooperation on productivity. 
The results confirm a major heterogeneity in the rationales and goals of R\&D cooperation, with competitor and supplier cooperation focused on incremental innovations improving the productivity performance of firms, while university cooperation and again competitor cooperation are instrumental in creating and bringing to market radical innovations, generating sales of products that are novel to the market, and hence improving the growth performance of firms (Klomp and Van Leeuwen, 2001). The findings provide qualified support for the notion that that cooperating firms are generally engaged in higher-level innovative activities (Tether, 2002). This holds unequivocally for firms collaborating with universities (e.g. to get access to basic research) and competitors (to allow R\&D for risky projects), but not for firms engaged in 'vertical cooperation' with suppliers and customers. If the latter types of cooperation are also partly focused on more "radical" innovations, than there is no evidence in our analysis that these efforts have an overall impact improving firms' performance in bringing novel products to the market. ${ }^{33}$

The findings go some way in explaining the more ambiguous results obtained in previous empirical work on the effects of cooperation on innovative sales and productivity, where single performance measures were used and no (variation in) lag structures could be examined because of the cross section nature of the data (e.g. Heshmati and Lööf, 2002; Monjon and Waelbroeck, 2003). Since different R\&D strategies can impact performance with different lag structures, future research should further explore the intertemporal structure of the impact of R\&D strategies on innovation output and firm performance. The increasing availability of consecutive CIS surveys will allow for the construction of panel data sets to examine the effectiveness of various innovation strategies in more detail.

\footnotetext{
3 This does not rule out that minority of such collaborations, e.g. "co-makerships" between firms thank an anonymous referee for poine fundamental and radically innovative research efforts. We
} 


\section{Appendix A Description of Variables}

Variable name Definition

1 Competitor cooperation

2 Supplier cooperation

3. Customer cooperation

4 University cooperation

5 Competitor Incoming spillover

6 Supplier Incoming spillover

7 Customer Incoming spillover

$8 \quad$ University \ncoming spillover

9 Innovation intensity
1 if the business unit reported engagement in innovation in cooperation strategy with competitors, else zero

1 if the business unit reported engagement in innovation in cooperation strategy with suppliers, else zero

1 if the business unit reported engagement in innovation in cooperation strategy with customers, else zero

1 if the business unit has reported engagement in innovation in cooperation strategy with unversities, innovation centers, or research institutions, else zero

Importance of competitors as source of knowledge for the firm's innowation process. Constructed as residual from the auxiliary regression of competitor spillover taken from 1998 survey on a competitor cooperation dummy taken from 1996 survey.

Importance of suppliers as source of knowledge for the firm's inmovation process. Constructed as residual from the auxiliary regression of supplier spillover taken from 1998 survey on a supplier cooperation dummy taken from 1996 survey.

Importance of customers as source of knowledge for the firm"s innovation process. Constructed as residual from the auxiliary regression of customer spillover taken from 1998 survey on a supplier cooperation dummy taken from 1996 survey.

Average of importance of universities, innovation centers, and research institutions ass source of knowledge for the firm's innowation process. Constructed as residual from the auxiliary regression of university spillover taken from 1998 survey on a university cooperation dummy taken from 1996 survey.

Total innovation expenditures/sales 
Chapter 3

10 Firm size

Logarithm of number of employees

11. Domestic

1 if the business unit is part of a domestic firm grouping, group else 0

12 Foreign mullinational

1 if the firm is an affiliate of a foreign multinational, else 0

13 Cost push

Importance of cost-saving objectives for the firm's innovations Constructed as a sum of scores on 4 categories of objectives, relating to processes, labor, materials, and energy.

14 Demand pull

Importance of demand-enhancing objectives for the firm's innovations. Constructed as sum of scores on 2 categories of objectives, relating to products quality and new products and markets.

15 Productivity growth Growth in the net value added per employee $=$ log (labor (value added) productivity 1998) - $\log$ (labor productivity 1996)

16 Productivity growth Growth in the value of sales new to the market per (new sales) employee 1996-1998 = log $(1+$ new sales/employees 1998) - $\log (1+$ new sales/employees 1996)

Note: all independent variables are for 1996 except for the spillover variables 


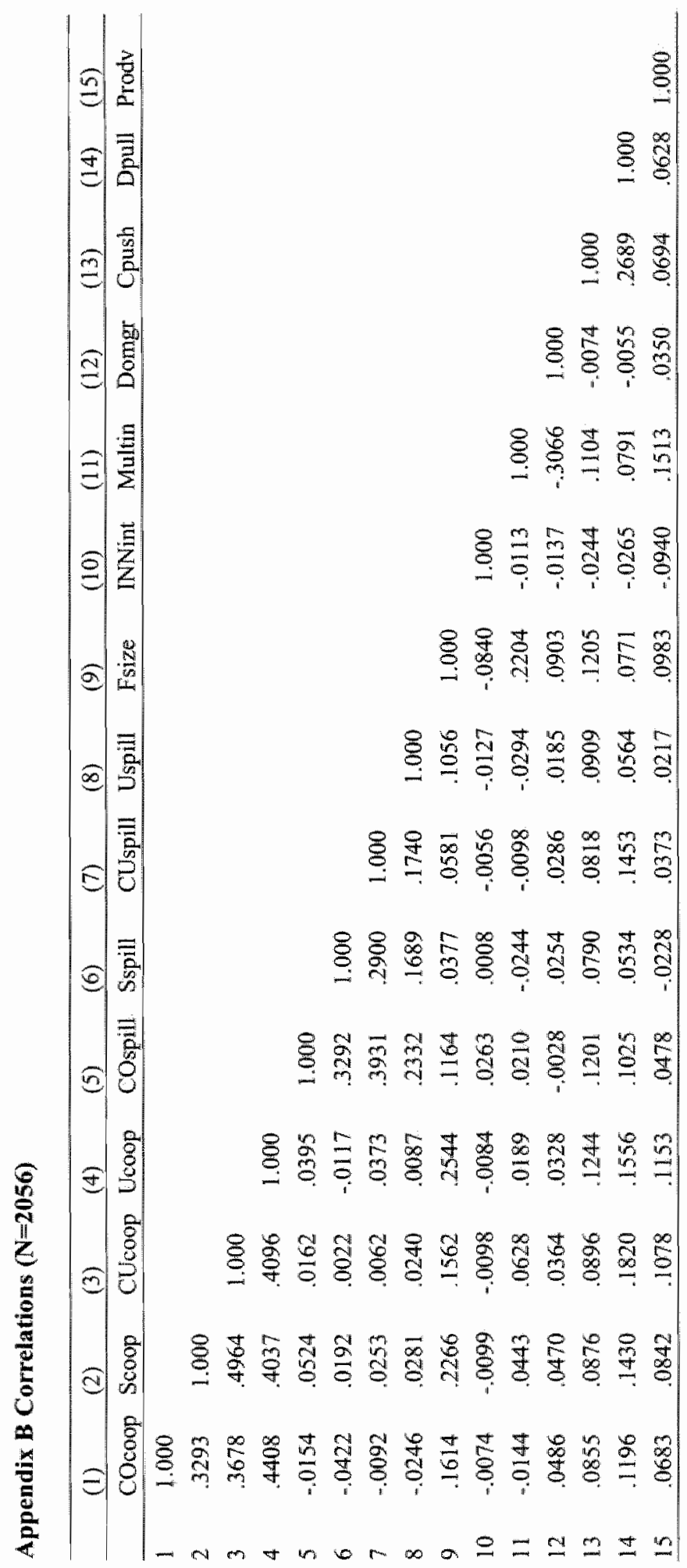




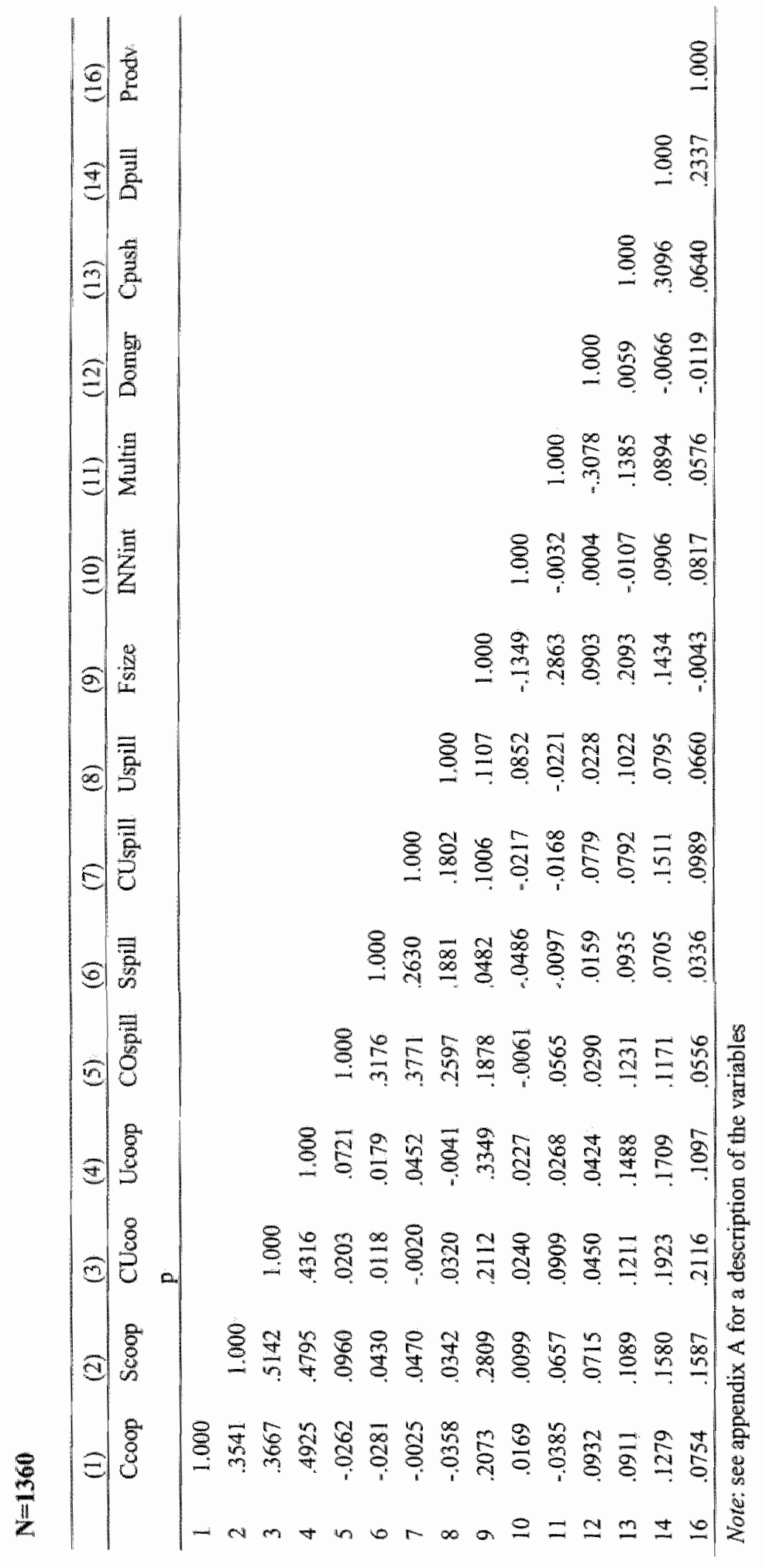


Cooperative R\&D and Firm Performance

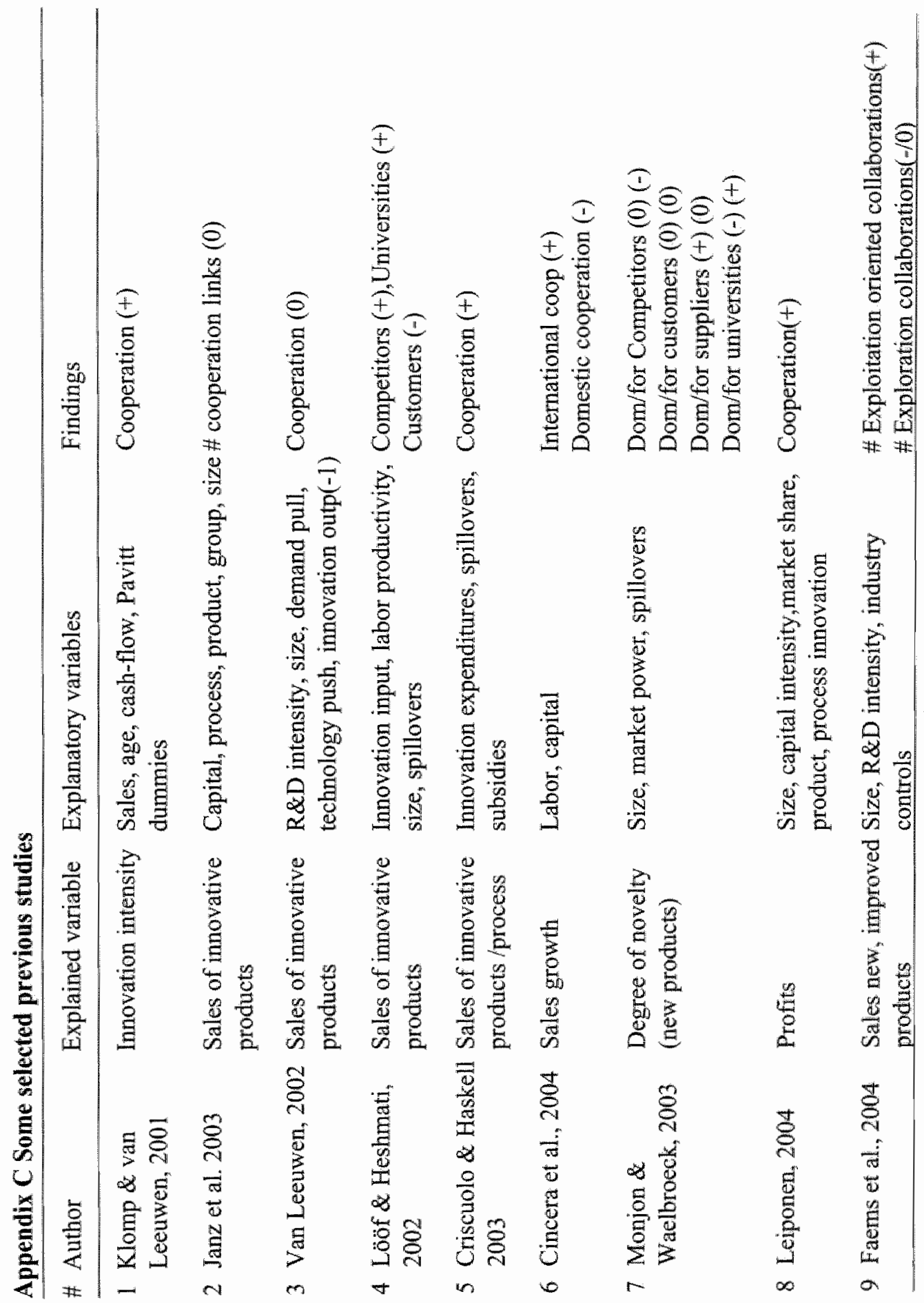




\title{
CHAPTER 4
}

\section{Testing for complementarity and substitutability in case of multiple practices}

\begin{abstract}
A number of recent empirical studies of firm-level productivity have been concerned with establishing potential complementarity between multiple organizational design practices. These papers have drawn conclusions on basis of the effect of the interaction term between each possible pair of practices. In this paper we show that this approach may lead to misleading results in case more than two practices are considered. We develop a proper testing procedure for complementarity and substitutability in case there are multiple organizational practices that affect output. The testing methodology is illustrated by an empirical example of three innovation practices. The testing framework can easily be applied to test for supermodularity.
\end{abstract}

Acknowledgement: The empirical part of this research has been performed at CEREM/Statistics Netherlands. The views expressed in this chapter are those of the author and do not necessarily reflect the policies of Statistics Netherlands. I thank Franz Palm for useful comments. 


\subsection{Introduction}

Researchers in the fields of industrial organization and management have long been interested in investigating complementary relations between various organizational practices of a firm. Complementarity is understood in this context to exist if the implementation of one practice increases the marginal or incremental return to other practices. Thus, a joint implementation of several practices may result in economies of scope in a sense proposed by Baumol et al. (1988). By the same token the implementation of one practice can decrease the marginal or incremental return to other practices. This is the case of substitutability. Examples of studies of complementarity in the economics and management literature are the relationships between human resource practices and firm strategy (Ichniowski et al., 1997), firms' internal R\&D and external technology sourcing (Arora and Gambardella, 1994), different government innovation policies (Mohnen and Röller, 2002), information technology, workplace reorganization, and new product and service innovations (Bresnahan et al, 2002), the adoption of different information technologies in emergency health care (Athey and Stern, 2002), and process and product innovation (Miravete and Pernias, 2004).

There are two econometric approaches that can be used to test for complementarity ${ }^{33}$ : the correlation and production function approach. The former, coined "adoption" approach has been by far the most popular among empirical researchers due to its simplicity (Arora, 1996). The adoption approach tests conditional correlations based on the residuals of reduced form regressions of the practices of interest on all observable exogenous variables. However, although this test can serve as supportive evidence of complementarity if practices are adopted simultaneously (i.e. positive correlation), it cannot serve as a definitive test. Estimated correlations between residual terms may be the result of common omitted exogenous variables or measurement errors. Even in case of robust correlation between practices, there is no guarantee that decision markers were sufficiently well informed such that they indeed chose efficiency or output enhancing combinations of practices.

The only conclusive test for complementarity or substitutability is based on the 'production function' approach, in which organizational performance is related to exclusive combinations of organizational practices. This approach has been used in recent empirical work testing for complementarity between two practices (e.g. Veugelers and Cassiman, 2003), in which case a complementarity or substitutability test is a simple one-tailed t-test on the interaction variable. However, no robust testing procedure has been available to test for complementarity or substitutability with more than two practices, which has prevented a wide use of the production function approach in applied empirical work. Previous research examining complementarity between more than two practices was limited to estimating the

\footnotetext{
${ }^{3}$ See Athey and Stern, 1998 for discussion
} 
pair-wise interaction effects, ignoring the interaction with other practices ${ }^{34}$. This approach is problematic for two reasons. Firstly, because it ignores the crossterms, which do not have to be zero, it is prone to an omitted variable bias which affects all coefficients used in the complementarity test. Secondly, the omitted cross-terms affect the test result directly, since they are involved in its computation (see definition below). In this chapter we argue that the entire point of complementarity in organizational practices is that the whole set of practices are complements, not just pairs of practices. Therefore, the proper complementarity or substitutability test requires testing that considers the whole set of organizational practices. We further show that the procedure that considers onlly pairs of practices, used in previous research may result in erroneous conclusions about complementarity.

The remainder of this chapter is organized as follows. In section two we review the definitions of complementarity received in the literature. Section three details the testing procedure of complementarity and substitutability in case of multiple (more than two) practices, using the multiple inequality restrictions (Kudo, 1963; Wolak, 1989). We discuss both cases when practices are measured with continuous as well as dichotomous variables. The latter category is potentially relevant in a broad set of empirical applications relating for example, to institutional reforms in trade or financial liberalization as well as decisions on $R \& D$ and innovation. The analytical solution and an empirical application concerning complementarity or substitutability in product, process and organizational innovation and their impact on labor productivity are demonstrated in section four. Section five concludes.

\subsection{Complementarity and substitutability}

This section describes the definitions and conditions concerning complementarity and substitutability both for the case of continuously measured practices and the case of dichotomous practices. Consider an objective function $f$ of which the value is determined by the practices $x_{p}(p=1, \ldots, n)$. In case the practices are measured continuously the following definition of complementarity holds (e.g. Baumol et al., 1988):

\section{Definition 1 (contimuous practices)}

Practices $x_{i}$ and $x_{j}$ are considered complementary in the function $f$ if and only if $\partial^{2} f / \partial x_{i} \partial x_{j}$ is always larger or equal to zero and larger than zero for at least one value of $\left(x_{1}, \ldots, x_{n}\right)$

34 Recent examples include: Athey and Stern, 2002; Bresnathan et al., 2002, Caroli and Van Reenen, 2001; Black and Lynch, 2001. 
The definition for substitutability is identical as definition 1 except that "larger" is replaced by "smaller". We use a cross-term specification of the objective function $f$ to test for complementarity or substitutability. The expressions for $n$ equal to 2,3 and 4 are:

$$
\begin{aligned}
& f\left(x_{1}, x_{2}\right)=\alpha_{0}+\alpha_{1} x_{1}+\alpha_{2} x_{2}+\alpha_{12} x_{1} x_{2} \\
& f\left(x_{1}, x_{2}, x_{3}\right)=f\left(x_{1}, x_{2}\right)+\alpha_{3} x_{3}+\alpha_{13} x_{1} x_{3}+\alpha_{23} x_{2} x_{3}+\alpha_{123} x_{1} x_{2} x_{3} \\
& f\left(x_{1}, x_{2}, x_{3}, x_{4}\right)=f\left(x_{1}, x_{2}, x_{3}\right)+\alpha_{4} x_{4}+\alpha_{14} x_{1} x_{4}+\alpha_{24} x_{2} x_{4}+\alpha_{34} x_{3} x_{4}+ \\
& +\alpha_{124} x_{1} x_{2} x_{4}+\alpha_{234} x_{2} x_{3} x_{4}+\alpha_{1234} x_{1} x_{2} x_{3} x_{4}
\end{aligned}
$$

The cross-derivatives $\partial^{2} f / \partial x_{1} \partial x_{2}$ are equal to $\alpha_{12}$ for equation (4.1), $\alpha_{12}+\alpha_{123} x_{3}$ for equation (4.2) and $\alpha_{12}+\alpha_{123} x_{3}+\alpha_{124} x_{4}+\alpha_{1234} x_{3} x_{4}$ for equation (4.3), respectively. This implies that there is complementarity for the case of practices 1 and 2 if $\alpha_{12}>0$. In case of three practices, $\alpha_{12}+\alpha_{123} \min \left(x_{3}\right) \geq 0$ and $\alpha_{12}+\alpha_{123} \max \left(x_{3}\right) \geq 0$ should hold with at least one of the inequalities holding. In case of four practices there are four inequalities of which at least one should hold strictly:

$$
\begin{aligned}
& \alpha_{12}+\alpha_{123} \min \left(x_{3}\right)+\alpha_{124} \min \left(x_{4}\right)+\alpha_{1234} \min \left(x_{3}\right) \min \left(x_{4}\right) \geq 0 \\
& \alpha_{12}+\alpha_{123} \min \left(x_{3}\right)+\alpha_{124} \max \left(x_{4}\right)+\alpha_{1234} \min \left(x_{3}\right) \max \left(x_{4}\right) \geq 0 \\
& \alpha_{12}+\alpha_{123} \max \left(x_{3}\right)+\alpha_{124} \min \left(x_{4}\right)+\alpha_{1234} \max \left(x_{3}\right) \min \left(x_{4}\right) \geq 0 \\
& \alpha_{12}+\alpha_{123} \max \left(x_{3}\right)+\alpha_{124} \max \left(x_{4}\right)+\alpha_{1234} \max \left(x_{3}\right) \max \left(x_{4}\right) \geq 0
\end{aligned}
$$

In case the practices take on discrete values variables (step size chosen equal to one) we replace the derivative in definition 1 by a difference. If we consider the first two practices, without loss of generality, the following definition holds:

\section{Definition 2 (discrete practices)}

Practices $x_{l}$ and $x_{2}$ are considered complementary in the function $f$ if and only if $f\left(x_{1}+1, x_{2}+1, x_{3}, \ldots, x_{n}\right)+f\left(x_{1}, x_{2}, x_{3,}, \ldots, x_{n}\right) \geq$ $f\left(x_{1}+1, x_{2}, x_{3}, \ldots, x_{n}\right)+f\left(x_{1}, x_{2}+1, x_{3}, \ldots, x_{n s}\right)$ with the inequality holding strictly for at least one value of $\left(x_{1}, \ldots, x_{n}\right)$

The case of dichotomously measured practices (practice is used or not) is a special case of this definition. In that case, functions (4.1), (4.2), and (4.3) can be more conveniently rewritten in terms of the possible combinations of practices. 
With two practices, the collection of possible combinations is defined in the usual binary order as $D=\{(0,0),(0,1),(1,0),(1,1)\}$. We introduce the indicator function $I_{D=(r, s)}$, equal to one when the combination is $(r, s)$, else zero. Similar collections of $D$ with corresponding indicators functions $I_{D=\{r, s, j}$ and $I_{D \text { as } r, s i, w\}}$ are introduced for the case of three and four practices. The functions $f($.$) are rewritten$ as:

$$
\begin{aligned}
& f\left(x_{1}, x_{2}\right)=\sum_{i=0}^{1} \sum_{s=0}^{1} \beta_{r s} I_{\left(x_{1}, x_{2}, j=(r, s)\right.} \\
& f\left(x_{1}, x_{2}, x_{3}\right)=\sum_{r=0}^{1} \sum_{s=0}^{1} \sum_{s=0}^{1} \beta_{r s t} I_{\left(x_{i}, x_{2}, x_{3}\right)=(r, s, t)} \\
& f\left(x_{1}, x_{2}, x_{3}, x_{4}\right)=\sum_{r=0}^{1} \sum_{s=0}^{1} \sum_{t=0}^{1} \sum_{u=0}^{1} \beta_{r s s t u} I_{\left(x_{1}, x_{2}, x_{3}, x_{4}\right)=\left(r, x, x_{s}, t\right)}
\end{aligned}
$$

The conditions of complementarity now correspond to $\alpha_{12}=\beta_{11}+\beta_{00}-\beta_{10}-\beta_{01}>0$ for two practices, $\alpha_{12}=\beta_{110}+\beta_{000}-\beta_{100}-\beta_{010} \geq 0$ and $\alpha_{12}+\alpha_{123}=\beta_{111}+\beta_{001}-\beta_{101}-\beta_{011} \geq 0$ for three practices and the following four inequalities for four practices:

$$
\begin{aligned}
& \alpha_{12}=\beta_{1100}+\beta_{0000}-\beta_{1000}-\beta_{0100} \geq 0 \\
& \alpha_{12}+\alpha_{123}=\beta_{1110}+\beta_{0010}-\beta_{1010}-\beta_{0110} \geq 0 \\
& \alpha_{12}+\alpha_{124}=\beta_{1101}+\beta_{0001}-\beta_{1001}-\beta_{0101} \geq 0 \\
& \alpha_{12}+\alpha_{123}+\alpha_{124}+\alpha_{1234}=\beta_{1111}+\beta_{0011}-\beta_{1011}-\beta_{0111} \geq 0
\end{aligned}
$$

\subsection{The testing procedure}

In case of two practices the test for complementarity is a one-sided t-test of the null hypothesis of $\alpha_{12}=0$ in equation (1). However, in case of more than two practices, the number of inequality constraints that have to be tested simultaneously is $2^{n-4}$. Statistical tests of $H_{0}: R \beta=r$ versus $H_{a}: R \beta \geq r$ with $R$ having rank $k$ in the 
standard linear model $y=X \beta+\varepsilon$ with one of the inequalities holding strictly have been considered in Gouriéroux, Holly, and Monfort (1982). Kudô (1963, p.414) derived the theorem underlying this test. The so-called normal orthant probability, $P\{\Omega\}$, being the probability that the variables with a multivariate normal distribution with mean zero and variance-covariance matrix $\Omega=R\left(X^{\prime \prime} X\right)^{-1} R^{\prime}$ are all positive, plays a central role in this theorem:

\section{Theorem 1 (the Kudo theorem):}

Let $\left(x_{1}, \ldots, x_{k}\right)$ have a multivariate normal distribution with mean zero and known variance-covariance matrix $\Sigma$ and let $L R=-2 \ln \lambda$ where $\lambda$ is the likelihood ratio test statistic of $H_{0}: E\left(x_{i}\right)=0$ for $i=l_{, \ldots}, k$ versus $H_{A}: E\left(x_{i}\right) \geq 0$ for $i=1_{0} \ldots, k$ where the inequality is strict for at least one value of $i$. Then $\operatorname{Pr}(L R \geq c)=\sum_{M \in R} \operatorname{Pr}\left(\chi_{m(M)}^{2} \geq c\right) P\left(\Sigma_{B}^{-1}\right\} P\left(\Sigma_{M: B}\right\}$ where the summation runs over all the subsets $M$ of $K=\{1, \ldots, k$ including $\emptyset, n(M)$ is the number of elements in $M, B$ is: the complement of $M$, so that $M \cap B=\emptyset$ and $M \cup B=K, \Sigma_{B}$ is the variancecovariance matrix of $x_{1}$ with $i \in B, \Sigma_{M-B}$ is the same for $x_{i}$ with $i \in M$ but under the condition that $x_{i}=0$ for $i \in B .^{35}$

From this theorem it follows that in case of $p$ inequality restrictions we have that the probability of $L R$ exceeding $c$ under the null hypothesis equals a mixed chisquare distribution of $\sum_{i=0}^{p} \operatorname{Pr}\left\{\chi_{i}^{2} \geq c\right\} w_{i p}$ (see also Shapiro, 1985, p.138 and Wolak, 1989, p.214). ${ }^{36}$ Therefore, the p-value equals $1-\sum_{i=0}^{p} \operatorname{Pr}_{r}\left(\chi_{i}^{2} \geq L R\right\} w_{i p}$. Shapiro (1985) proves that the weights sum up to unity. The statistic can be compared to Table 1 from Kodde and Palm (1986) who provide critical values $\left(c_{i}\right.$ and $\left.c_{u}\right)$ for significance levels ranging in size from 0.25 to 0.001 and degrees of freedom from $I$ to 40 . In case the computed value falls in the indecision region, an exact p-value must be computed. The weights for two restrictions $(n=3)$ are $w_{i 2}=\cos ^{-1}\left(\Omega_{12} / \sqrt{\Omega_{11} \Omega_{23}}\right) / 2 \pi$ where $\Omega_{i j}=R_{i}\left(X^{\prime} X\right)^{-1} R_{j}^{\prime}$ with $R_{j}$ being the $j$ th row of $R, w_{12}=1 / 2$ and $w_{22}=1 / 2-w_{02}$ (see Shapiro, 1985). Computation of weights requires some more work for four ( $n$ is 4 ) or more restrictions. The normal orthant

\footnotetext{
35 For the empty set $M=0$ we have that $\chi_{m(M)}^{2}=\chi_{0}^{2}$ is a constant zero and $P\left(\Sigma_{N}^{-1}\right)=P_{R} \Sigma_{H K}=1$

${ }^{36}$ Because $\left.P r x_{0}^{2} \geq a\right\}=0$ for all $a$, the summation could also run from I up till $p$. In empirical applications the variance-covariance matrix has to be estimated and the mixed chi-square distribution only holds asymptotically.
} 
probability plays a central role in this computation ${ }^{37}$. The weights $w_{p y}$ and $w_{0, p}$ are equal to $P\{\Omega\}$ and $P\left\{\Omega^{-1}\right\}$, respectively, where $\Omega$ is the positive-definite covariance matrix of $\left(x_{1}, \ldots, x_{p}\right)$. Define $P=\{1, \ldots, p\}$ and $M(k)$ the subsets of $P$ of exactly $k$ elements $\left(\begin{array}{l}p \\ k\end{array}\right)$ in number). The weights $w_{k p}$ where $k=1, \ldots, p-1$ are then as follows:

$$
w_{k p}=\sum_{M(k) \subseteq P} P\left\{\Omega_{M(k), 11}-\Omega_{M(k), 12} \Omega_{M(k), 22}^{-1} \Omega_{M(k), 21} j P_{\left\{\Omega_{M(k), 22}\right\}}\right\}
$$

where $\Omega_{M(k, 1)}$ is the $k x k$-matrix obtained from $\Omega$ after only keeping the rows and columns corresponding to the elements of $M(k), \Omega_{\text {arkm }}$ is the $k x(p-k)$-matrix obtained from $\Omega$ after keeping the rows corresponding to the elements of $M(k)$ and the columns corresponding to all the elements of $P$ that are not in $M(k)$, $\Omega_{M(k, 21}$ is the $(p-k) \times k$-matrix obtained from $\Omega$ after keeping the rows corresponding to all the elements of $P$ that are not in $M(k)$ and the columns corresponding to the elements of $M(k)$, and $\Omega_{w / 22}$ is the $(p-k) x(p-k)$-matrix obtained from $\Omega$ after keeping the rows and columns corresponding to all the elements of $P$ that are not in $M(k)$.

We illustrate (4.7) for the case of four practices and, hence, $p$ equal to 4 . For four practices we have that $w_{04}+w_{14}+w_{24}+w_{34}+w_{44}=1$ (Shapiro, 1987), where $w_{14}$ and $w_{34}$ are as follows:

$$
\begin{aligned}
& w_{14}=P\left\{\sigma_{11}\right\} P\left\{\left(\begin{array}{lll}
\sigma_{22} & \sigma_{23} & \sigma_{24} \\
\sigma_{23} & \sigma_{33} & \sigma_{34} \\
\sigma_{24} & \sigma_{34} & \sigma_{44}
\end{array}\right)^{-1}\right\}+P\left\{\sigma_{22}\right\} P\left\{\left(\begin{array}{lll}
\sigma_{11} & \sigma_{13} & \sigma_{14} \\
\sigma_{31} & \sigma_{33} & \sigma_{34} \\
\sigma_{41} & \sigma_{43} & \sigma_{44}
\end{array}\right)^{-1}\right\} \\
& +P\left\{\sigma_{33}\right\} P\left\{\left(\begin{array}{lll}
\sigma_{11} & \sigma_{12} & \sigma_{14} \\
\sigma_{21} & \sigma_{22} & \sigma_{24} \\
\sigma_{41} & \sigma_{42} & \sigma_{44}
\end{array}\right]^{-1}\right\}+P\left\{\sigma_{44}\right\} P\left\{\left(\begin{array}{lll}
\sigma_{11} & \sigma_{12} & \sigma_{13} \\
\sigma_{21} & \sigma_{32} & \sigma_{23} \\
\sigma_{31} & \sigma_{32} & \sigma_{33}
\end{array}\right]^{-1}\right\} \\
& w_{24}=\sum_{j=1}^{3} \sum_{j=i+1}^{4} q_{i j} \text { where } q_{i j}=P\left\{\Omega_{M(k), k i}-\Omega_{M(k), j} \Omega_{M(k), j l}^{-1} \Omega_{M(k), j l}\right\} P\left\{\Omega_{M(k), j j}^{-1}\right\}
\end{aligned}
$$

\footnotetext{
${ }^{37}$ Several methods are available for numerical computation of the multivariate normal integral, see e.g. Sun (1988b), Genz (1993) and Hajivassiliou et al. (1996). In the empirical example in Section 5 we use GHK and Sun's method which proved to be more precise.
} 


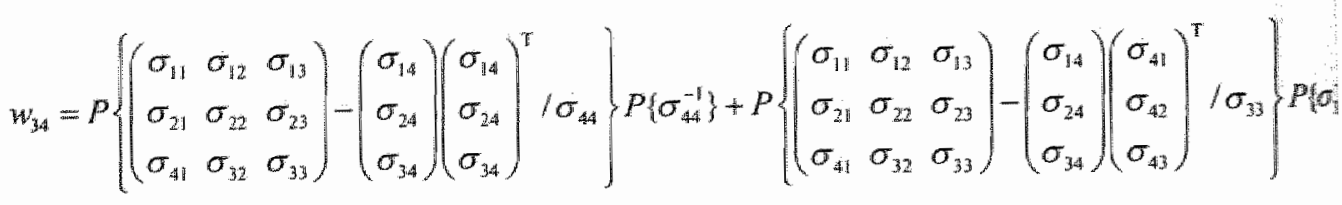

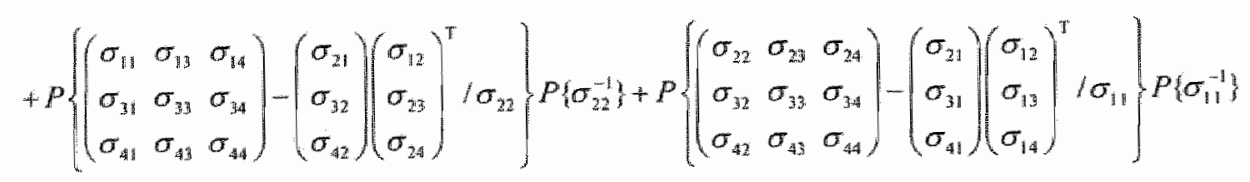

\subsection{Empirical illustration}

To illustrate the method we present an empirical application in which we consider three broad innovation dichotomous strategies, i.e. implementation by a firm of process, product and organizational innovation. We estimate a labor productivity equation that includes the set of mutually exclusive dummies $D$. Our data come from two consecutive Community Innovation Surveys conducted by Statistics Netherlands among Dutch firms for the years of 1996 and 1998. The performance variable is labor productivity in 1998. The independent variables include the innovation strategies as well as firm size, $R \& D$ intensity, and labor productivity in 1996. The lagged dependent variable is included to control for firm-specific effect and to some extent for the omitted capital stock data ${ }^{38}$. All independent variables are taken from the 1996 survey to reduce possible simultaneity between the decision variables and the output measure. The descriptive statistics are listed in Table 4.1.

\section{Table 4.1 Descriptive Statistics}

\begin{tabular}{|c|c|c|}
\hline Variables & Mean & S.D \\
\hline & (1) & (2) \\
\hline Log(Value added/employee) & 4.578 & 0.483 \\
\hline Log(Employment) $)_{-\|}$ & 4.610 & 1.168 \\
\hline R\&D intensity & 0.033 & 0.051 \\
\hline Log(Value added/employee) & 4.501 & 0.579 \\
\hline \multicolumn{3}{|l|}{ State dummies } \\
\hline product, process, org. innovation: no, no, no & 0.073 & 0.261 \\
\hline product, process, org. innowation: no, no, yes & 0.109 & 0.311 \\
\hline product, process, org. innovation: no, yes, no & 0.028 & 0.164 \\
\hline
\end{tabular}

38 The capital stock data were unavailable from CBS. 
product, process, org. innovation: no, yes, yes

\begin{tabular}{ll}
0.044 & 0.205 \\
0.182 & 0.386 \\
0.207 & 0.405 \\
0.130 & 0.336 \\
0.229 & 0.420 \\
\hline
\end{tabular}

Three innovation strategies that we consider can be pursued simultaneously or exclusively: (1) product innovation, (2) process innovation, and (3) organizational innovation that is manifested through reorganization or implementation of new marketing and management practices. The constructed vector $D$ thus includes eight elements. The results of the unconstrained estimation and the estimation under the alternative hypotheses are reported in Table 2.39

In the first step the model is estimated three times, once unconstrained (results are presented in Table 3), once imposing less or equal restrictions, and once imposing greater or equal restrictions. In the second step, the constrained model that produced the highest log-likelihood value in the first step (the model for which the imposition of the inequality restrictions are least objectionable) is tested against the equality restricted alternative using the $\mathbb{L R}$ test. In the first step, we compare the log-likelihood values of the inequality-constrained models with the unrestricted loglikelihood value. This suggests testing for substitutability in case of product \& process innovation, and complementarity in the cases of product $\&$ organizational innovation and process \& organizational innovation. In the second step, the loglikelihood ratio tests show that we cannot reject the null hypothesis of no substitutability in the product \& process innovation case, nor can we reject the null of no complementarity in the process and organizational innovation case. As can be seen from the Table 4.2, neither is significant at 10 percent level. The second-step result does reveal a complementary relationship between process and organizational innovation: the LR test against the null of no complementarity is rejected, the value 14.6106 being greater than the critical value $c_{u}$ (the calculated p-value is 0.0002 ). The result supports the notion that process innovations are more effective if accompanied by necessary changes in organizational practices.

${ }^{39}$ The full results are available from the authors upon request. Further details on the data are available in Belderbos et al. (2003). 


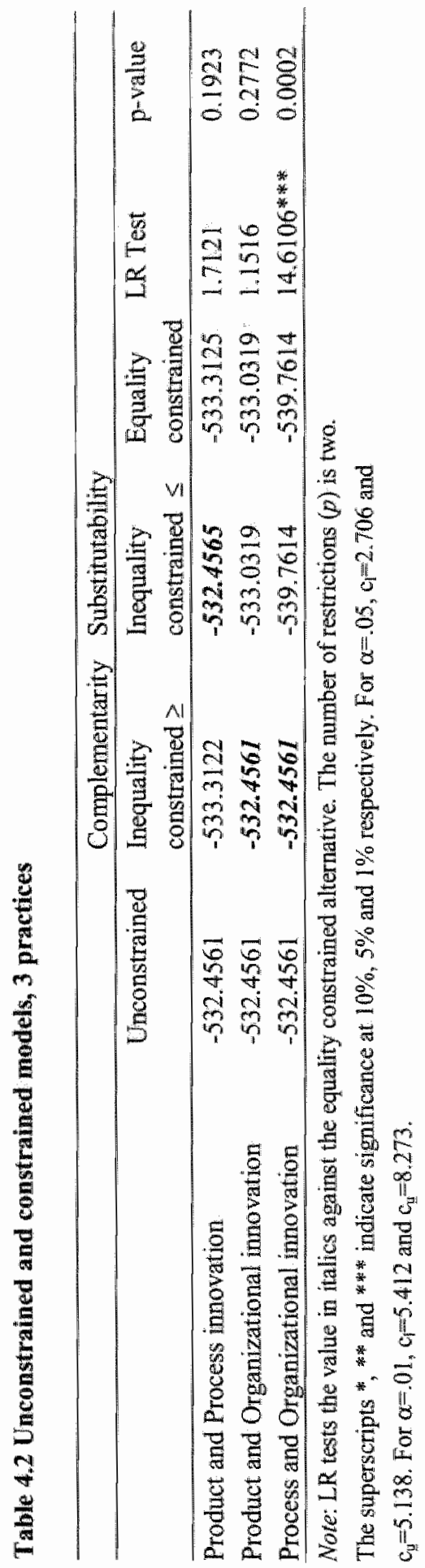


Table 4.3 Unconstrained OLS resuits

Dependent: $\log ($ Value added per employee, 1998)

Lagged variables

Log(Employment, 1996)

(1)

R\&D intensity, 1996

$0.0802(0.0118)$

Log(Value added per employee, 1996)

$0.2566(0.2493)$

$0.3562(0.2331)$

Srate dummies

product, process, org innovation: no, no, no

$2.6772(0.1079)$

product, process, org. innovation: no, no, yes

$2.4528(0.1038)$

product, process, org. innovation: no, yes, no

$2.6947(0.1255)$

product, process, org. innovation: no, yes, yes

$2.5890(0.1139)$

product, process, org. innovation: yes, no, no

$2.5746(0.1018)$

product, process, org innovation: yes, no, yes

$2.6054(0.1027)$

product, process, org. innovation: yes, yes, no

$2.5948(0.1062)$

product, process, org. innovation: yes, yes, yes

$2.6371(0.1026)$

Number of observations

1050

$\mathrm{F}$

46.09

LL

$-532.4561$

Standard errors are in parentheses. In column (1) are the unconstrained estimates of the model in the example. Full sets of estimates are available from the authors upon request. $R \& D$ intensity is the ratio of the R\&D personnel to total personnel. Size is measured as the logarithm of the total number of employees. Inclusion of the industry dummies produces estimates very close to the ones reported.

Table 4.4 Complementarity results obtained by interacting dummies

Dependent: Log(Value added per employee, 1998)

(1)

\section{Log(Employment)}

R\&D intensity -1

R\&D intensity -1

Log(Vaine added per employee)-1

Product innovation

\begin{tabular}{lllll} 
Log(Employment) $)_{-1}$ & 0.0840 & 0.0833 & 0.0826 & 0.0839 \\
& $(0.0150)$ & $(0.0151)$ & $(0.0150)$ & $(0.0151)$ \\
R\&D intensity -1 & 0.2918 & 0.2872 & 0.2741 & 0.2988 \\
& $(0.2440)$ & $(0.2447)$ & $(0.2452)$ & $(0.2472)$ \\
Log(Vaiue added per employee) & 0.3570 & 0.3562 & 0.3571 & 0.3588 \\
& $(0.0685)$ & $(0.0688)$ & $(0.0690)$ & $(0.0687)$ \\
Product innovation & 0.0004 & 0.0390 & -0.0300 & 0.0125 \\
& $(0.0401)$ & $(0.0281)$ & $(0.3797)$ & $(0.0252)$ \\
\hline
\end{tabular}




\begin{tabular}{lllll}
\hline Process imnovation & 0.0345 & 0.162 & 0.03456 & -0.0500 \\
& $(0.0527)$ & $(0.0537)$ & $(0.0326)$ & $(0.0434)$ \\
Organizational innovation & -0.0671 & -0.0195 & -0.0512 & -0.0427 \\
& $(0.0374)$ & $(0.0272)$ & $(0.0361)$ & $(0.0299)$ \\
Product* Process innovation & -0.1627 & -0.1456 & & \\
Product Organizational innovation & $(0.0680)$ & $(0.0671)$ & & \\
& 0.0663 & & 0.0763 & \\
Process* Organizational innovation & 0.1423 & & $(0.0489)$ & \\
& $(0.0605)$ & & & 0.1396 \\
Observations & 1050 & 1050 & 1050 & 1050 \\
$\mathrm{R}^{2}$ & 0.301 & 0.406 & 0.407 & 0.406 \\
\hline
\end{tabular}

Standard errors are in parentheses. R\&D intensity is the ratio of the R\&D personnel to total personnel. Size is measured as the logarithm of the total number of employees.

In the introduction to this chapter we noted that the common procedure to testing complementarity has relied on pair-wise comparisons between two practices. We have argued that in case of multiple practices this may lead to erroneous conclusions. Consider a case of three practices, $A, B$ and $C$ where interaction $A B$ is positive and raises productivity, but $(A B)$ and $C$ are strong substitutes. The omission of $\mathrm{C}$ will lead to a conclusion that strategies $\mathrm{A}$ and $\mathrm{B}$ are complements, while considering the full set of practices they are not. To further make this point, we compare in our empirical application the two approaches: a pair-wise test and full information set complementarity test. Table 4.4 presents the results obtained from a similarly specified model by simply interacting pairs of dummy variable strategies. A simple t-test performed on these interaction terms reveals an additional significant relationship in our sample, i.e. between process and product innovation. More generally, a procedure that relies on a t-test on an interaction dummy in this case would lead to some misleading conclusions especially when opposing effects (some pairs being complements and some pairs are substitutes) are present among the strategies.

\subsection{Conclusion}

This chapter develops a test for complementarity and substitutability using an output function approach in which organizational practices affect performance. The testing procedure uses a structural estimation framework and applies inequality constrained least squares estimation. The analytical solution is given for the general case and demonstrated for three and four practices. We note that recent work (Athey and Stern, 2002; Bresnahan et al, 2002; Caroli and Van Reenen, 2001; Black and Lynch, 2001) has drawn conclusions on complementarity based on inadequate testing methods. With empirical studies of complementarity gaining prominence in 
a number of economics and management domains, the proposed framework should make adequate testing for complementarity more accessible for applied researchers. We also note that the proposed test is equivalently applicable for testing for superand submodularity of the objective function in organizational design practices (e.g. Milgrom and Roberts, 1990). As shown in Topkis (1998), it is sufficient to check the pair wise inequalities in case there are more than two dimensions in the lattice. Hence, in case all pair wise relations satisfy complementarity, the objective function is supermodular. Thus, in our example, the test satisfies the requirements for supermodularity of the objective function in product, process and organizational innovation practices. 


\section{CHAPTER 5}

\section{Complementarity in $R \& D$ cooperation strategies}

This chapter assesses the performance effects of simultaneous engagement in R\&D cooperation with different partners (competitors, clients, suppliers, and universities $\&$ research institutes). We test whether these different types of R\&D cooperation are complements in improving productivity. The results suggest that the joint adoption of cooperation strategies could be either beneficial or detrimental to firm performance, depending on the specific combination of strategies and firm size. Customer cooperation helps to increase market acceptance and diffusion of product innovations and so enhances the impact of competitor and university cooperation. On the other hand, smaller firms in particular also face diseconomies in pursuing multiple $R \& D$ cooperation strategies, which may stem from higher costs and complexity of simultaneously managing multiple partnerships with different innovation objectives.

Acknowledgement: The empirical analysis for this paper has been performed at CEREM/Statistics Netherlands. We thank Bert Diederen of CEREM for his assistance. The views expressed in this chapter are those of the authors and do not necessarily reflect the policies of Statistics Netherlands. 


\subsection{Introduction}

Both the industrial organization and the management literature on strategic alliances have devoted substantial attention to the analysis of R\&D cooperation. The industrial organization literature has largely focused on the effects on R\&D investment and welfare of R\&D cooperation between competing firms (e.g. Amir et al, 2003; Martin, 1995; Suzumura, 1992). ${ }^{40}$ In practice, however, R\&D links formed by firms with suppliers, customers or research institutes and universities are as frequent as cooperation with competitors, and a substantial share of innovating firms are engaged in $R \& D$ cooperation with several partners simultaneously (Belderbos et al. 2004a, 2004b; Leiponen, 2001; Tether, 2002; Veugelers and Cassiman, 2003). The alliance literature has emphasized the complexity of rationales behind cooperative strategies and the need to establish multiple alliances (e.g. Contractor and Lorange, 2002; Das and Teng, 2002; Tyler and Steensma, 1995). Alliance networks, their determinants, and composition have mostly been studied from the perspective of social network theory (e.g. Gulati, 1995). This literature, though focusing on networks of R\&D partnerships, has not differentiated alliances partners by type of firm and has ignored the role of $R \& D$ alliances with universities and other public research institutions.

The fact that many firms are engaged in multiple cooperative agreements raises the question whether there are synergetic effects between these strategies, i.e. whether forming a new alliance in R\&D enhances the effectiveness of other existing R\&D collaborations. Such a synergy, or complementarity, has been formally defined by Milgrom and Roberts (1990) and is assumed to exist if the implementation of one practice or strategy increases the marginal return to other practices. A number of studies have examined complementary effects of practices related to workplace organization, use of information technology and obstacles to innovation (Bresnahan et al, 2002; Ichniowski et al., 1997; Mohnen and Röller, 2005). However, despite the growing literature on R\&D cooperation in both the fields of management and industrial economics, surprisingly little evidence has emerged on the interaction of different cooperation strategies in innovation. Aurora and Gambardella (1990) find a positive correlation between residuals of equations explaining large pharmaceutical firms' R\&D agreements with research institutes, minority participations and acquisitions of new biotechnology firms, and take this to indicate that networked R\&D strategies are most effective for firms active in biotechnology. However, Aurora (1996) points out that such a correlation approach (also coined "adoption' approach) cannot serve as conclusive evidence of the greater effectiveness of joint adoption of the different cooperation strategies. ${ }^{41}$

40 Exceptions are models that examine vertical cooperation (Steurs, 1995) and vertical alongside competitor cooperation (Atallah, 2002).

4 Estimated correlations between residual terms may be the result of common omitted exogenous variables or measurement errors. Even in case of robust correlation between practices, there is no guarantee that decision markers were sufficiently well informed such that they indeed chose efficiency or output enhancing combinations of practices. 
Other empirical work has examined the impact of R\&D cooperation on firms" innovation output, i.e. sales of innovative products (e.g. Criscuolo and Haskell, 2003, Faems et al., 2004; Janz et al., 2003; Klomp and van Leeuwen, 2001; van Leeuwen, 2002; Löf and Heshmati, 2002) but in most cases aggregate over cooperation types. Belderbos et al. (2004b) explicitly examine the differential impacts of R\&D cooperation with customers, suppliers, competitors and research institutes \& universities on labor productivity and sales of innovative products for a large sample of Dutch firms, but do not analyze potential complementarities between these R\&D cooperation strategies.

This paper is the first to examine whether different types of R\&D partnerships are complementary. We distinguish four types of partner-specific innovation strategies: cooperation with competitors, customers, suppliers, and universities \& research institutes. Building on our previous work (Belderbos et al., 2004b), we analyze the possible complementarities in these cooperation strategies in their effects on labor productivity for a large sample of innovating firms in two waves of the biannual Dutch Community Innovation Survey (1996, 1998) and production statistics. The analysis allows for an appropriate time lag with which the impact of R\&D cooperation (1996) feeds through in productivity growth (1996-1998). We apply an appropriate testing framework for complementarity between multiple practices when these practices are measured by discrete variables. Based on a review of related theoretical and empirical literature we find that pursing different types of R\&D cooperation, to the extent that they also relate to pursuit of different innovation objectives, may not necessarily result in improved performance due to possible redundancies in knowledge spillovers, costs of search and management of multiple links, and limitations in monitoring capability and managerial attention. Our results suggest mixed effects of joint cooperation strategies, with substantial differences between large and small firms.

The remainder of the chapter is organized as follows. Section two provides a review of the theoretical and empirical literature on R\&D cooperation and firm performance. In section three we describe the model and the econometric methodology used to examine complementarity between cooperation strategies. The empirical model, data and empirical findings are presented in section four. The final section contains our conclusions, a discussion of caveats, and suggestions for further research.

\subsection{Literature review}

Previous research has argued that different types of R\&D cooperation may serve different purposes (Belderbos et al. 2004a; Teece, 1980). Firms seek cooperation with customers to source new ideas for innovations and to reduce the risk of uncertainty associated with market introduction of these innovations (von Hippel, 1988). Further, collaboration may be essential to insure market expansion when 
products are novel and complex or when they require adaptations in use by the customers (Tether, 2002). In contrast, cooperation with suppliers is often labeled short-term and is related to the core business cost-reduction, with outsourcing activities combined with cooperation focused on input quality improvement aimed at further cost reductions and process innovations (Hagedoom, 1993). Cooperation with rivals is often motivated by the need to share R\&D costs (Miotti and Sachwald, 2003), the pursuit of synergistic effects through pooling of the firms" resources (Das and Teng, 2000), or dealing with regulations and industry standards (Nakamura, 2003). Cooperation with universities and research institutes is generally more aimed at radical breakthrough product innovations that may open up entire new markets or market segments (Monjon and Waelbroeck, 2003; Tether, 2002). Universities are also more likely to be a firm's partner in new technological fields or when speed of technological change is high and commercial outcome of cooperation is uncertain (Belderbos et al. 2004a; Hal] et. all, 2004, Rahm et al. 2000).

Few theoretical studies have examined the interaction of different innovation or cooperation strategies. ${ }^{42}$ Athey and Schmutzler (1995) consider a simultaneous implementation of product and process innovations by a single firm. Their twoperiod model predicts that investments that improve product design and increase process flexibility are complementary. This is driven by a complementary output effect of product innovations: product innovations increase output and therewith the returns to process innovations. They also concede, however, that these results may not hold if simultaneous investments in product and process flexibility are hampered due to limitations in information processing capabilities and attention of workers and managers, as suggested in a case study by Henderson and Clark (1990). Lin and Saggi (2002) examine sequential investments in product and process $R \& D$ in a duopoly, allowing for strategic interaction in innovation decisions and product $R \& D$ cooperation between the firms. They find that if two strategies are performed contemporarily, cooperation in product $R \& D$ leads to increases in both product and process R\&D, but full cooperation (in both process and product $R \& D)$ leads to a reduction in $\mathbb{R} \& D$. This result arises because cooperation in process R\&D reduces the incentives of the firms to invest in $R \& D$ in order to compete on costs and price in the output market. In a related paper, Rosenkrantz (2003) models the simultaneous decisions to engage in R\&D cooperation and the

\footnotetext{
42 Theoretical models that link R\&D cooperation and performance concentrate primarily on cooperation with competitors. In a model due to Martin (1994) firms are engaged in competitor cooperation in R\&D projects and maximize expected own firm value. Martin shows that when firms are engaged in radical innowation R\&D competitor cooperation will lead to reduced expected profits. Building on the work of Suzumura (1992), Kline (2000) develops a model where firms concentrate on cost-reducing innovation. He finds that under cooperation firms have incentives to cut back on cost-reducing research under imperfect (limited) spillovers. This so-called cost paradox leads to the result that if enough firms are engaged in cost-reduction and cooperation, industrywide profits decline. In Cabral's (2000) model firms cooperate in product innovation and can sustain monopoly profits under R\&D cooperation.
} 
levels of product and process R\&D investments. Here cooperation with rival firms leads to a shift in R\&D efforts towards product R\&D, reduced price competition, and a smaller reduction in marginal costs due to a decline in process R\&D. Atallah (2002) presents a model of spillovers and R\&D cooperation decisions by two vertically related duopolies and generally finds a more positive effect of combined cooperation strategies. Although results depend on the degree of vertical, horizontal, and diagonal spillovers, one finding is that vertical cooperation can mitigate the reduction in $R \& D$ due to competitor cooperation even if initial spillover levels are low.

The above theoretical models are clearly not unequivocal about the benefits of combining diverse cooperation and innovation strategies, although they do not deal specifically with the simultaneous engagenent in different R\&D partnerships. Leyden and Limk (1999) are more articulate on this issue where it concerns multiple partners in one and the same research joint venture (RJV) involving a public research laboratory. They argue that an increase in the number of cooperating firms in a RJV with a government research laboratory as one of partmers leads to a significant increase in monitoring costs and a reduced ability of member firms to individually appropriate the research output. This loss can outweigh the benefits received from economies of technological scope and results in lower firm profits. The authors conclude that for RJVs benefits from research laboratory participation in cooperative research may not be justified. Another complicating issue in simultaneously managing R\&D partnerships with multiple partners is the potential associated increase in complexity and costs. Bolton and Dewatripont (1994) point out that a trade off exists between firms' specialization and coordination. When coordination and communication efforts are dispersed on multiple cooperation arrangements, this will increase organizational costs of processing and communicating information. Specialization and focus on collaboration with a smaller set of partners reduces the costs of communication and this may offset the benefits of multiple partner cooperation.

The empirical literature on performance effects of R\&D cooperation has tended to explore the direct performance effects of process and product innovation on firm performance (e.g. Geroski, 1991; Huergo and Jaumandreu, 2004; Vivero, 2004). The majority of empirical models that included $R \& D$ cooperation have used an aggregated cooperation variable and often found a positive impact of engaging in R\&D cooperation on innovation performance i.e. sales of innovative products (e.g. Criscuolo and Haskell, 2003; Janz et al., 2003; Klomp and van Leeuwen, 2001; van Leeuwen, 2002; Lööf and Heshmati, 2002), patenting (Brouwer and Kleinknecht, 1999; Vanhaverbeke et al., 2002), sales growth (Cincera et al. 2004), and firms" stock price (Wu and Wei, 1998). Some of these papers have also examined the effect of different cooperation types but with ambiguous results. Monjon and Waelbroeck (2003) used a latent-class model to investigate the effects of collaboration and spillovers on the degree of innovativeness of firms, distinguishing 
between radical and incremental imnovators. ${ }^{43}$ They find that cooperation with universities increases firms" innovative performance if the firm is a radical innovator. However, cooperation with competitors and (foreign) suppliers reduced the probability of introduction of a radical innovation. Cincera et al. (2004) distinguish between overseas and domestic collaboration by Belgian firms and find a positive impact on productivity of the latter but a counter-intuitive negative impact of the former. Lobf and Heshmati (2002) include a selected group of cooperation types in an innovation output equation for Swedish firms and found that cooperation with competitors and universities impact output levels positively while cooperation with customers had a negative effect. Belderbos et al. (2004b) find that supplier and competitor cooperation have a significant impact on labor productivity growth, while cooperation with customers and universities \& research institutes positively affects growth in sales per employee of products and serwices new to the market.

The empirical literature on $\mathrm{R} \& \mathrm{D}$ alliances has only recently begun to assess the performance effects of R\&D cooperation (Das and Teng, 2002). One line of research has examined why not all R\&D partnerships are equally profitable. Partnerships in which firms have high compatibility in organizational processes and partner-specific absorptive capacity allowing for effective transfer of know-how tend to outperform partnerships in which overlapping knowledge is narrow (Dyer and Singh 1998; Mora-Valentin et al., 2004). ${ }^{44}$ Other emerging evidence points out that a network of R\&D alliances should be organized such as to minimize redundancies in knowledge spillovers (e.g. Vanhaverbeke et al, 2002) and that large alliance networks are not necessarily generating the highest innovative output.

Overall, the scarce predictions of theory and previous empirical work suggest a positive impact of R\&D cooperation on firm performance. The complementarity between different R\&D cooperation strategies, on the other hand, may be limited due to increased complexity and cost of managing multiple R\&D partnerships with different objectives, limited time and attention of management and R\&D personnel, and possible loss of appropriability when collaborating with public institutions. The first two concerns are likely to be greater for small firms than for llarger firms. In the sections below we explore whether combining individual and multiple R\&D cooperation partnerships increases labor productivity and if these results differ between large and small firms.

\footnotetext{
4.3 Sigel (2003) finds higher innovative performance for firms located in university science parks, which is likely to be due to a more intensive interaction and collaboration between the firm and universities.

Anbarci et al. (2002) make the same point of the important role of complementarity between the lirms " R\&D processes and R\&D inputs in the performance effects of RJVs
} 


\subsection{Testing for Complementarity}

The test of complementarity that we use in this chapter is based on the "production function' approach, in which a measure of organizational performance ('production') is related to exclusive combinations of organizational practices. Consider a typical firm that maximizes some performance measure $\mathrm{G}$ (such as profits, sales or value added), with respect to the vector of strategies $x=\left(x_{1}, \ldots, x_{n}\right)$ :

$$
G(w)=\max _{x} f(x, w)
$$

Where the function $G$ is twice continuously differentiable and the vector $w=$ $\left(w_{1}, \ldots, W_{n}\right)$ contains other firm and industry characteristics. We follow Baumol et al. (1988) and Athey and Stern (1998) in defining complementarity: ${ }^{45}$

Practices $x_{i}$ and $x_{j}$ are considered complementary in the function $f$ if and only if $\partial^{2} f / \partial x_{i} \partial x_{j}$ is always larger or equal to zero, and larger than zero for at least one value of $\left(x_{1}, \ldots, x_{n}\right)$.

The definition for substitutability (subadditivity) ${ }^{46}$ is identical to the definition above except that 'larger' is replaced by the 'smaller' sign. In case the practices take on discrete values variables (step size equal to one) the derivative is replaced by a unity difference. In that case functions can be more conveniently rewritten in terms of the possible combinations of practices. For example, with two practices the collection of possible combinations is defined in the usual binary order as $D=\{(0,0),(0,1),(1,0),(1,1)\}$. In case of four practices (the case we will examine in the empirical application) we can express the collection $D$ by an indicator function $I_{D=(r, s, s, s)}$. We rewrite the function $f$ as:

$$
f\left(x_{1}, x_{2}, x_{3}, x_{4}\right)=\sum_{r=0}^{1} \sum_{s=0}^{1} \sum_{t=0}^{1} \sum_{u=0}^{1} \beta_{r s t u} I_{\left(x_{1}, x_{3}, x_{3}, x_{4}\right)=(r, s, u, u)}
$$

The conditions for complementarity between two practices $x_{1}$ and $x_{2}$, for example, correspond to the following four inequalities, where at least one of the inequalities has to hold strictly:

$$
\beta_{1100}+\beta_{0000}-\beta_{1000}-\beta_{0100} \geq 0
$$

45. This definition is also called 'strict supermodularity' (Milgrom and Roberts, 1990) and is equal to complementarity in the conventional sense of scope economies (adoption of practice B strictly increases the marginal returns of adoption of practice $A$ ). If supermodularity is not defined "strictly", it does not exclude the possibility that practice B has no impact on the returns to practice A.

${ }^{46}$ It may be argued that the term subadditive used in Milgrom and Roberts (1990) better captures the meaning of the relationship between the strategies. Substitution in our context does not imply that one strategy can be substituted for another, but rather that their joint use resulis in suboptimal performance. 


$$
\begin{aligned}
& \beta_{1110}+\beta_{0010}-\beta_{9010}-\beta_{0110} \geq 0 \\
& \beta_{1101}+\beta_{0001}-\beta_{1001}-\beta_{0101} \geq 0 \\
& \beta_{1111}+\beta_{0011}-\beta_{1011}-\beta_{0111} \geq 0
\end{aligned}
$$

In the empirical analysis and without loss of generality, we normalize $\beta_{0000}$ to zero. ${ }^{47}$ In the case of two practices, this approach reduces to testing the significance of the interaction effect, in which case complementarity testing $(5.3-\mathrm{a})$ can be implemented as a straightforward one-tailed t-test on the interaction effect of two dummy variables for discrete practices ${ }^{48}$. Previous research examining complementarity between more than two practices has however, with the exception of Mohnen and Röller (2005) been limited to estimating the pair-wise interaction effects, ignoring that complementarity is only established if it holds regardless of the other practices adopted (i.e. ignoring restrictions 5.3-b, 5.3-c, 5.3-d in this case). ${ }^{49}$ This approach is problematic because it ignores terms and is prone to an omitted variable bias which affects all coefficients used in the complementarity test. Therefore, the proper complementarity or substitutability test requires consideration of the complete set of organizational practices: testing a set of multiple linear inequality restrictions. In this chapter, we use the testing methodology provided by Lokshin et al. (2004). ${ }^{50}$

We note, however, that the above testing framework, though robust to assess the existence of complementarity between multiple practices, may not in all cases provide the answers to relevant questions. Consider the case, when strategies $x$ and $y$ display complementarity when strategy $z$ is zero but subadditivity when $z$ takes the value of one. The outcome of the test for complementarity is likely to be that $x$ and $y$ are neither complements nor subadditive. Yet, the information on the effect of strategy $z$ on the returns to adopting $x$ and $y$ could have important managerial and policy implications. The estimates for the coefficients $\beta$ will provide us with the answers to these type of questions. With $\beta_{0 A \infty}$ normalized to zero, the remaining coefficients indicate the performance impact of adopting (combinations of) cooperation strategies compared to a strategy of no R\&D cooperation. For example, a positive value of $\beta_{\text {noo }}$ tells us if it is worthwhile to pursue both cooperation

\footnotetext{
47 In the empirical model this implies that we estimate a constant term as well as 15 dummy vartiables for exclusive (combinations of) cooperation strategies.

44 One example of this approach that has been used in recent empirical work testing for complementarity between two practices is Veugelers and Cassiman, 2005.

${ }^{49}$ Recent examples include Athey and Stern, 2002; Black and Lynch, 2001; Bresnahan et al., 2002, and Caroli and Van Reenen, 2001.

so For brevity we do not detail here the econometrics of the testing procedure, which has been described in Lokshin et al. (2004) and is based on a minimum distance or LR test. Mohnen and Röller (2005) propose an altarnative testing framework, but this method does not allow testing directly for complementarity in the sense of strictly positive cross derivatives (strict
supermodularity) and is not in all cases conclusive.
} 
strategies simultaneously in the absence of adoption of a third strategy. Furthermore, comparison of $\beta_{1100}$ with the coefficients of single cooperation strategy adoption ( $\beta_{100}$ and $\beta_{0100}$ ) provides us with information on the incremental effect of adding the second cooperation strategy.

\subsection{Empirical model, Data, and Descriptive statistics}

We examine the impact of $R \& D$ cooperation on the growth in labor productivity from $1996(\mathrm{t}-1)$ to $1998(\mathrm{t})$. In addition to including explanatory variables measured from the preceding period (to limit simultaneity bias), we include the lagged level of productivity (in 1996). ${ }^{51}$ We estimate the following growth in productivity equation (5.4):

$\Delta \log (\operatorname{prod} v)_{i}=\alpha+\sum_{r=0}^{1} \sum_{s=0}^{1} \sum_{t=0}^{1} \sum_{t=0}^{1} \beta_{r s s t u} I_{\left(c c_{s}, s u, c u t, u n\right)=\left(r_{,}, s, t, t w\right)}+$

$\gamma$ Spill $_{i}+\kappa R D_{i}+\delta W_{i}+\theta \log (\text { prodv })_{i}+\varepsilon_{i}$

where $\mathrm{co}^{=}=$competitor cooperation, $\mathrm{su}=$ supplier cooperation, cu=customer cooperation, and un=cooperation with universities and research institutes. All right hand side variables are measured at time $t-1$, while $\Delta \log (\operatorname{prod})_{i}=\log \left(\right.$ prod $\left._{i, t}\right)-\log \left(\right.$ prodv $\left._{i, r-1}\right)$ is the growth in productivity from period $\mathrm{t}$ to $\mathrm{t}-1$ measured as value added per employee. The indicator function $I$ captures all exclusive (combinations of) cooperation strategies (where the case of no cooperation is normalized to zero) corresponding to equation (5.2). ${ }^{52}$ These terms capture the effects of engaging in these (combinations of) R\&D partnerships compared to a strategy of no cooperation. The lagged $\log ($ Prodv) term is the level term of the dependent variable taken in the base year (1996). Firms that are highly productive and are at the frontier of productivity may be less likely to have strong growth rates in productivity than firms that are followers. In that case we expect $\theta$ to fall within the interval $[-1,0]$. If $\theta$ is zero, this effect is absent and there is no gradual convergence between leading firms and productivity laggards. If $\theta$ is -1 , than a productivity lead in one period is fully neutralized in the next and past

51 In the absence of the possibility of including fixed firm effects, this specification has the advantage that it partly adjusts for unobserved firm attributes that are relatively constant over time. A related advantage is that it allows for the effects of the exogenous variables to be interpreted as one-period Granger-causation. The Granger approach to the question of whether $x$ caluses $y$ is to see to what extent the current $y$ is explained by past values of $y$ and then to consider whether adding lagged values of $x$ can improve the statisticall explanation. The variable $y$ is said to be Grangercaused by $x$ if the coefficients on the lagged values of $x$ are statistically significant.

52 We do mot include cooperation with consultants in the empirical analysis because of its heterogeneous character and doubts whether linkages with consultants are genuine R\&D efforts. 
productivity has no impact on future productivity levels. ${ }^{53}$ The models controls for the R\&D interisity of the firms ${ }^{54}$ and the degree to which the firm benefited from external knowledge spillovers. The $W$-vector consists of firm-level control variables, such as size, dummies controlling for foreign and domestic groups, and dummies for the industry of the firm at the two-digit level.

\section{Data and Descriptive statistics}

The empirical analysis uses the data from two consecutive Community Innovation Surveys (CIS) conducted in 1996 and 1998 in the Netherlands, as well as information from the production statistics database in the same years. To create a two-year data set, 6327 innovating establishments in 1998 were matched with information on these firms in 1996 survey: 2353 firms could be linked to the 1996 survey and were classified as innovating firms in that survey. We then linked these firms via a unique id number to the production statistics data. The data are at the establishment level and include manufacturing as well as service firms. Due to the missing values for some of the explanatory variables, the complete sample includes 2053 firms. ${ }^{55}$ The distribution of cases by industry and descriptive statistics are presented in Tables 5.1 and 5.2. There are 627 firms with R\&D cooperation of any type among the innovating firms in the combined sample. Competitor cooperation, the main focus of much of the industrial organization literature on R\&D cooperation, is certainly not the most frequently adopted cooperation strategy (225 cases). Supplier cooperation is most frequently adopted, with 372 firms indicating to be engaged in this type of strategy, followed by customer cooperation (35॥ firms), and university cooperation (277). Some 1426 firms reported to have none of the four types of links. The comparison across industries indicates that the propensity to cooperate is not dissimilar between services and manufacturing industries. Cooperation is comparatively more frequent in (petro) chemicals, metallurgy, and business services. Science-based industries such as electronics and chemicals, but also the food and metallurgy industries, report a higher share of university cooperation compared to other types of cooperation.

\footnotetext{
${ }^{53}$ To see this one can simply rewrite the relevant part of (1) as $\log \left(\right.$ prodv $\left._{s+1}\right)=\ldots .\left(1+\theta_{i}\right)(\text { prod })_{i}$

s.t We use a broad measure of R\&D expenditure available in the Innovation Surveys: total expenditure on innovation (including expenditures on pilot production, licenses, marketing and industrial design).

${ }^{55}$ A more detailed description of the data is given in Belderbos et al. (2004a).
} 
Complementarity in R\&D cooperation strategues

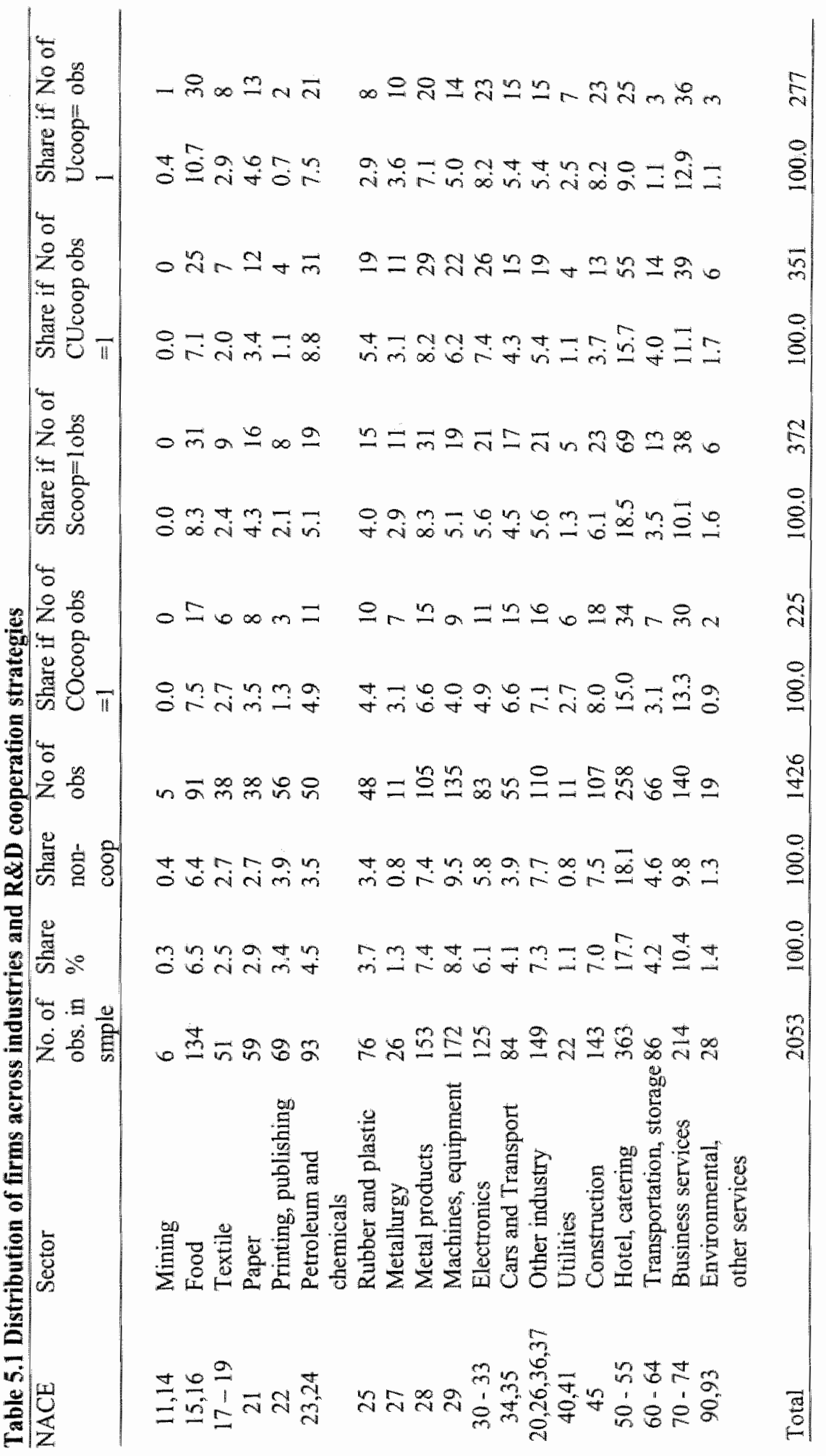


Table 5.2 Contingency table: Distribution of cooperation cases

\begin{tabular}{|c|c|c|c|}
\hline Cooperation type & $\begin{array}{l}\text { Number of } \\
\text { cases }\end{array}$ & $\begin{array}{l}\text { Number of } \\
\text { cases small } \\
\text { furms }\end{array}$ & $\begin{array}{l}\text { Number of } \\
\text { cases large } \\
\text { firms }\end{array}$ \\
\hline None & 1426 & 907 & 519 \\
\hline Competitors & 43 & 26 & 17 \\
\hline Customers & 77 & 51 & 26 \\
\hline Supplier & 98 & 39 & 59 \\
\hline University & 46 & 14 & 32 \\
\hline Competitors and suppliers & 13 & 7 & 6 \\
\hline Competitors and customers & 16 & 10 & 6 \\
\hline Competitors and university & 26 & 10 & 16 \\
\hline Customers and suppliers & 77 & 31 & 46 \\
\hline Supplier and university & 35 & $\mathbb{1} 3$ & 22 \\
\hline Customers and university & 29 & 10 & 19 \\
\hline Competitors, customers, suppliers & 26 & 12 & 14 \\
\hline Competitors, suppliers, university & 15 & 8 & 7 \\
\hline Competitors, customers, university & 18 & 8 & 10 \\
\hline Customers, suppliers and university & 40 & 12 & 28 \\
\hline $\begin{array}{l}\text { Competitors, customers, suppliers, } \\
\text { universities }\end{array}$ & 68 & 17 & 51 \\
\hline Total & 2053 & 1175 & 878 \\
\hline
\end{tabular}

Note: The R\&D cooperation categories represent exclusive (combinations of) cooperation types: numbers represent the number of firms that are only engaged in the listed types of R\&D partnerships.

Table 5.2 lists the count of occurrence of particular combinations of cooperation strategies: the number of cases where the dummies representing exclusive (combinations of) cooperation strategies take on the value 1. Vertical cooperation is most prominent: supplier only (98), customer only (77), combined. (77) or both combined with university cooperation (40). A total of 68 firms have cooperative agreements of all four types. A number of cooperation strategies are not often combined and have relatively few observations: competitors and suppliers with or without university cooperation (15, 13), and competitor and customer with or without university cooperation $(16,18)$. In the analysis, we make a distinction between 'small' firms, defined as firms with less than 100 employees, and all other firms (for convenience labeled 'large' firms). The sub-samples have 878 (large) and 11.75 (small) firm observations. As one would expect, cooperation is most prevalent among large firms. We note that in these sub-samples the number of cases of particular exclusive combinations of cooperation strategies is further reduced to 
single digit numbers, which may make it more difficult to estimate the performance impact of such joint strategies with preeision.

\subsection{Empirical results}

Table 5.3 reports the results of equation (1) in the first column. Of the single cooperation strategies, competitor cooperation and supplier cooperation are significantly positive (the latter at just under the 5 percent level). In two cases, combinations of two strategies have a positive and significant impact, one triple strategy is positive and significant as well, and so is the strategy of combining all four types of $R \& D$ cooperation. None of the cooperation dummy variables have significantly negative impacts. Overall, these results clearly confirm a positive impact of R\&D cooperation on productivity growth. A general observation that can be made is that the highest coefficients (competitor customer, competitor supplier) are observed for two joint strategies, whereas adding a third or fourth strategy does not increase productivity growth. This observation is consistent with the notion that increasing the complexity of $R \& D$ and $R \& D$ cooperation may also increase management costs disproportionately and hence may fail to increase performance. ${ }^{56}$ The results for the other variables show a positive and significant effect of the measure of incoming knowledge spillovers and of R\&D intensity (expenditures on innovation as a percentage of sales). Productivity growth is also higher for foreign MNE-owned affiliates and group affiliated firms (to a lesser extent). The lagged productivity variable is highly significant and negative, indicating that productivity leaders are less able to show further productivity growth. The estimated coefficient indicates that a one percent higher past productivity is associated with half of a percent less productivity increase.

Table 5.3 Estimates of Equation (5.4): determinants of firm productivity growth, 1996-1998

\begin{tabular}{llll}
\hline & All firms & Small firms & Big firms \\
\hline Log(productivity)96 & $(1)$ & $(2)$ & $(3)$ \\
\hline \multirow{2}{*}{ R\&D intensity } & -0.506 & -0.617 & -0.234 \\
& $(0.064)^{* * * *}$ & $(0.071)^{* * * *}$ & $(0.037)^{* * *}$ \\
Incoming spillovers & 0.005 & 0.005 & 0.313 \\
& $(0.000)^{* * *}$ & $(0.000)^{* * *}$ & $(0.280)$ \\
& 0.007 & 0.007 & 0.001 \\
& $(0.002)^{* * *}$ & $(0.003)^{* *}$ & $(0.002)$ \\
\hline
\end{tabular}

\footnotetext{
56 Note that the individual coefficients for the exclusive state dummy variables are not very informative concerning the presence or absence of complementarity or subadditivity, as this has to be established through testing for restrictions on multiple dummy combinations (in accordance with equations $5.3 a-5.3 d$ ).
} 
Chapter 5

\begin{tabular}{|c|c|c|c|}
\hline Firm size & $\begin{array}{l}0.011 \\
(0.016)\end{array}$ & $\begin{array}{l}0.002 \\
(0.044)\end{array}$ & $\begin{array}{l}0.032 \\
(0.015)^{* *}\end{array}$ \\
\hline Foreign multinational & $\begin{array}{l}0.135 \\
(0.034)^{* * *}\end{array}$ & $\begin{array}{l}0.198 \\
(0.056)^{* * *}\end{array}$ & $\begin{array}{l}0.064 \\
(0.036)^{*}\end{array}$ \\
\hline Domestic multinational & $\begin{array}{l}0.045 \\
(0.024)^{*}\end{array}$ & $\begin{array}{l}0.054 \\
(0.036)\end{array}$ & $\begin{array}{l}0.032 \\
(0.028)\end{array}$ \\
\hline $\begin{array}{l}\text { Industry dummies } \\
\qquad R \& D \text { Cooperation. }\end{array}$ & Yes & Yes & Yes \\
\hline Competitor & $\begin{array}{l}0.102 \\
(0.046)^{* *}\end{array}$ & $\begin{array}{l}0.063 \\
(0.061)\end{array}$ & $\begin{array}{l}0.093 \\
(0.072)\end{array}$ \\
\hline Customer & $\begin{array}{l}-0.037 \\
(0.065)\end{array}$ & $\begin{array}{l}0.003 \\
(0.086)\end{array}$ & $\begin{array}{l}-0.037 \\
(0.048)\end{array}$ \\
\hline Supplier & $\begin{array}{l}0.065 \\
(0.034)^{*}\end{array}$ & $\begin{array}{l}0.163 \\
(0.065)^{* *}\end{array}$ & $\begin{array}{l}0.010 \\
(0.041)\end{array}$ \\
\hline University & $\begin{array}{l}0.064 \\
(0.053)\end{array}$ & $\begin{array}{l}0.155 \\
(0.108)\end{array}$ & $\begin{array}{l}-0.047 \\
(0.058)\end{array}$ \\
\hline Competitor, supplier & $\begin{array}{l}0.254 \\
(0.174)\end{array}$ & $\begin{array}{l}0.5 \rrbracket 5 \\
(0.316)\end{array}$ & $\begin{array}{l}0.009 \\
(0.096)\end{array}$ \\
\hline Competitor, customer & $\begin{array}{l}0.220 \\
(0.089)^{*}\end{array}$ & $\begin{array}{l}0.273 \\
(0.084) * * *\end{array}$ & $\begin{array}{l}0.016 \\
(0.164)\end{array}$ \\
\hline Competitor, university & $\begin{array}{l}0.096 \\
(0.082)\end{array}$ & $\begin{array}{l}-0.016 \\
(0.118)\end{array}$ & $\begin{array}{l}0.108 \\
(0.090)\end{array}$ \\
\hline Supplier, customer & $\begin{array}{l}0.007 \\
(0.044)\end{array}$ & $\begin{array}{l}-0.044 \\
(0.075)\end{array}$ & $\begin{array}{l}-0.000 \\
(0.049)\end{array}$ \\
\hline Supplier, university & $\begin{array}{l}0.136 \\
(0.069)^{* *}\end{array}$ & $\begin{array}{l}0.019 \\
(0.072)\end{array}$ & $\begin{array}{l}0.132 \\
(0.069)^{*}\end{array}$ \\
\hline Customer, university & $\begin{array}{l}0.032 \\
(0.070)\end{array}$ & $\begin{array}{l}0.220 \\
(0.092)^{* *}\end{array}$ & $\begin{array}{l}-0.130 \\
(0.087)\end{array}$ \\
\hline Conpetitor, customer, supplier & $\begin{array}{l}0.133 \\
(0.104)\end{array}$ & $\begin{array}{l}0.134 \\
(0.123)\end{array}$ & $\begin{array}{l}0.150 \\
(0.173)\end{array}$ \\
\hline Competitor, supplier, university & $\begin{array}{l}0.033 \\
(0.072)\end{array}$ & $\begin{array}{l}0.040 \\
(0.078)\end{array}$ & $\begin{array}{l}0.079 \\
(0.107)\end{array}$ \\
\hline Competitor, customer, university & $\begin{array}{l}0.149 \\
(0.067)^{* * *}\end{array}$ & $\begin{array}{l}0.114 \\
(0.225)\end{array}$ & $\begin{array}{l}0.043 \\
(0.062)\end{array}$ \\
\hline Customer, supplier, university & $\begin{array}{l}0.053 \\
(0.058)\end{array}$ & $\begin{array}{l}-0.078 \\
(0.116)\end{array}$ & $\begin{array}{l}0.017 \\
(0.056)\end{array}$ \\
\hline $\begin{array}{l}\text { Competitol, customer, supplier, } \\
\text { University }\end{array}$ & $\begin{array}{l}0.095 \\
(0.041)^{* * *}\end{array}$ & $\begin{array}{l}0.132 \\
(0.088)\end{array}$ & $\begin{array}{l}0.009 \\
(0.048)\end{array}$ \\
\hline Observations & 2053 & 1175 & 878 \\
\hline R-squared & 0.40 & 0.53 & 0.13 \\
\hline$F(k, n)$ & $1009.74^{* * * *}$ & $1430.28 * * *$ & $2.12 * *$ \\
\hline
\end{tabular}

Robust standard errors in parentheses * signiticant at $10 \% ; * *$ significant at $5 \%$;** significant at $1 \%$ 
The estimation results of equation (5.4) for the separate samples of 'small" and 'large' firms are presented in columns 2 and 3 of Table 3 . In general, fewer significant effects are observed, which will also be related to the smaller sample sizes and the fact that the exclusive state dummies include fewer observations. Not one significant effect of adopting a single cooperation strategy is observed for large firms, while for small firms supplier cooperation has a relatively large and significant positive impact. Small firms furthermore benefit from combining customer cooperation with university or competitor cooperation. For large firms there is just one marginal significant impact found for a combination of supplier and university cooperation. Looking at the other variables, small firms ' productivity growth benefits from incoming knowledge spillovers and innovation expenditures, while no such evidence is found for large firms. Generally, large firms' productivity is much less sensitive to R\&D (cooperation). This is related to the much lower coefficient $(-0.23)$ on past productivity. It indicates that large firms maintain a substantial part of their productivity lead (77 percent), whereas a leading performance is much more difficult to sustain for smaller firms (only 38 percent).

The complementarity test results are presented in Table 4 . For the full sample there are two statistically significant impacts: the pairs of competitor/customer cooperation and competitor/university cooperation. The results suggest that combining competitor and customer cooperation gives rise to complementarity in the innovation process and improves productivity. On the other hand, competitor and university cooperation are subadditive, in other words, when used simultaneously, they weaken productivity growth. This result is consistent with the suggestion by Leyden and Link (1999) that threats to appropriability of R\&D efforts arise when working simultaneously with a competitor and public institutions, as spillovers from university may leak to competitors not involved in the collaboration. Another possibility is that competitor cooperation may be geared towards incremental, and university cooperation towards radical innovation, which can be seen as diverging rather than converging objectives, increasing the complexity of R\&D management (Mohnen and Hoareau, 2003). The results confirm these effects if tests are performed for small firms only. In addition, two more sub-additive joint R\&D cooperation strategies are present: cooperation with customers and suppliers, and cooperation with universities and suppliers, while customer and university cooperation are complementary. A intuitive explanation here is that cooperation with universities focuses on more radical types of product innovation, for which commercialization often requires customer collaboration to enhance acceptance and diffusion (Belderbos et al, 2004a; Tether 2002). On the other hand, supplier cooperation tends to focus more often on cost reduction and incremental process and product innovations, and this innovation strategy may be more difficult to combine with innovation efforts involving more radical objectives. These findings only hold for small. firms, whilst for larger firms none of the combinations leads to significant performance effects. This suggests that the issues of lack of management time and increased complexity of the innovation process may more often lead to 
underperformance of joint cooperation strategies in smaller firms, while lager firms with more abundant resources can handle multiple innovations objectives and management of multiple R\&D collaborations.

It is useful to note a number of caveats in the above empirical exploration of complementarities in R\&D cooperation strategies. First, although labor productivity is a rather comprehensive performance measure, on which $R \& D$ activities have a major impact, the results may still be dependent on the type of performance measure used. One may expect that innovation effort geared towards cost reduction has a more direct impact on (labor) productivity than innovative efforts aimed at creation of entirely new products. The non-significant impact of university and customer cooperation as single cooperation strategies may hence be partly due to the choice of performance measure. If university and customer cooperation are more directed towards product innovations, they may have a relatively greater impact on growth rather than on cost reductions and productivity increases. ${ }^{57}$ Second, we also note that the insignificant results for large firms may be due to the imperfect (binary) measure of $R \& D$ cooperation strategies.

\footnotetext{
"5vidence when the performance measure is growth of sales in completely new products (new to the market products) is presented in Belderbos et al. (2004b).
} 
Complementarity in R\&D cooperation strategies

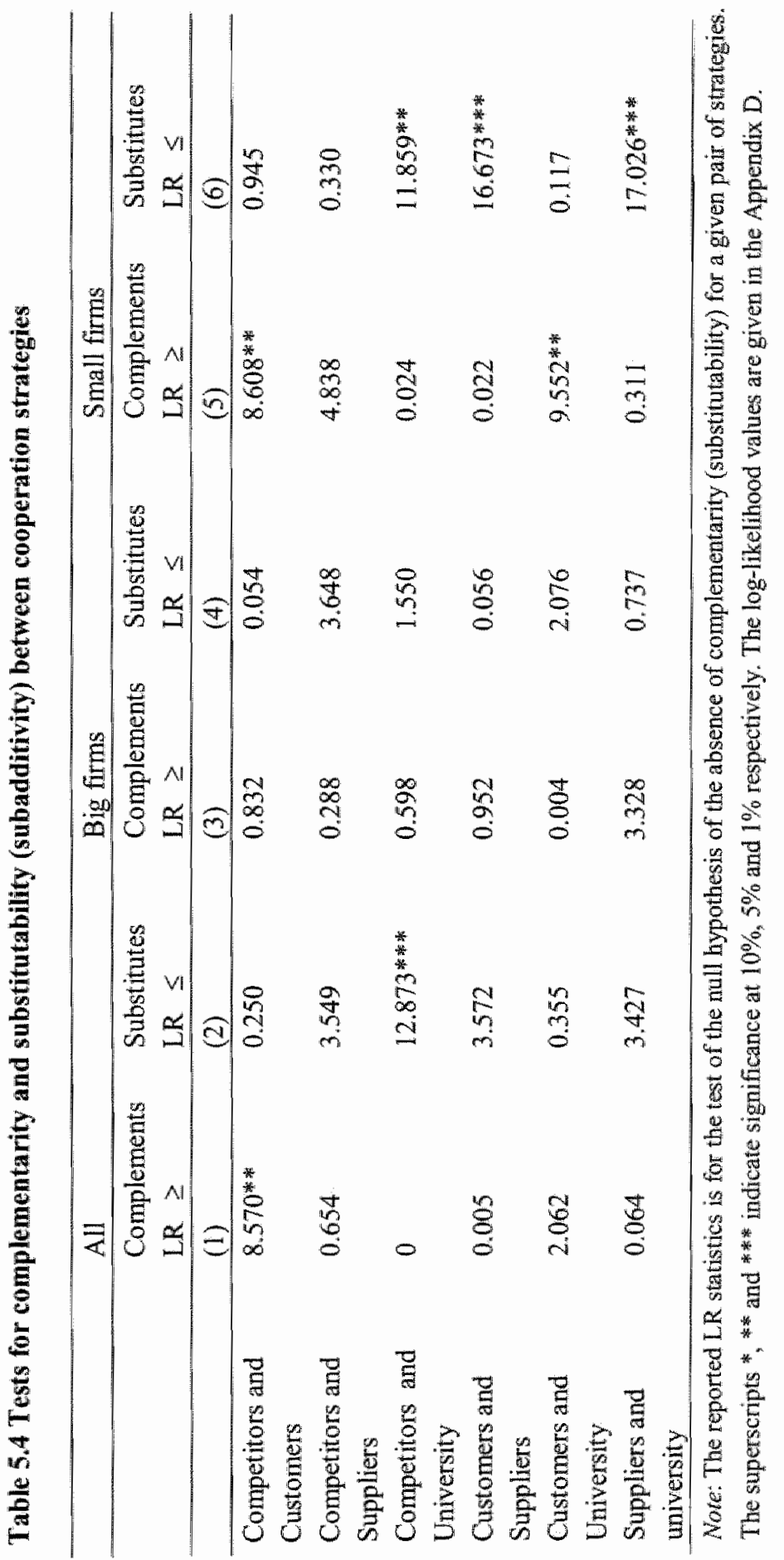


Whereas for small firms, a cooperative strategy is in most cases likely to involve a single collaborative effort, for larger firms the presence of $\mathrm{R} \& \mathrm{D}$ cooperation can hide substantial heterogeneity in the number and scale of such R\&D collaborations. The fact that large firms adopt specific $R \& D$ cooperation strategies is much less informative of the firms" innovative efforts. Complexily issues are likely to arise within the group of collaborating firms as a function of the number of collaborative partners of a specific type, rather than in the combination of R\&D partnerships of different types. Hence, we are inclined to consider our analysis as more representative for the sub-sample of smaller firms.

\subsection{Conclusions}

In this chapter we analyzed possible complementarities in cooperation strategies as they impact labor productivity growth for a large sample of innovating firms in two waves of the biannual Dutch Community Innovation Survey (1996, 1998) and production statistics. We distinguished four types of partner-specific innovation strategies: cooperation with competitors, customers, suppliers and universities \& research institutes. We allowed for an appropriate time lag with which the impact of R\&D cooperation (1996) feeds through in productivity growth (1996-1998) and applied a robust testing framework for complementarity between multiple practices based on multiple inequality constraints. The test indicates whether the impact of the adoption of one cooperative strategy significantly increases if another practice is adopted simultaneously. The results confirm a positive impact overall of $\mathrm{R} \& \mathrm{D}$ cooperation on labor productivity growth, but with distinct differences in magnitude and significance of impacts depending on (combinations of) cooperation types. Competitor and supplier cooperation have the most direct positive impact on productivity growth. The empirical results on complementarities were mixed. Complementarity was found for joint cooperation strategies with competitors and customers, and with customers and universities. This may be related to the role of customer cooperation in facilitating commercialization and quicker diffusion of product innovations that are due to competitor and university cooperation. At the same time, a number of instances were found where the combination of cooperation strategies led to underperformance: supplier cooperation combined with either uniwersity or competitor cooperation, and competitor cooperation combined with university cooperation. The former result may be explained from diverging objectives of different collaborative efforts: supplier cooperation tends to focus more often on cost reduction and incremental and process innovations, and this innovation strategy may be more difficult to combine with innovations efforts involving more radical and product innovations associated with university and competitor collaboration, respectively. The combination of competitor and university collaboration may suffer from threats to appropriability of R\&D efforts when working simultaneously with a competitor and public institutions, as 
spillovers from university may leak to competitors not involved in the collaboration (Leydem and Link, 1999). All these impacts were found for small firms while no significant impact was found for larger firms. On the one hand, this may be due to our inability to measure actual importance of R\&D partmerships for large firms. On the other hand, the lack of a sub-additive relationship is consistent with the suggestion of earlier studies that lack of management time and the increased complexity of the innovation process can lead to underperformance of joint cooperation strategies, and that this is more likely to happen in smaller firms than in lager firms with more abundant resources. In general the empirical results support such an 'increasing complexity' hypothesis and show a decreasing marginal impact of multiple cooperation strategies in particular when these imply multiple objectives, with the largest impacts seen for combinations of two types of R\&D partnerships.

The results of our analysis also raise a number of questions, which suggest pertinent issues for further research. Given the mixed findings on the benefits of pursuing multiple cooperation strategies simultaneously and the suggestion that complexity issues play a role here, a natural extension of analysis is to examine the impact of different cooperation strategies when adopted sequentially. This will require the construction of panel data, utilizing data from more than two innovation surveys. Other extensions concern the analysis of potential differences in the performance effects of R\&D cooperation across industries, and the robustness of results for different performance measures than labor productivity. A problem that is not easily solved is the lack of an indicator of the scale or number of R\&D collaborations of each type in the European Community innovation survey data used here. To accurately examine the impact of R\&D cooperation for larger firms, information on the number and importance of such partnerships may be indispensable. Here an alternative approach would be to utilize databases on R\&D alliances that have been subject of analysis in most of the management literature. Last but not least, empirical analysis in this area could greatly benefit from more theoretical work on combined R\&D cooperation strategies, and in particular the role of collaboration with other partners than competitors. 
Chapter 5

\section{Appendix A Description of Variables}

Variable name Definition

Competitor cooperation $\quad 1$ if the business unit reported engagement in innovation in cooperation strategy with competitors, else zero

Supplier cooperation $\quad 1$ if the business unit reported engagement in innovation in cooperation strategy with suppliers, else zero

Customer cooperation $\quad 1$ if the business unit reported engagement in innovation in cooperation strategy with customers, else zero

University cooperation $\quad 1$ if the business unit has reported engagement in innovation in cooperation strategy with universities, innovation centers, or research institutions, else zero

Incoming spillovers

Constructed as residual from the auxiliary regression of sum of university, competitor, and supplier spillovers taken from 1998 survey on a cooperation dummy taken from 1996 survey.

R\&D intensity Total innovation expenditures/sales

Firm size Logarithm of number of employees

Domestic group $\quad 1$ if the business unit is part of a domestic firm grouping, else 0

Foreign multinational $\quad$ if the firm is an affiliate of a foreign multinational, else 0

Productivity growth

(value added)

Growth in the net value added per employee $=\log$ (llabor productivity 1998) - log (labor productivity 1996)

Note: all independent variables are for 1996 except for the spillover variables 


\section{Appendix B Means and Standard Deviations of Variables}

\begin{tabular}{|c|c|c|}
\hline & Mean & S.D. \\
\hline & (1) & (2) \\
\hline \multicolumn{3}{|l|}{ Cooperation with: } \\
\hline Competitors & 0.021 & 0.143 \\
\hline Suppliers & 0.047 & 0.213 \\
\hline Customers & 0.038 & 0.190 \\
\hline Universities & 0.022 & 0.148 \\
\hline Suppliers, universities & 0.017 & 0.129 \\
\hline Customers, universities & 0.014 & 0.118 \\
\hline Customers, suppliers & 0.038 & 0.190 \\
\hline Customers, supplier and universities & 0.019 & 0.138 \\
\hline Competitors, universities & 0.013 & 0.112 \\
\hline Competitors and suppliers & 0.006 & 0.079 \\
\hline Competitors and suppliers and universities & 0.007 & 0.085 \\
\hline Competitors and Customers & 0.008 & 0.088 \\
\hline Competitors and customers and universities & 0.009 & 0.093 \\
\hline Competitors and customers and suppliers & 0.013 & 0.112 \\
\hline Competitors, customers suppliers, universities & 0.033 & 0.179 \\
\hline Log(value added per employee) 96 & 4.455 & 0.657 \\
\hline Spillovers & 9.442 & 4.799 \\
\hline Firm size & 4.498 & 1.190 \\
\hline R\&D intensity & 0.284 & 11.035 \\
\hline Foreign MNE & 0.203 & 0.402 \\
\hline Domestic group & 0.270 & 0.444 \\
\hline observations & 2053 & \\
\hline
\end{tabular}




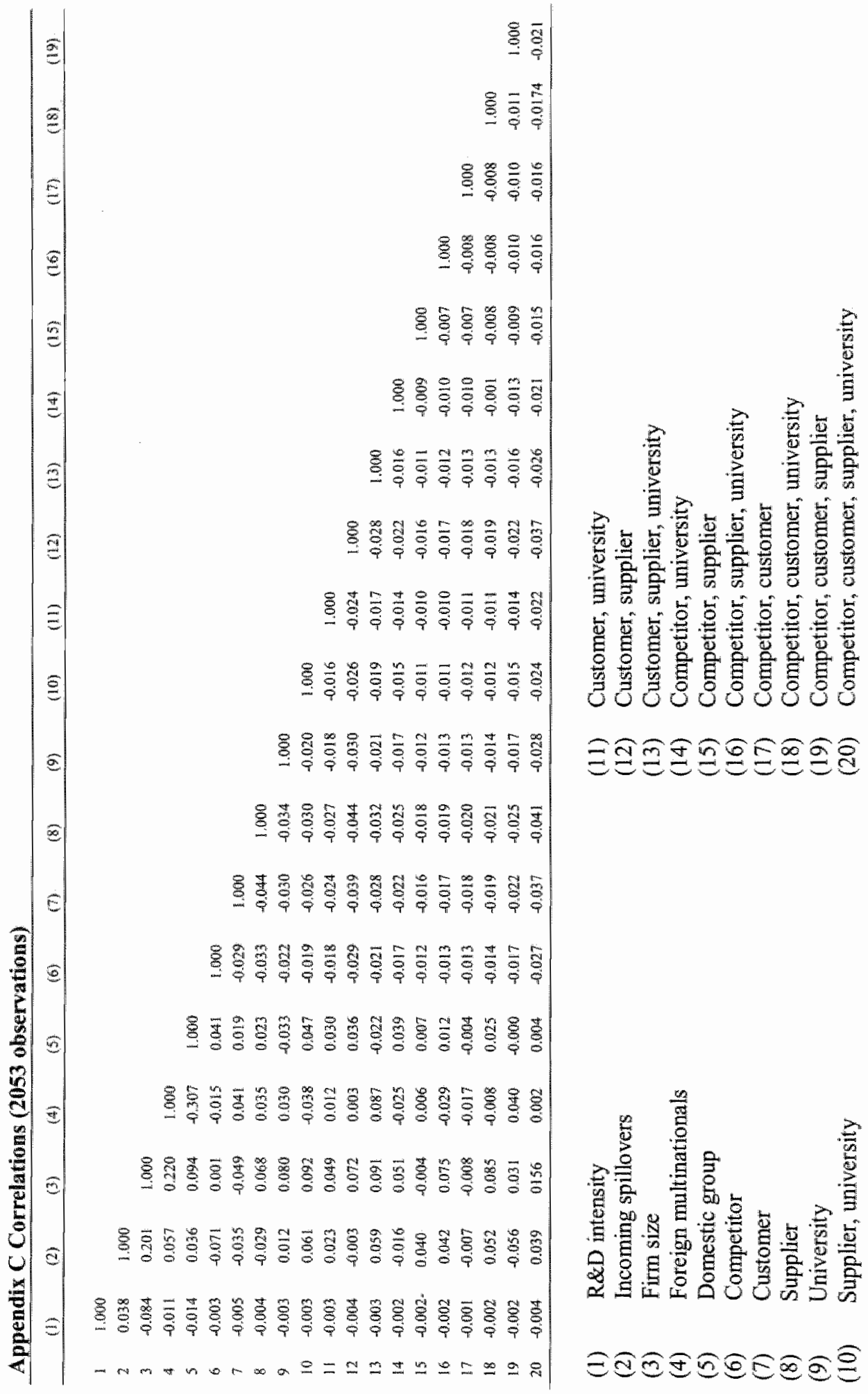


Complementarity in R\&D cooperation strategies

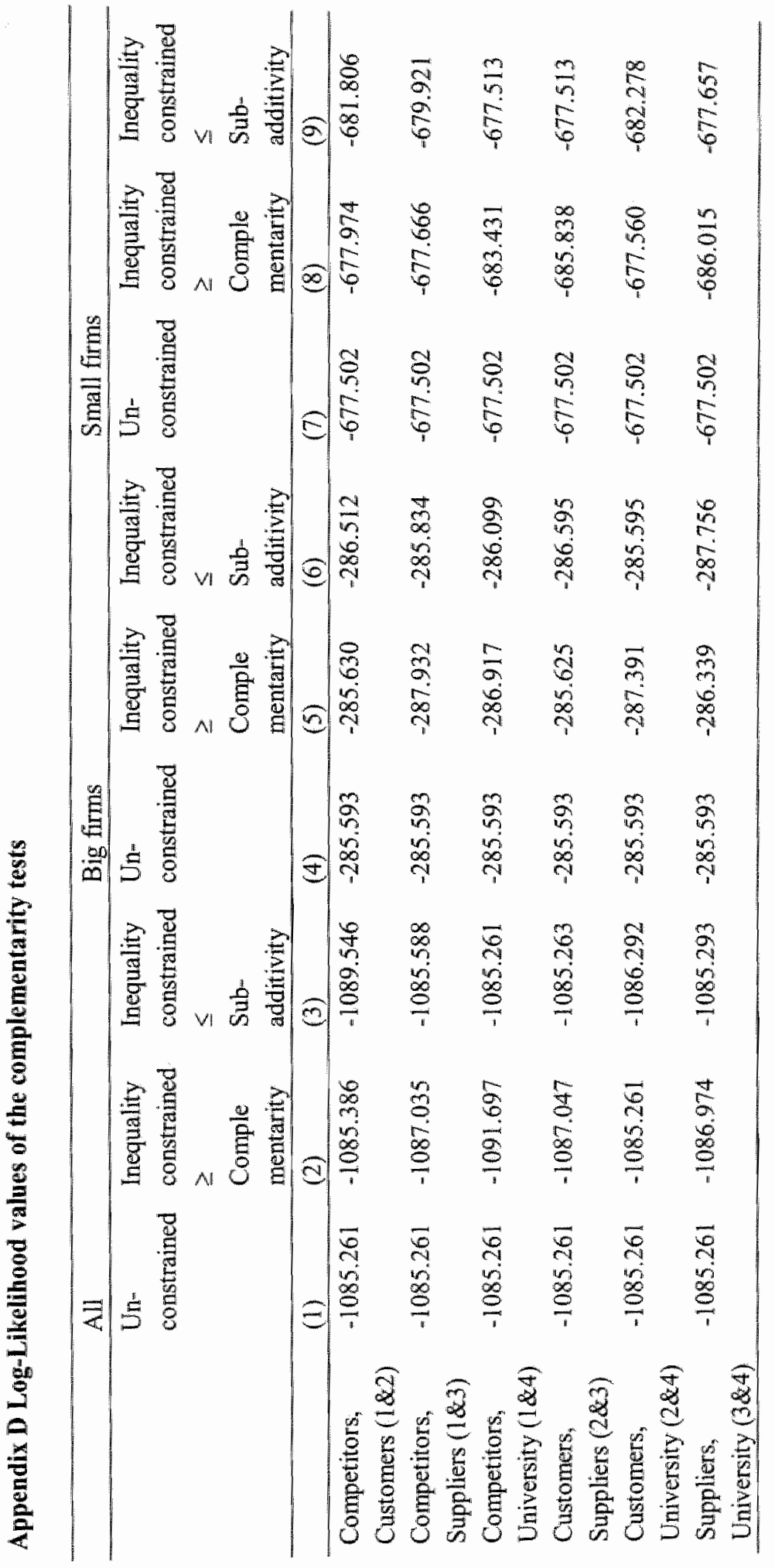




\section{CHAPTER 6}

\section{The productivity effects of internal and external R\&D: Evidence from a dynamic panel data model}

We examine the impact of internal and external R\&D on labor productivity in a 6year panel of 372 innovating firms. Applying a dynamic linear panel data model we find positive impacts of both types of $R \& D$ and a negative interaction between them in a linear model. Estimation of a non-linear model reveals complementarity (supermodularity) in combining internal and external R\&D, which appears consistent with the frequent joint adoption of internal and external R\&D strategies. The positive effect is only evident when substantial internal R\&D is present. This finding supports the dual role (absorptive capacity and productivity accelerator) played by internal $R \& D$. The estimates reveal declining returns to increases in either internal or external R\&D expenditures. Hence, combining internal and external $R \& D$ rather than focusing on one type of $R \& D$ can improve performance, despite the existence of negative interaction between the two R\&D strategies in the linear model. We note that empirical work examining complementarities between continuously measured practices should adopt more general non-linear specifications to allow for correct inferences.

Acknowledgement: The empirical part of this research uses micro-level data provided by CEREM/Statistics Netherlands, drawing on the MICRONOOM data integration project at Statistics Netherlands supervised by Bert Diederen. The views expressed in this paper are those of the author and do not necessarily reflect the policies of Statistics Netherlands. I thank Pierre Mohnen for helpful comments. 


\subsection{Introduction}

The growing technological diversification of companies and increasing demands on their portfolio of competencies makes successful integration of new external knowledge into the innovation process furthermore important. Such successful integration fosters innovation performance, while the effective use of external R\&D strategies ultimately lead to higher profitability of the firm. Academic research in both fields of management and industrial economics has been focusing on these themes for some time now (Arora et. al., 2001; Chiesa et al, 2004). Moreover, some authors have argued that the trend of access to external sources of knowledge is accelerating due to technological convergence and declining transaction costs of acquiring external R\&D inputs as well as availability of multiple nondistinguishable sources of these inputs and shortening product life cycle times (Narula, 2001, Grandstrand et al. 1992b). This development is accompanied by a parallel decrease of the presence of internal R\&D departments (Howells et al., 2004; Chesbourgh 2003) and is especially pronounced in research intensive industries (Bönte, 2004). Firms are therefore increasingly confronted by the issue of management of internal and external innovation strategies, having to decide which technological elements should be produced in-house and which can be sourced externally.

It has been argued that to absorb the externally acquired information, an effective absorptive capacity (i.e. internal R\&D capabilities) is essential (Cohen and Levinthal, 1989, Griffith et al., 2004), suggesting complementarity between internal R\&D and external technology acquisition (Cassiman and Veugelers, 1999). Empirically, the effective balance between internal R\&D and external sourcing and interaction between these two strategies has however remained relatively unexplored and has been hampered by a lack of adequate data. Cassiman and Veugelers (2002) argued that external R\&D is, in a sense, conditioned on a firm already having invested in in-house $R \& D$ and is therefore, positively correlated with it. They find evidence of complementarity if 'make' and 'buy' are treated as discrete practices. Audretsch et al (1996) find evidence that external and internal R\&D are alternatives for firms in medium and low tech industries, but not in high tech industries. Fernandez-Bagues (2003) analyses the impact of the number of R\&D projects started in-house and under outsourcing agreements in a panel of pharmaceutical firms and finds a negative relationship between make and buy.

In this chapter we contribute to the empirical literature by examining the impact of internal and external R\&D on labor productivity in a 6-year panel of innovating firms in the Netherlands. This is the first empirical study that has been able to explore such a panel data set to examine the effects of internal and external R\&D. Earlier micro-level work had to rely on cross section data, which hampered separation of true complementarity effects from the effect of time-invariant and time-variant heterogeneity (Fernandez-Bagües, 2004). Our study's inferences are based on a dynamic panell data model, which allows us to control for the existence 
of fixed effects as well as time-variant unobserved factors that are likely to affect innovation practices decisions. We look at the productivity effects of external and internal R\&D strategies as opposed to looking at the correlation (adoption) structure, a method that was shown to have measurement problems and inference difficulties (Arora, 1996). ${ }^{58}$ Instead of analyzing the effect of discrete practices ("make" versus 'buy') or counts of practices, our analysis is of actual expenditures on internal and external R\&D, allowing us to examine non-linear effects.

The rest of the chapter is organized as follows. The next section reviews the previous research on "make" and "buy" R\&D strategies and discusses in greater detail the potential for competing hypotheses on the interaction of external and internal sourcing. In section three we present the model and discuss our estimation methodology. The following section presents the data. In section five we discuss the results. A final section concludes.

\subsection{External and internal technology sourcing}

Recent work by Griffith and co-authors $(2004,2003)$ makes an important contribution to the discussion about two functions performed by R\&D, i.e. as direct stimulus for productivity growth, but also its role in increasing the absorptive capacity facilitating technology transfers. By examining the productivity growth at the industry level across a panel of OECD countries, the authors find that R\&D expenditure by the business sector increases such technology transfer and allows countries that as yet fail to attain the technological frontier to catch up with technology leaders. Reinterpreting the idea of incoming spillovers we can think of such technological transfer as an inflow of new knowledge that stimulates the internal innovation process. The catch up through, for example, imitation and learning by doing is only possible given the minimum absorptive capacity that allows assimilating external innovation. These results imply a positive relationship between external and internal R\&D activity. On the other hand, a recent paper by Gans and Stern (2000) shows that relationship between in-house $\mathbb{R} \& D$ and technology sourcing is theoretically ambiguous ${ }^{59}$. In their model of technological competition, which allows licensing, the incumbent firm considers the entrant's

\footnotetext{
5. Alongside the established GMM techniques we are using a new bias-corrected (BC) estimator proposed recently by Bun and Carree (2005). It is computed as a bias correction to the LSDV estimator, and thus does not require, unlike Kiviet's approach an initial consistent estimator. Although related to the Kiwiet bias-correction procedure for a dymamic panel data model, the $\mathrm{BC}$ estimator has several important advantages. It does not depend on the often difficull choice of initial consistent estimator, and unlike GMM does not have a problem of uninformative moment conditions. In addition, as some studies have shown (Mairesse et al., 1999) because it uses the within estimates instead of GMM's first differences, the bias-corrected estimator may be more robust to the random measurement errors.

59 There is a scarcity of theoretical research that explicitly models external and internal R\&D and interaction between them. One example, is a recent paper by Lee (2003) where axogenous technological knowledge is negatiwely related with current own R\&D expenditure.
} 
R\&D as a strategic substitute for own in-house R\&D when the license fee is not very high. This result is in contrast with the previous paient-race literature that predicted strategic complementarity.

The empirical industry-based studies tend to argue that there is a trend of increasing share of external in total R\&D, implying that acquired R\&D substitutes in greater degree for intemal research. In one such recent industry-level longitudinal study Bönte (2003) cites the evidence from the National Science Foundation that for the majority of the surveyed industries the share of the external R\&D gradually increased since the $1980 \mathrm{~s}$ into the mid $1990 \mathrm{~s}$. The empirical model further presents some evidence of the positive relationship between the share of the external R\&D share in total R\&D and productivity ${ }^{60}$. In the high-technology sub-sample, however, the external R\&D is characterized by decreasing returns to scale, while the nonlinear relationship in not significant for the other industries. The inability to pin down whether these results are driven by the changes in the firms' strategies or by the distributional changes within industries, however, weakens the conclusions of the study.

Audretsch et al. (1996) discuss institutional economics arguments of asymmetry, asset specificity and principle agent relationship that may entice firms to prefer external over internal sourcing. They apply a probit model and use as a dependent variable the decision by a firm to engage in external R\&D. In their empirical cross-section study on 1106 Dutch manufacturing firms reporting internal and external R\&D activity they find that in low and medium technology industries external R\&D is a substitute to internal R\&D, but the reverse is true in the hightechnology industries. Much like Hertog and Thurik (1993) earlier, Veugelers and Cassiman (1999) find that relationship between "make" and "buy" is complex. Small firms in their cross-section sample of Belgian firms are likely to restrict themselves to either "make" or "buy" strategy, possibly reflecting scarcity of the internal capabilities to manage both. On the other hand, larger more resourceful firms have a propensity to combine both. However, the decision to source externally depends on appropriation regime ${ }^{6 !}$. In their later empirical study Veugelers and Cassiman (2002) argue that the "make" and "buy" are complements. The argument relies on the absorptive capacity (i.e. inter-temporal relation) idea: external R\&D is "...conditioned on a firm's already having invested in in-house R\&D" and is, therefore, positively correlated with it. Because of the cross-sectional nature of the study, they can only observe the co-temporal interaction between "make" and "buy". As already indicated in the introduction, inability to control for neither firm

\footnotetext{
${ }^{60}$ There is other literature that considered at the effects of the R\&D produced within and outside a given economic sector on firm's performance within that sector. Geroski (1991) finds that the effect on productivity of the outside-sector innovations is 3.7 times larger compared to the effect of "produced" innovations (p. 1441). He confirms similar conclusions obtained earlier for example, by Scherer (1982), and Grilliches and Lichtenberg (1984a).

6i Similar conclusions were reached by Love and Roper (2003) who look at the determinants of the firm's choice between internal and external R\&D. Technological opportunity, however, was not found to be rolevant in this decision.
} 
effects nor possible simultaneity in the static model may be an explanation of the mixed results ${ }^{62}$. Another study that finds complementarity in a UK-sample between "buy" (technology purchase through license agreements) and "make" (in-house R\&D) is Lowe and Taylor (1998). However, their conclusions are derived solely from the correlation structure of the external and internal strategies, a method highly prone to omitted variable bias. As shown in Miravette and Pernias (2004) such testing methods based on correlation in a cross-section framework are not robust to the existence of unobserved heterogeneity.

Fernandez-Bagües (2002) proposes a new methodology to test for complementarity between internal $R \& D$ and external sourcing in a panel of pharmaceutical firms. His main finding is that while initial cross-sectional evidence shows contemporaneous positive correlation between strategies, the use of dynamic panel data tests reveal a negative relationship. This result can be attributed to the existence of common unobservables or opposite relation between strategies in the short (complementary) and long (substitutes) run. Blonigen and Taylor (2000), using a sample of 217 electronic and electrical equipment firms, find that internal R\&D and external sourcing via acquisitions are substantially negatively related. Remarkably, this relationship is in a sample of high-technology firms that holds for both within and between dimensions of their panel. Basant and Fikkert (1996) use a panel of Indian firms to estimate the impact of own R\&D and technology purchases on their productivity, controlling for domestic and international spillovers. They find a robust relation that holds across different specifications suggesting that own R\&D and technology purchase expenditures are substitutes in the production function, meaning that one mode of knowledge lowers the marginal productivity of the other ${ }^{63}$. Piga and Vivarelli (2004) model the decision to acquire external R\&D jointly with the decision on internal R\&D. They find some evidence that firms that have objectives in both process and product innovation are likely to have propensity for external sourcing.

62 In the adoption model they estimate a simultaneous system of propensities to engage in both external and internal R\&D sourcing and look at the sign of generalized tresiduals. In the productivity model they look at the direct effect of binary wariables "make" and "bury" on the share of new products in firm's sales, the dependent wariable. While their productivity approach reveals comlementarity between concurrent make and buy decisions, results from the adoption model are mixed and largely depend on the specification.

${ }^{63}$ In similar lines, Love and Roper (1999) estimate a system of equations linking firm's investment in R\&D, technology transfer and networking in a cross-section of UK firms. They also find that own $R \& D$, technology transfer and networking are substitutes in the innovation process and can be viewed as alternative means of acquiring necessary inputs. This is in contrast to earlier findings of Deolalikar and Evension (1989), Katrak (1989, 1985), Mohnen and Lepine (1991) that find a complementary relation. 


\subsection{Model construction and estimation techniques}

Our modeling framework is derived from an augmented Cobb-Douglas production function for firm $i$ at time $t$ :

$$
Y_{i t}=C_{i t}^{a} L_{i r}^{\beta} K_{i t}^{\gamma} e^{\sigma_{i r}}
$$

where $\mathrm{Y}$ is output, $\mathrm{L}$ is labor input, $\mathrm{C}$ is the physical capital stock and $\mathrm{K}$ is the knowledge stock. Alfa, beta, and gamma are elasticities with respect to physical capital, labor and knowledge capital. Sigma is an efficiency parameter, which we will assume to be related to past productivity in order to allow for persistency in productivity differences between firms.

In this chapter, we want to analyze the contribution of two sources of knowledge, internal and external, to the firm's production. Furthermore, we assume that these two sources of knowledge interact with each other, possibly creating a complementary effect. Dividing both sides by labor, taking the log and differencing the resulting equation in the two consecutive periods, we obtain the equation in the growth form:

$$
\Delta q_{i t}=(\beta-1) \Delta l_{i t}+\alpha \Delta c_{i t}+\gamma \Delta k_{i t}+\Delta \sigma_{i t}
$$

where $q_{i t}$ denotes productivity with lower case letters denoting variables in logs. We specify the change in the efficiency parameter is a function of past productivity:

$$
\Delta \sigma_{i t}=\theta q_{i t-1}
$$

Firms that are highly productive and are at the frontier of productivity may be less likely to have strong growth rates in productivity than firms that are followers. In that case we expect $\theta$ to fall within the interval $[-1,0]$. If $\theta$ is zero, the catch-up effect is absent and there is no gradual convergence between leading firms and the productivity laggards. If $\theta$ is -1 , then a productivity lead is fully neutralized in one period.

The standard framework often treats the accumulation of physical capital using the perpetual inventory method, i.e. $C_{i b}=(1-\delta) C_{i t-1}+I_{i t-1}$. Unfortunately, sufficiently long enough series of investment are not available to us in order to be able to construct the capital stock in this way. Instead, in our model we approximate the stock variable with a flow, i.e. with capital investment. We make an assumption that the change (log difference) in the physical capital, $\Delta c$, is proportionate to the change in physical investment: 


$$
\Delta c_{i t}=\log \left(\frac{C_{i t}}{C_{i t-1}}\right)=\log \left(I_{i t}\right)-\log \left(I_{i t-1}\right)+\log \left(\frac{(1-\delta) C_{i t-1}+I_{i t}}{(1-\delta) C_{i t-2}+I_{i t-1}} \cdot \frac{I_{i t-1}}{I_{i t}}\right) \approx \Delta i_{i t}
$$

The last term in (6.3), where lower case denoting variables in logs, is zero if the change in capital stock is proportionate to the change in physical investment, regardless of the value of the depreciation parameter $\delta$. In the case the growth rate of investment is smaller than the depreciation rate, $\delta$, the consequence will be an upward bias of the estimate on the rate of return (Mairesse and Sassenou 1991).

We assume that the annual change of firm-specific knowledge stock in period $t$ is a function of the two types of R\&D investment: created by firm $i$ through own $R \& D$ investment (internal $R \& D$ ) and through the acquired $R \& D$ (external $R \& D$ ).

$$
\gamma \Delta k_{i i}=f\left(R_{i r-1}^{\mathrm{int}}, R_{i t-1}^{\mathrm{ext}}\right)
$$

In our empirical analysis we approximate the unknown function (6.5) with Generalized Leontief Linear functional form ${ }^{64}$ (Basant and Fikkert, 1996). The resulting approximation leads to the following expression:

$$
\gamma \Delta k_{i r}=\sum_{n} \eta_{n} \sqrt{R_{i t-\mathrm{i}}^{n}}+\sum_{n} \sum_{m} \eta_{n n t} \sqrt{R_{i n-1}^{n} R_{i t-1}^{m n}}+v_{i r}, \quad n=\text { internal, } m=\text { external }
$$

where $v_{\mathrm{it}}$ reflects measurement errors. Keeping in mind the previous discussion in the theoretical literature about the reasons for external and internal R\&D to be complements or substitutes, our functional form allows testing such a relationship ${ }^{65}$. Combining equation (6.2), (6.3) and (6.6) leads to the following dynamic equation:

$$
q_{i t}=(1+\theta) q_{i t-1}+(\beta-1) \Delta l_{i t}+\alpha \Delta i_{i r}+\sum_{n} \eta_{n} \sqrt{R_{i r-1}^{\prime \prime}}+\sum_{n} \sum_{i m} \eta_{n m} \sqrt{R_{i r-1}^{n} R_{i r-1}^{m}}+\varepsilon_{i r}
$$

where $\varepsilon_{i f}$ is an error term. As is common with panel data, it is assumed that the error term in equation (6.7) is composed of a year-specific intercept, reflecting possibly, common technology shock, the unobserved time-invariant firm-specific effect $\eta_{i,}$ a

Fuexible functional forms previously used in the literature can be wiewed as liner-in-parameters expansions which approximate an arbitrary function (see, for example, Fuss, McFadden and Mundlack, 1978 for known functional forms taken by $h$ ). Generalized Leontief Linear functional form is attributed to Diewwert (1971).

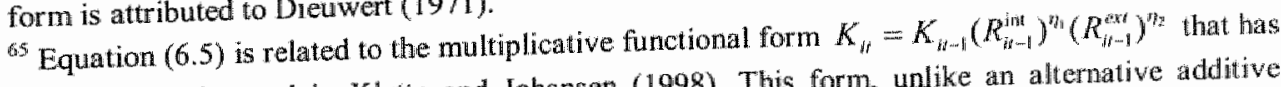
been previously used in Klette and Johansen (1998). This form, unlike an alternative additive specification, allows for complementarity between already existing and newly acquired knowledge. 
possibly autoregressive productivity shock $w_{\text {it }}$ and $v_{\mathrm{il}}$ reflects the serially uncorrelated measurement errors:

$$
\varepsilon_{i t}=\lambda_{i}+\eta_{i}+u_{i t}+v_{i t} \quad \text { for } \quad i=1, \ldots, N ; t=1, \ldots, T
$$

We estimate two versions of equation (6.7), first restricting (similar to the analysis in Basant and Fikkert, 1996) $\eta_{n m}=0$ for $\mathrm{n}=\mathrm{m}$ and the second, unrestricted quadratic form equation allowing for non-linear effects in internal and external R\&D, i.e. (dis)economies of scale in external and internal R\&D and (dis)economies of scope in R\&D. In addition, the resulting model allows for firm fixed effects and the persistence of performance differences emphasized by previous productivity literature (Klette, 1996, Blundell and Bond 2000).

In our model the dependent variable, log of labor productivity, is determined by one-period lagged labor productivity, firm-level investment, size, internal $R \& D$ and external $R \& D$. In the resulting equations we have the flow variables for $R \& D$ and physical capital (investment) in place of more usual stock variables ${ }^{66}$. When growth rates are constant (steady state) stocks can be reliably inferred from flows (Jones, 2002). The advantage of estimating this expanded model is that it allows us to look at the complementarity between internal and external $R \& D$ while controlling for decreasing returns to $\mathbb{R} \& D$.

We carry out the estimation of equation (6.7) with several panel data techniques, including GMM and a recently proposed bias-corrected estimator for dynamic panel data models (Bun and Carree, 2005). We use several consistent estimators for dynamic panel data models for robustness. A system GMM has been shown to perform often better in small time-series dimension production function data compared with difference GMM, but its performance may be unsatisfactory due to weak instruments (Blundell and Bond 2000). Although the recent developments in GMM estimation make it a standard choice for estimation of a dynamic panel data model, it requires a non trivial decision on the number of instruments. The only criterion for selection of the instrument list is the Hansen/Sargan test of over-identifying restrictions. Furthermore, GMM performance depends on the ratio of variance of the individual specific effects and the variance of the general error term (Kitazawa, 2001). In contrast, a newly developed bias-corrected estimator is relatively simple to apply. Monte-Carlo studies have argued that the bias-corrected estimator outperforms GMM in some standard cases (Judson and Owen, 1999). In addition, the bias-corrected estimator may be more robust to the random measurement errors (Mairesse et al., 1999). It assumes, however, that the explanatory variables are weakly exogenous.

\footnotetext{
*6 The process for $K$ assumes the most inpact is carried by R\&D lagged one year. Equation 5 can be modified to include more lags of R\&D, however, we point to previous studies, e.g. Pakes and Schankerman (1984), Hall, Griliches and Hausman (1986) and Klette (1998) that find out that the most significant effect or R\&D is from one-year lag.
} 


\section{Data}

The empirical analysis makes use of the data from the Dutch Community Innovation Survey (CIS) and R\&D survey. The latter contains information about R\&D and innovation activities of the firms, including information on type and amount of $R \& D$ expenditures. CIS contains information on innovation in partnership data and sources of knowledge used in innovation process. The production statistics database includes information on output, employment and value added. The CIS and production statistics surveys are sent out to all large firms and to a random sample of smaller firms in the Netherlands, covering as little as 10 employees. The data are at the establishment level and include manufacturing as well as service firms. After the matching using a unique firm identifier and removing the outliers, we end up with a balanced panel of 372 firms covering years $1996-2001$.

The dependent variable, labor productivity, is measured as value added per employee, taken from the production statistics. All the level right hand side variables are measured at time $t-1$. Table 6.1 lists some descriptive statistics on the variables used in estimation. The $R \& D$ expenditure variables are taken from the annual $R \& D$ survey. Internal $R \& D$, the variable "make", is defined as firm's expenditure on intramural $R \& D$ while the external $R \& D$ is the expenditure on outsourced (contracted) R\&D. Because R\&D survey has a detailed breakdown of the innovation expenditures by category, we are able to experiment with the definition of "buy". We tried several alternatives: for example, taking external R\&D as a broader measure of the expenditure on external innovation, including purchases of licenses, industrial design, and other external knowledge. However, we found little empirical difference in our modeling with respect to different definitions of "buy".

Table 6.1 Variables used in estimation and descriptive statistics

\begin{tabular}{|c|c|c|c|c|}
\hline & Variable & Mean & S.D. & Description \\
\hline 1. & Productivity & 3.90 & 0.49 & Net value added divided by employees, in log \\
\hline 6. & $\Delta$ Labor & 0.02 & 0.19 & Growth of the number of employees \\
\hline 7. & Dinvestment & 0.02 & 3.88 & Investment, in logarithm \\
\hline 2. & Sqr R\&D $D^{\text {internal }}$ & 27.60 & 39.66 & $\begin{array}{l}\text { Square root of expenditure in thousand Euros on } \\
\text { in-house R\&D }\end{array}$ \\
\hline 3. & Sqr R\&D ${ }^{\text {external }}$ & 9.50 & 22.15 & Square root of expenditure on contracted R\&D \\
\hline 4. & $R \& D^{\text {internal }}$ & 2333.9 & 10417 & Expenditure in thousand Euros on in-house R\&D \\
\hline 5. & $\mathrm{R} \& \mathrm{D}^{\mathrm{exteninal}}$ & 580.7 & 3299 & Expenditure on contracted $\mathrm{R} \& \mathrm{D}$ \\
\hline 6. & Spillover & 7.22 & 3.78 & $\begin{array}{l}\text { Incoming spillovers, constructed sum of scores of } \\
\text { importance of customers, suppliers, competitors } \\
\text { and universities in R\&D innovation }\end{array}$ \\
\hline 7. & Cooperation & 1.31 & 2.31 & R\&D cooperation \\
\hline
\end{tabular}


A large body of literature that examines the role of knowledge spillovers in firm performance (e.g. Audretsch and Feldman, 1996; Jaffe, 1989; Branstetter, 2001; Acs et al, 1994) generally confirms the positive effect of incoming knowledge spillovers on productivity. In our model we include as a control variable firm-specific direct measures of incoming spillovers. The incoming spillover variable is taken from the CIS surveys. One of CIS survey questions asks to rate the importance of various external sources of information in terms of the "effectiveness in the firms" innovation process", such as importance of competitors, suppliers, customers and universities as sources of information ${ }^{67}$. The aggregated spillover is the sum of scores of importance of information received from each of these sources $^{68}$.

Table 6.2 reports the overall means of key variables across the estimation years. This exercise does not reveal considerable variation in "make"/ buy" patterns. Table 6.3 reports propensities (over five year means) for external and internal strategies according to the three different $\mathrm{R} \& D$ intensity quintiles. Like in many other studies, R\&D intensity is defined as the ratio of total R\&D expenditures to sales. A clear inverse relationship emerges between $R \& D$ intensity and purely internally-based R\&D. For the lowest R\&D intensity quintile (below $2.5 \%$ ), almost $50 \%$ of the firms report only "make" activities (and zero "buy"). For the upper R\&D intensity quintile ( $5 \%$ and more) this number drops to about a quarter of firms. At the same time difference in share of external in total R\&D between the lowest and top quintile is not so big and is on average at most 5\%. Another difference between low and higher intensity firms is their use of R\&D cooperation strategies. Relatively high intensity firms report twice as high a level of engagement in R\&D cooperation strategies (mean of 1.13) compared to low-intensity firms (mean of 2.06).

\section{Table 6.2 Means across years}

\begin{tabular}{|c|c|c|c|c|c|c|}
\hline Year & $\begin{array}{l}\text { Expenditure } \\
\text { Make }\end{array}$ & $\begin{array}{l}\text { Expenditure } \\
\text { Buy }\end{array}$ & $\begin{array}{l}\text { Average R\&D } \\
\text { intensity, } \\
\text { percent }\end{array}$ & $\begin{array}{l}\text { Percentage } \\
\text { of firms that } \\
\text { only make }\end{array}$ & $\begin{array}{l}\text { Percentage } \\
\text { of firms that } \\
\text { only buy }\end{array}$ & $\begin{array}{l}\text { Share of } \\
\text { external in } \\
\text { total R\&D }\end{array}$ \\
\hline 1996 & 1898.2 & 423.4 & 3.21 & 40.59 & 0.27 & 18.24 \\
\hline 1997 & 2127.4 & 466.4 & 2.82 & 41.94 & 1.34 & 17.98 \\
\hline
\end{tabular}

\footnotetext{
62 The four aggregated spillover sources included in the model identify directly the source of the information in line with theoretical models and identify most relevant potential sources of information, regardless of the channel of information transfer.

Sin Several alternative indireet measures of spillovers have been used in previous empirical work, e.g., based on uncentered correlation (Jaffe 1988, Adams 1990), Euclidean distance, and geographic distance. According to a comparative study of performance of these various spillover measures Kaiser (2002b) concludes that both uncentered correlation and direct measures (used in our model) appear to capture spillovers quite accurately.
} 


\begin{tabular}{lllllll}
\hline 1998 & 2285.3 & 606.4 & 3.03 & 37.63 & 1.08 & 20.97 \\
1999 & 2673.3 & 682.3 & 2.60 & 43.55 & 1.34 & 20.33 \\
2000 & 2685.4 & 725.0 & 3.01 & 43.55 & 0.81 & 21.26 \\
\hline
\end{tabular}

Table 6.3 Means according to R\&D intensity quintilles

\begin{tabular}{lllll}
\hline $\begin{array}{l}\text { R\&D intensity } \\
\text { quintile }\end{array}$ & $\begin{array}{l}\text { Number of } \\
\text { observations }\end{array}$ & $\begin{array}{l}\text { Percentage } \\
\text { make only }\end{array}$ & $\begin{array}{l}\text { Average share of } \\
\text { external in total } \\
\text { R\&D (in \%) }\end{array}$ & $\begin{array}{l}\text { Average number of } \\
\text { external R\&D } \\
\text { cooperation links }\end{array}$ \\
\hline $0 \%-2.5 \%$ & 1325 & 45.74 & 11.98 & 1.13 \\
$2.5 \%-5.0 \%$ & 281 & 37.37 & 12.33 & 1.44 \\
$5.0 \%$ and more & 254 & 23.62 & 16.19 & 2.06 \\
\hline
\end{tabular}

Table 6.4 presents the distribution of cases in the sample by industry and reports the average $R \& D$ intensity (internal and external $R \& D$ ) across industries, as well as the average productivity growth for the 6 year period. A sample-average growth in productivity covering the time period of our analysis is approximately $2.3 \%$. The comparison across industries indicates a slight bias in representation of medium-technology firms over the low-technology sectors. However, the relative scarce population of high-technology sectors (electronics with addition of biotechnology and pharmaceuticals) makes estimation of industry-wise regressions problematic which would be preferable given a significant variation of external R\&D share.

\subsection{Estimation results}

The results of the basic dynamic production function are reported in Table 6.5. Several consistent estimators are available when the number of firms $(N)$ is large and the number of years $(\mathrm{T})$ is fixed. For comparison the model is estimated with one-step difference and system GMM, for which the inference based on the asymptotic variance matrix that has been found to be more efficient compared to the two-step estimator (Arellano and Bover, 1995; Blundell and Bond, 1998) as well as the bias-corrected (Bun and Carree, 2005) estimator ${ }^{69}$.

\footnotetext{
The GMM estimation was carried out in Stata 8.0 with the help of a user-written routine xtabond2- written by David Roodman, Center for Global Development, Washington, DC. The estimation of the bias-corrected estimator was carried out by our own Fortran code.
} 


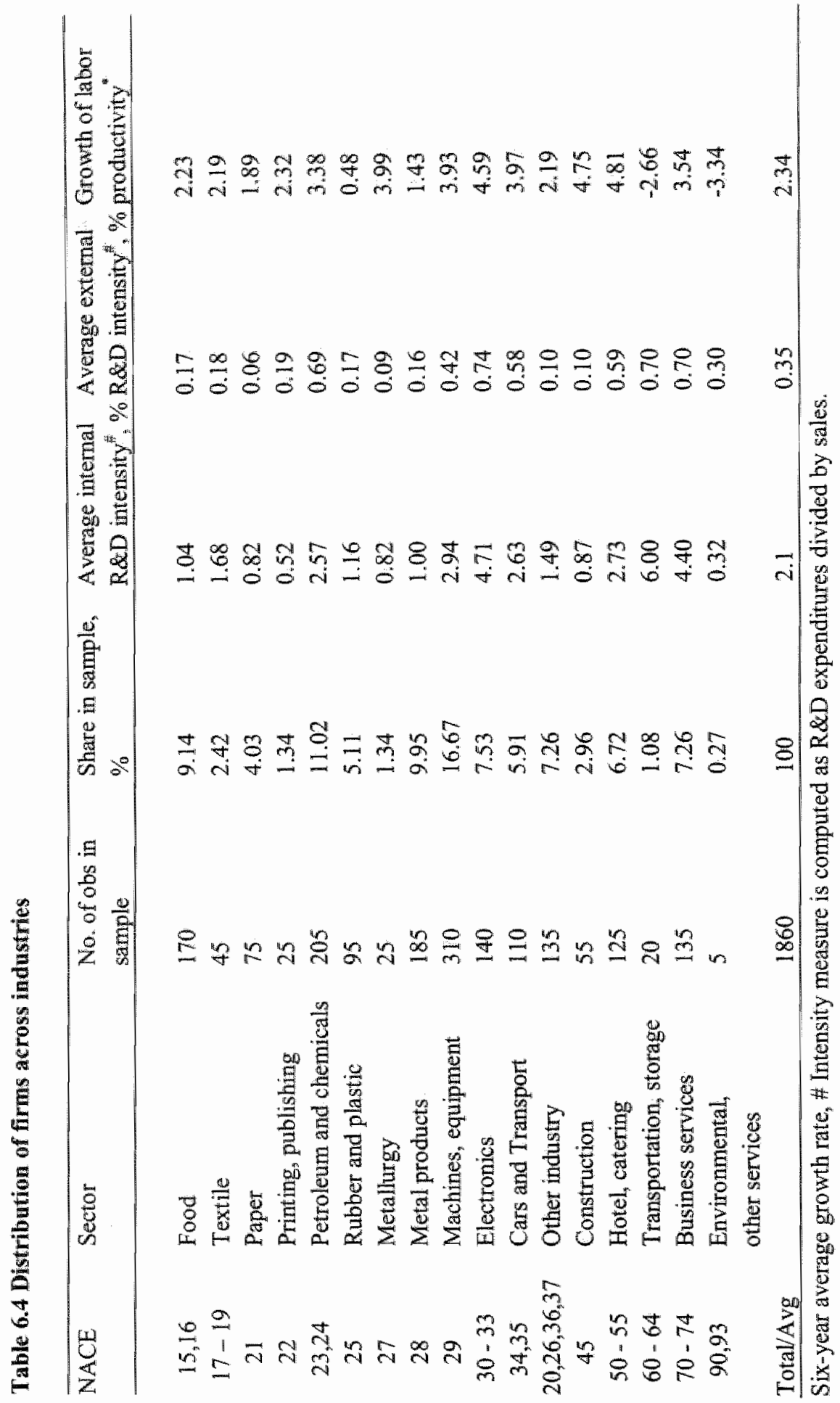


In columns (1)-(3) we present the estimates from the base specification (3) restricting (similar to the analysis in Basant and Fikkert, 1996) $\eta_{m n}=0$ for $\mathrm{n}=\mathrm{m}$. The three consistent estimators agree on the signs and magnitudes of most of the coefficients, whereas the $\mathrm{BC}$ estimator is able to better identify the dynamic process. The BC estimator produces a better fit, as it has the lowest SSR and the highest F-value. The difference GMM gives the worst fit according to these criteria. Previous studies (e.g. Blundell and Bond, 2000) have demonstrated that the difference GMM may also underestimate the coefficient on the lagged dependent variable. In all of the estimates in Table 5 both the internal and external R\&D are significant regardless of the estimation technique and specification. The results would also suggest that private returns on $R \& D$ expenditures are higher than those on internal $\mathrm{R} \& \mathrm{D}$, confirming similar conclusions in earlier work (e.g. Basant and Fikkert, 1996).

As far as identifying the dynamic process, a relatively more efficient system GMM estimator produces a coefficient of 0.54 , which may appear smaller than expected. This means a catch-up parameter $\theta=0.54-1=-0.46$ meaning that only about half of the productivity lead is neutralized by the next period. Other research (e.g. Blundell and Bond, 2000) using GMM techniques find similar values for the lagged productivity term in production function equations. The biggest discrepancy between the estimators is on the coefficients of external R\&D. An explanation could be in a different way of removing the fixed effects (differencing in GMM and orthogonal deviations in $\mathrm{BC}$ estimation). In addition, in GMM the variablles are treated as endogenous and are therefore instrumented with own lags.

The results clearly suggest that both internal and external $R \& D$ matter significantly for the productivity growth. The coefficient on own R\&D is larger compared to the external R\&D in the GMM results and the reverse is true for the $\mathrm{BC}$ results. There is also some evidence, that incoming spillovers are significant contributor to productivity. The interaction term between internal and external R\&D is negative, suggesting substitution between make and buy confirming previous results by Basant and Fikkert (1996) from similar specification and recent discussion in among other Blonigen and Taylor (2000) and Fernandez-Bagues (2002). We follow up with this analysis by re-estimating the model in the unrestricted form, allowing for non-linearity in internal and external R\&D. 


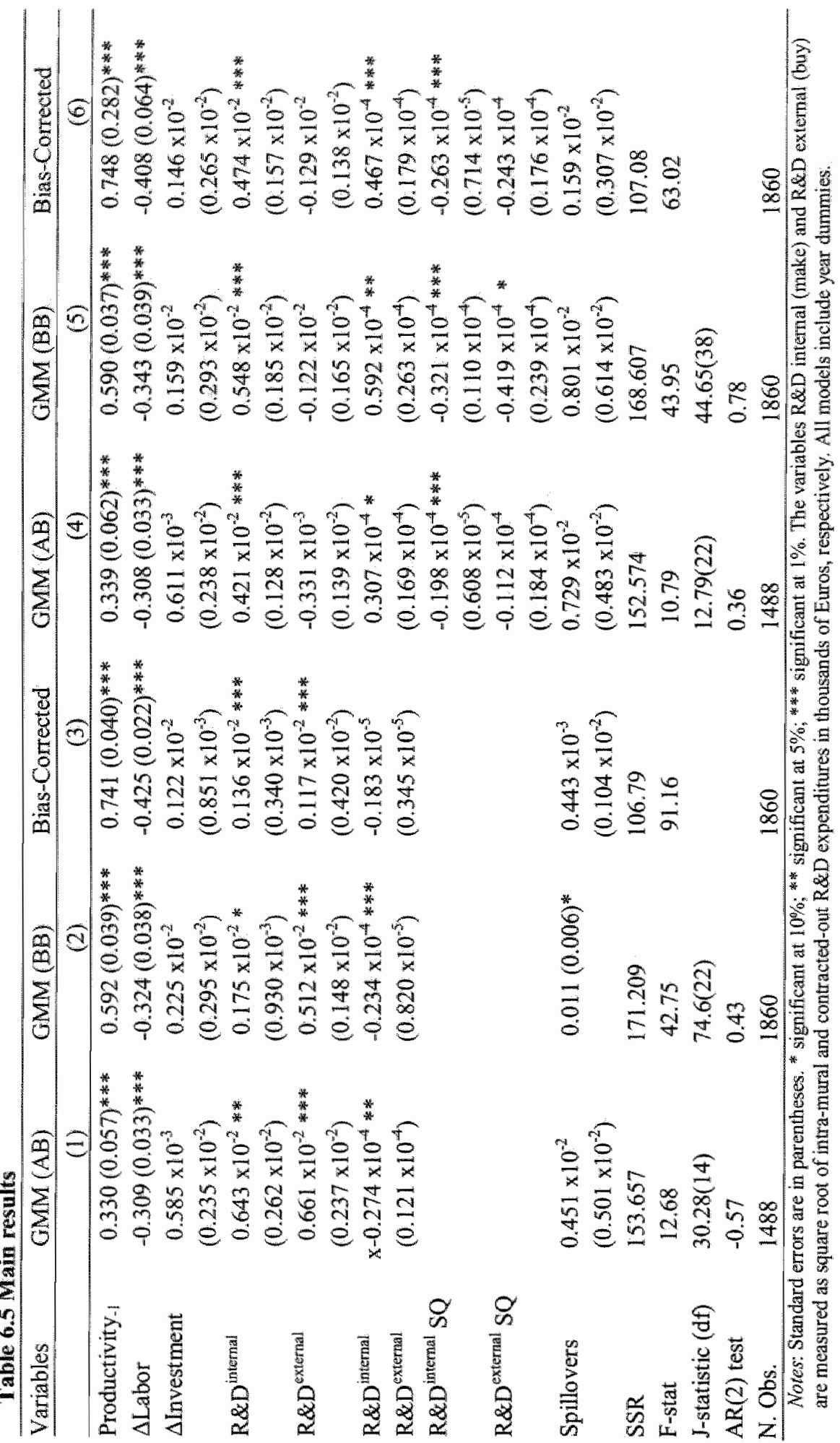


Columns (4) - (6) in Table 6.5 present the results of an extended specification. Here, we estimate the quadratic terms as well as the cross term of the key variables. Different estimation methods again, apart from the dynamic process, produce fairly close estimates. The $\mathrm{BC}$ estimator produces a somewhat better fit compared to the GMM, but the expanded model is hardly more statistically significant compared to its linear counterpart. In contrast, the expanded system GMM model has lower SSR compared to the linear counterpart. The results clearly suggest that there are diseconomies of scale in internal R\&D and there is some support for the diseconomies of scale in outsourced R\&D, although the quadratic term is not significant in the $\mathrm{BC}$ regression. Furthermore, the interaction term of internal and external R\&D changes sign and is now positive in all estimation methods and is significant, implying economies of scope (complementarity) between these two types of R\&D: an increase in one type increases the marginal effect of the other. Given that the contribution of either type of R\&D to productivity is positive, this would suggest a relative inefficiency of an allocation when either one is set at zero, suggested by the linear model. This is especially clear with internal R\&D (see Figure 1). This observation would confirm the extensive theoretical absorptive capacity literature (e.g. Griffith et al. 2004) that argues that in order to benefit from outside R\&D a firm must itself undertake own R\&D, as well as the observation of frequent joint adoption of both R\&D practices (Cassiman and Veugelers, 2002b).

\section{Figure 6.1 Plot value function}

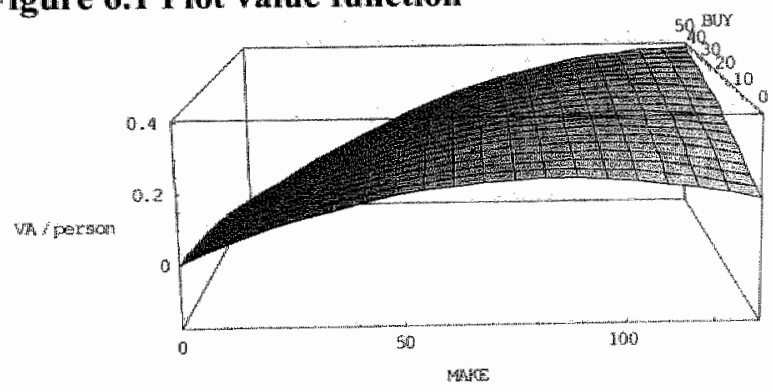

Figure $^{70} 6.1$ plots the estimated equation as a function of two variables, internal and external R\&D (in thousands of Euros). The parameter values are taken from the estimated bias-corrected equation and the range of the variables is determined by their actual range in the sample ${ }^{71}$. The visual representation helps to track how the value function changes with the change in allocation and to locate the optimum combination of the two sources of R\&D. The inclusion of the quadratic

70 The variables "make" and "buy' are measured as square root of intra-mural and contracted-oul $\mathbb{R} \&$.D expenditures in thousands of Euros, respectivelly.

${ }^{71}$ The bulk of the observations lie in the range for intra-mural expenditures from zero to 15 and for contracted-out R\&D from zero to 2.5 million Euros. The vertical scale is logarithmic. 
and cross terms allows us to evaluate in fact two non-linear effects: the economies of scale in internal and external $\mathrm{R} \& \mathrm{CD}$ and economies of scope in combining the two sources of R\&D. The intra-mural R\&D is clearly characterized by decreasing returns to scale. Based on the system GMM results, we can compute the inflexion point, identified in Figure 6.1. It is located around $7.3 \mathrm{ml}$. Euros, assuming no extra mural expenditures.

It is evident from the plot that the allocation that sets one type of R\&D to zero and maximizes the other is not optimal. In fact, starting from the allocation of $(0,0)$ the value function increases with the increase initially steeper along 'intemal' $R \& D$ axis, followed by a steeper increase in the "external" direction. This indicates that once the firm has expended on internal R\&D beyond a certain threshold, a certain absorptive capacity is built, which allows the firm to achieve higher productivity through switching from purely internal expansion mode into combination of external R\&D and internal R\&D inputs, i.e. by combining them.

The economies of scope for smaller values of internal and external sourcing produces thus a stronger positive effect compared to the negative effect of diseconomies of scale in purely internal R\&D. In a further simulation (we do not present the otherwise similarly looking graphs for brevity) the model predicts that for large values of the external and internal $R \& D$ the value of the function declines in both directions which points to the inefficiency created by large simultaneous outlays on external and internal $R \& D^{72}$.

Using the system GMM estimates presented in column 5, table 6.5, we calculate average marginal rate of return on $R \& D$ and internal rate of return on R\&D. Appendix C explains the details of the computation. Using the mean values of the variables, the marginal rate of return on internal $R \& D$ for the whole sample is $24.3 \%$, while the internal rate of return is $9.4 \%$. These estimates are comparable with those reported in for example, Klette and Johansen (1998) for a sample of Norwegian firms and are somewhat lower than the internal rate of return computed by Basant and Fikkert (1996) for the sample of Indian firms using similar method. We can also compute the second derivative (of. Definition 1 , Chapter 4) of the equation (6.6) with respect to internal and external R\&D. The second derivative, evaluated at the mean of the variables, is positive, again, pointing to complementarity between "make" and 'buy'. Appendix $\mathrm{C}$ details the formula.

\section{Extensions}

Previous research (e.g. Klomp and van Leeuwen, 2001; Monjon and Waelbroeck, 2003; Belderbos et al., 2004b) has posited that R\&D cooperation has a positive impact on performance, possible with a main impact with up to two-year lag. As an extension to the main model we re-estimate the main model including $R \& D$

\footnotetext{
"2 The optimum share and R\&D outlays are industry-specific. It would be ideal to re-estimate the model for each of the industries. Data constraints (low number of observations) unfortunately prevent us from doing so. The above analysis is obviously an aggregated picture.
} 
cooperation variable. These results are presented in Appendix A. Cooperation is significant in difference GMM but not in the other models. This marginally significant result may indicate that the positive effect of $R \& D$ cooperation has been already captured by external $R \& D$ variable.

In recognition of the fact that $R \& D$ may play different roles in industry and services sectors, Appendix B presents the estimation results for the industry subsample only. These results are somewhat stronger than the overall sample results. The physical investment, which is expected to add more to productivity in production, than in services, is now significant in the system GMM and BC models. On the other hand, all the models for the manufacturing sample produce slightly better fit compared to the combined sample.

\subsection{Concluding remarks}

This paper has produced micro-level econometric evidence that there are substantial productivity gains that the firms can achieve by combining internal and external R\&D sourcing. Our analysis is based on the results from a dynamic labor productivity model estimated using more traditional GMM and a newly developed bias-corrected technique using a six-year panel of 372 innovating Dutch firms. In a linear dynamic model, controlling for incoming spillovers and fixed effects, we find positive impacts of both types of R\&D and a negative interaction between them. The latter result confirms the conclusions in some earlier studies (e.g. Basant and Fikkert, 1996). We have further argued that interpreting a negative interaction term as decisive evidence against complementarity may be misleading. A further estimation of a non-linear model reveals consistent complementarity (supermodularity) in combining internal and external R\&D, which appears consistent with the frequent joint adoption of internal and external R\&D strategies. The positive effect of combining both types of R\&D is only evident, however, when a substantial internal $R \& D$ is present. This finding supports the dual role played by internal R\&D emphasized in recent macro-level research (e.g. Griffith et al. 2004). The first role $\mathrm{e}^{73}$ of in-house research and development activity is in stimulating innovation and productivity. The second role, not less important according to the results obtained in this paper, is its role as an absorptive capacity needed to derive benefits from the externally acquired R\&D. The estimates from a non-linear (quadratic in square roots) specification reveal stronger declining returns to focused increases in either internal or external R\&D expenditures. Hence, combining internal and external $R \& D$ rather than focusing on one type of $R \& D$ can improve performance, despite the existence of a negative interaction between the two R\&D strategies in the linear model. The analysis is robust across various estimation

" Cohen and Levinthal (1989) first coined a term "two faces of R\&D". This double role has recently been re-emphasized by Griffith et al. (2004) in their macro study. 
techniques, different specifications and definitions of external R\&D (such as inelusion of expenditures on industrial design, marketing or purchases of licenses).

The model presented in this chapter is aggregated in a sense that it assumes constant parameter values across all industries. It can be argued this assumption is unrealistic because the rates of return on $R \& D$ differ across industries. A further and a more refined analysis would be to re-estimate this model by the industry level allowing for such differences. Unfortinately, we are not able to perform these additional regressions because there are too few observations per two-digit industry in our sample. Despite the need for further extensions, we believe the analysis presented in the chapter serves as an intuitive and tractable approach to understanding firm-level productivity and provides sufficient argument for the thesis that empirical work examining complementarities between continuously measured practices should adopt more general non-linear specifications to allow correct inferences. Further empirical studies in this area would greatly benefit from an extension of theoretical work modeling internal and external $R \& D$, and their interaction. 
The productivity effects of internal and external R\&D

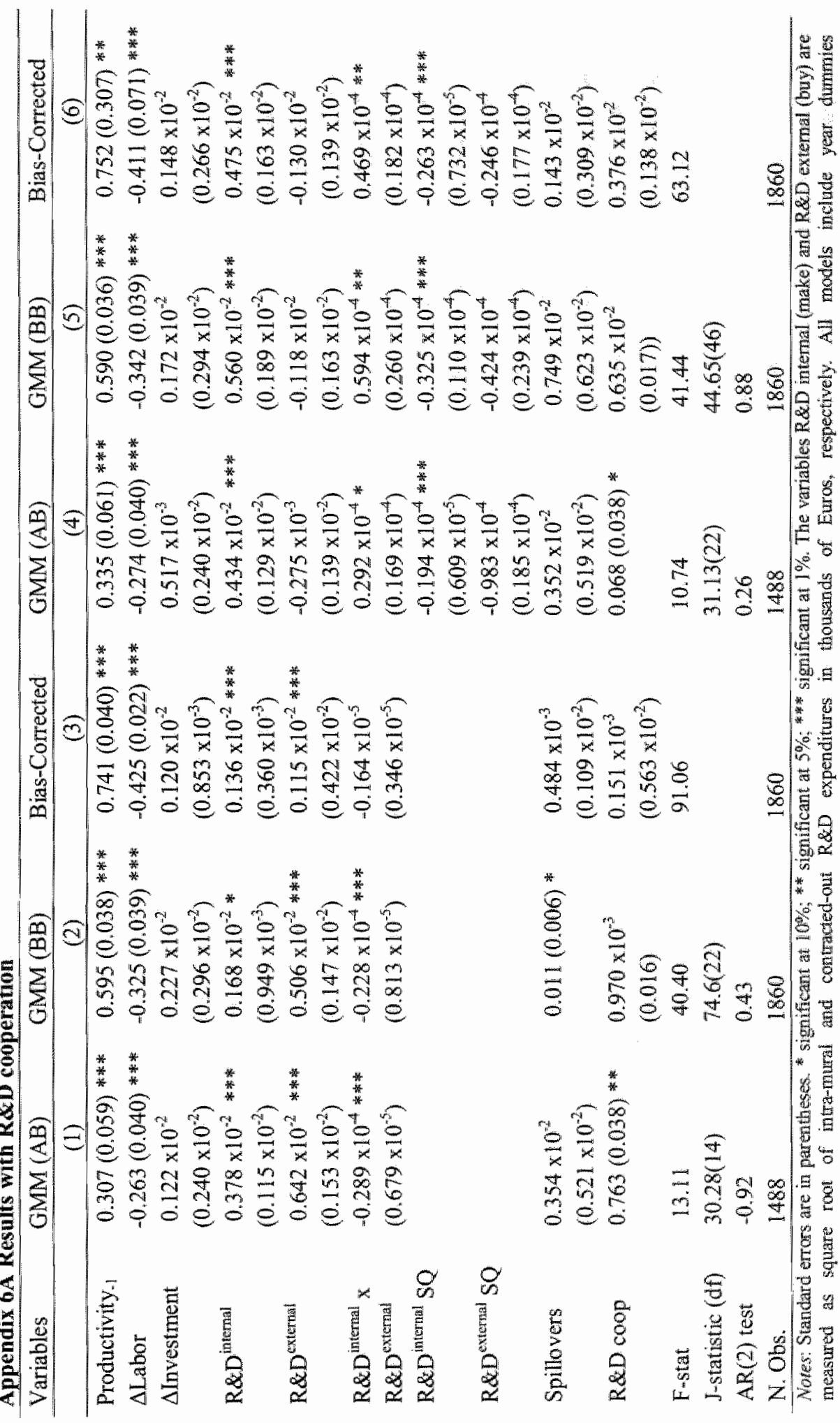




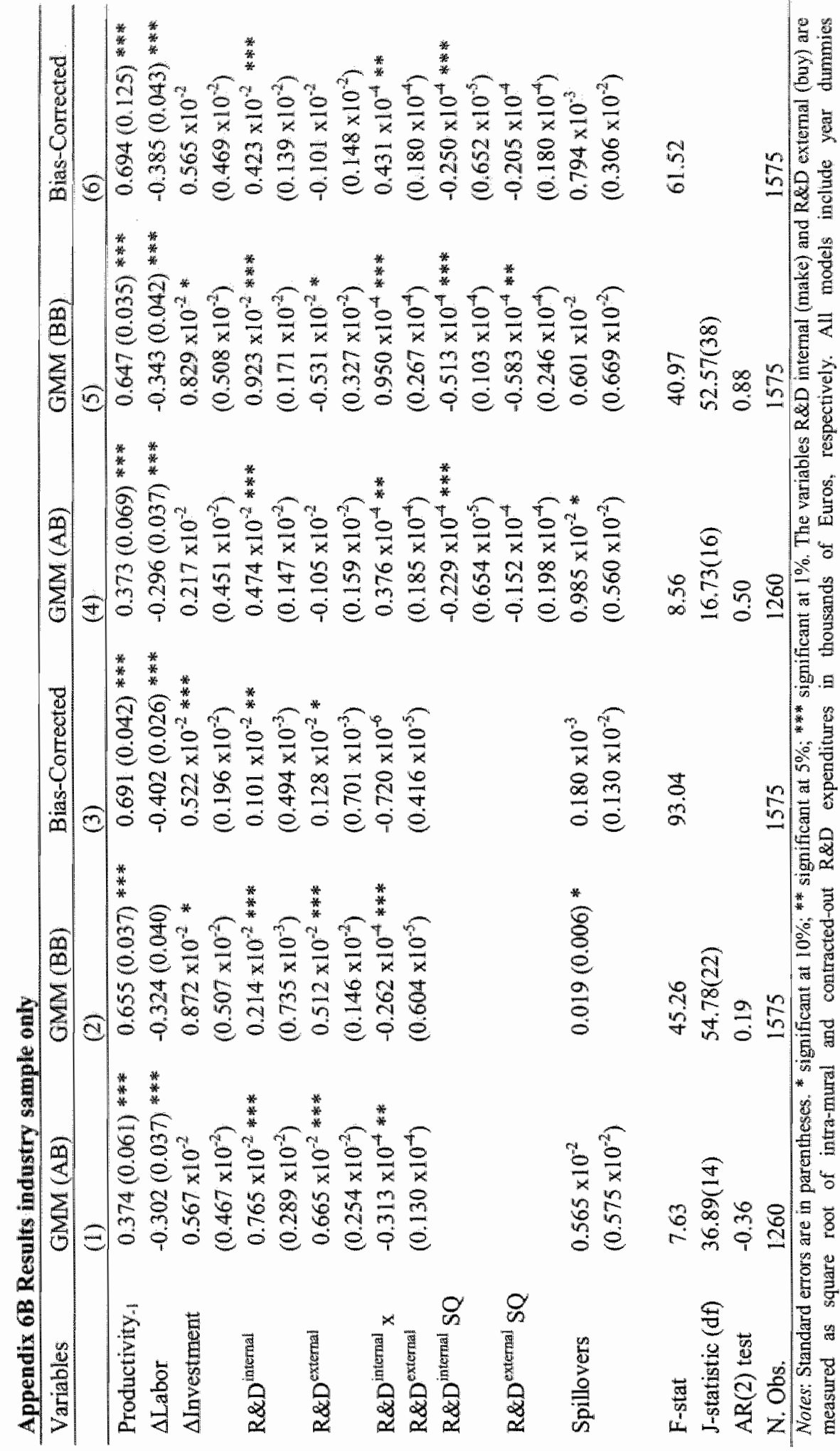




\section{Appendix $6 \mathrm{C}$ Marginal, internall rate of return}

We can use the estimated equation (6.6) to compute the (average) marginal rate of return on internal and external R\&D.

$$
q=a_{1} q_{-1}+a_{2} l+a_{3} i+a_{4} s p i l+b_{1} R_{\mathrm{int}}^{0.5}+b_{2} R_{\mathrm{int}}+b_{3} R_{e x t}^{0.5}+b_{4} R_{e x t}+b_{5} R_{e x t}^{0.5} R_{\mathrm{int}}^{0.5}
$$

From the estimated equation (C1) we can compute a partial derivative with respect to $R$ (internal, extemal), with the resulting expressions:

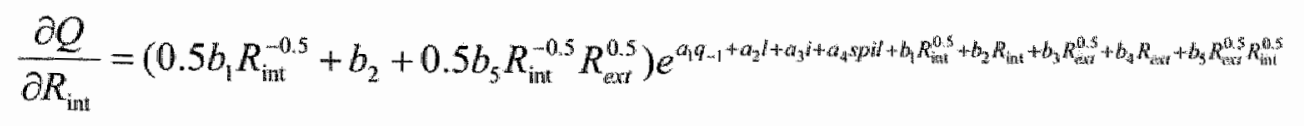

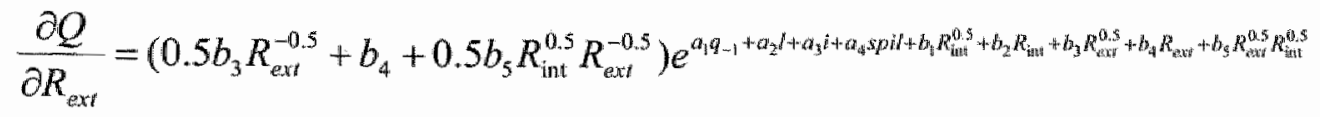

Given that the coefficients $a_{l}-a_{4}$ and $b_{l}-b_{5}$ are known estimated quantities, we can evaluate equations $\mathrm{C} 2-\mathrm{a}$ and $\mathrm{C} 2-\mathrm{b}$ at the means of the variables $Q$, differenced labor ( $l$ ) and investment (i), spillovers (spil) and the R\&D variables. The means are presented in Table $\mathbb{1}$. The result is multiplied by a sample mean of employment, to obtain the marginal effect on output (value added).

The second derivative, using $(6.6)$ has the following expression:

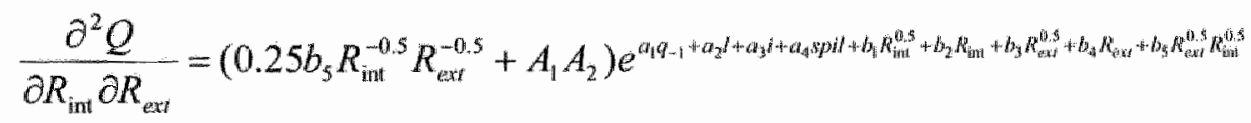

where $A_{1}=0.5 b_{1} R_{\mathrm{ibi}}^{-0.5}+b_{2}+0.5 b_{5} R_{\text {int }}^{-0.5} R_{\text {ext }}^{0.5}$ and $A_{2}=0.5 b_{3} R_{\text {eids }}^{-0.5}+b_{4}+0.5 b_{3} R_{\text {int }}^{0.5} R_{\text {exts }}^{-0.5}$

In addition to computing the average marginal rate of return, we can also compute the internal rate of return on own and acquired R\&D by solving the following expression:

$$
\int_{i}^{\infty}\left(\frac{\partial Q}{\partial R_{-1}}\right) e^{-r(t+\theta)+(g-\delta) r} d t=1
$$


In expression (C4) $g$ is the growth of output, $\delta$ is the depreciation rate of $R \& D$, and $r$ is internal rate of return of R\&D, the lag between expenditure on R\&D and output $Q$ is $\theta$.

For some constant $A=\frac{\partial Q}{\partial R_{-1}}$ which does not depend on time, $t$, we can transform (C4) using the substitution $(r+\delta-g) t=u$ and $d t=\frac{d u}{r+\delta-g}$, to get ${ }^{74}$

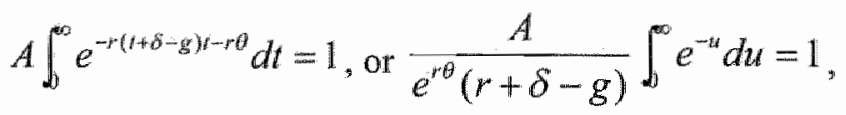

which simplifies to

$$
\frac{(r+\delta-g)}{A}=e^{-r \theta}
$$

Equation (C5) can be solved numerically, or graphically. For example, for a case of $g=0.023$ (sample average), $\delta=0.15$ and $\theta=1$ (one year lag), given that $A=0.229$ (based on $\mathrm{BC}$ model), we obtain the solution for $r=8.4 \%$. The solution is illustrated on plot $\mathrm{Cl}$.

\section{Figure 6.C1 Graphical solution internal rate of return}

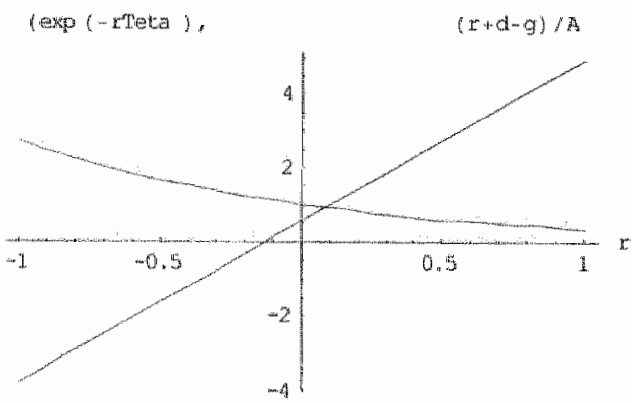

Assuming $\mathrm{A}>0$ and $\theta>0$, equation (C5) has a unique solution for internal rate of return, $r$. We briefly show that this is true.

Let $\mathrm{d}=(\delta-\mathrm{g}) / \mathrm{A}$

Now we can write (C5) as

\footnotetext{
${ }^{74}$ We further note that $r+\delta-g>0$, in order not to have the integral diverge.
} 
$\frac{r}{A}=e^{-r \theta}-d$

The left-hand side (LHS) of this expression is a line going through the origin, monotonically increasing from minus infinity to plus infinity. The right-hand side (RHS) is monotonically decreasing from plus infinity to $d$. Therefore, the solution exists and is unique. Whether it is greater or less than zero is determined by $d$.

1) If $d<1$, then the RHS crosses the ordinate abowe the origin (when $r=0$, then RHS is positive). This means that the unique solution to (A6) is in the first quadrant, i.e. $r^{*}>0$.

2) If $d=1$, then the RHS crosses ordinate at the origin and the unique solution is $r^{*}=0$.

3) If $d>1$, then the RHS crosses the ordinate below the origin (the RHS of A7 is negative when $r-0$ ). This means that (C6) has a unique solution that is in the third quadrant, i.e. $r^{*}<0$. 


\section{CHAPTER 7}

\section{Conclusions and limitations}

The economic phenomenon of short- to medium-term cooperation in R\&D has recently grown in importance. Such factors as high initial fixed costs of research and development, and risks related to commercialization of innovations have contributed to this trend. At the same time there is an understanding among economists and policymakers, reflected in the Lisbon agenda, that sharing of knowledge can accelerate creation of new knowledge capital. Such knowledgesharing through formal cooperative $R \& D$ agreements has been spurred by recent market shifts that included increasing complexity of technology, shortening of innovation cycles and declining transaction costs of acquiring technology from outside the firm. As a result, firms no longer rely exclusively on their internal $R \& D$ activities to maintain their technological competitiveness.

The aim of this dissertation is to contribute to our understanding of the phenomenon of R\&D cooperation, contracted-out and internal R\&D and its impact on firm productivity and innovative performance of firms. The objective of this work was three-fold. First, I address the question of what stimulates firms to engage in various types of R\&D collaborative agreements. Second, I want to establish what effect (if any) such engagement has on firms' productivity and innovative performance. Third, I want to investigate the issue of complementarity between internal, external, and collaborative R\&D strategies. To this end, this dissertation presented five empirical essays. Chapter 2 focuses on determinants of R\&D collaboration, differentiating between its types. Chapter 3 assessed the effects of R\&D cooperation on productivity and innovation performance of firms. Chapters 4 and 5 addressed the issue of complementarity between collaborative R\&D strategies. In addition, in Chapter $6 \mathrm{I}$ look at the dynamic links between internal and external $R \& D$, complementarity between them and firm labor productivity. This thesis aims to explain these economic relationships by developing and applying advanced econometric techniques to a previously less explored panel of firms from the Netherlands.

The purpose of this concluding chapter is to summarize the main results of the study, point out to the major results that come out of the analysis and briefly discuss limitations of the study as well as to outline the directions for further research. The conclusions, limitations of this study and suggestions for further research are presented by the issues around which this thesis is organized. 


\subsection{Summary}

Determinants of cooperative $R \& D$

The focus of Chapter 2 of this book is on heterogeneity in the determinants of firms" decisions to engage in vertical (suppliers, customers), horizontal (competitors) and research institutional (universities and research labs) $R \& \&$ cooperation. A broad set of determinants is analyzed with a particular attention to the effects of different types of spillovers, a central focus in the industrial organization literature on $R \& D$ cooperation. The model uses lagged values of the explanatory variables to limit simultaneity bias between cooperation and its determinants and is estimated with system method to reflect that firms consider the decisions to cooperate with various partners simultaneously. The significantly positive correlations between the equations are present. However, in contrast to previous studies, we argue that this could not be interpreted as hard evidence for complementary between cooperation decisions, but could be due to unobserved firm heterogeneity. The estimation results confirm the theoretical conjectures (Atallah, 2003; Poyago-Theotoky, 1995) that incoming source-specific spillovers are an important determinant of $R \& D$ cooperation. One of our main findings is that cooperation with a particular partner is significantly more likely if incoming spillovers from that type of partner are more important for the firms' innovation process. Together with the result that public and intra-firm spillovers are insignificant in our model, this would imply primarily facilitation of source-specific spillovers can make R\&D cooperation more attractive to firms. The impact of competitor spillovers on horizontal cooperation is somewhat smaller, which is consistent with stylized results from theoretical industrial organization models of R\&D cooperation, i.e. the notion that firms in horizontal partnerships also face greater risks of leakage of proprietary knowledge. Another finding of Chapter 2 is that incoming spillovers from universities and research institutes stimulate cooperation of all types. This suggests that this knowledge is more generic in nature and improves the technological opportunities and general effectiveness of the firm's $R \& D$ activities and $R \& D$ cooperation strategies. $R \& D$ intensity has a positive impact on vertical and institutional cooperation, with a decreasing marginal impact for highly $R \& D$ intensive firms. There is a minimum critical firm size, which allows firms to cooperate effectively with science institutions. Commercial risk factor and organizational constraints in the firm's innovation process generally have a positive impact on $R \& D$ cooperation. $R \& D$ cooperation with institutions, customers, and competitors were found to be more likely in case of a greater speed of technological change in terms of new product introductions in the industry. The estimated impact of R\&D subsidies proved to be sample sensitive: received subsidies had a positive effect on R\&D cooperation in the full sample model, but not in the model for new cooperation, suggesting that the positive impact is not generic but stems from those subsidies that are granted conditional on cooperation. 
Overall, the results suggest that there is significant merit in disaggregating the R\&D cooperation by type of partner because there are significant differences in the motives and determinants of each type of cooperation.

\section{Cooperative $R \& D$ and productivity}

Chapters 3 and 4 presented evidence on the performance effect of R\&D collaboration. More specifically, Chapter 3 provides an assessment of the impact of R\&D cooperation on firm performance jointly with the impact of $R \& D$ expenditures and the effect of incoming knowledge spillovers that are not due to formal collaborative agreements. The analysis differentiates, like in Chapter 2, between the type of R\&D partner (competitors, suppliers, customers, and universities \& research institutes) and considers two performance measures: labor productivity and productivity in innovative sales new to the market. The results confirm a major heterogeneity in the rationales and goals of R\&D cooperation. Competitor and supplier cooperation are focused on incremental innovations improving the productivity performance of firms, while university cooperation and again competitor cooperation are instrumental in creating and bringing to market radical innovations, generating sales of products that are novel to the market, and hence improving the growth performance of firms (Klomp and Van Leeuwen, 2001). New product sales are furthermore stimulated by incoming knowledge spillovers that not due to collaboration from customers and universities \& research institutes. We find that the results are sensitive to the lag with which innovation strategies are allowed to impact productivity growth. Generally, allowing for a more variable lag structure by examining the impact of cooperation strategies that are sustained over a $2-4$ year period demonstrated a more robust impact of cooperation on productivity.

The findings of Chapter 3 provide qualified support for the notion that cooperating firms are generally engaged in higher-level innovative activities (Tether, 2002). This holds unequivocally for firms collaborating with universities (e.g. to get access to basic research) and competitors (to allow R\&D for risky projects), but not for firms engaged in 'vertical cooperation' with suppliers and customers. If the latter types of cooperation are also partly focused on more 'radical" innovations, than there is no evidence in our analysis that these efforts have an overall impact improving firms' performance in bringing novel products to the market. This does not rule out that a minority of such collaborations, e.g. 'comakerships" between firms and major suppliers, does involve more fundamental and radically innovative research efforts.

The major insight from the analysis presented in Chapters 2 and 3 is that collaborative R\&D is not an aggregated phenomenon, but rather that horizontal, vertical and institutional links have all different motives and varying contributions to productivity. They are common, however, in that the propensity to engage in each of them is to a significant degree determined by the incoming knowledge 
spillovers. The results of the investigation have also important policy implications. The evidence presented in Chapter 2 suggests that facilitating the exchange and sharing of information, along with more traditional R\&D subsidies, constitutes an effective instrument for a policy that aims to foster R\&D collaboration. On the other hand, through stimulation of cooperative R\&D, a positive effect on innovation output and productivity could be achieved. According to our study a policy of promotion of R\&D private-public collaboration (with universities, research centers), would lead to increased innovation output.

\section{Complementarities in cooperative, internal and external $R \& D$ strategies}

A significant part of the thesis is devoted to the analysis of complementarity in R\&D innovation strategies. Whereas Chapter 3 argues that $R \& D$ cooperation can benefit firms, Chapter 5 investigates the effect of the cross-terms (engaging in multiple cooperative agreements). This issue is potentially important, because in case of multiple decision variables, (e.g. different types of collaborative links) all of them must be complements to ensure that their increases are mutually reinforcing. In Chapter 4 we develop a test for complementarity and substitutability using an output function approach in which organizational practices affect performance. The testing procedure uses a structural estimation framework and applies inequality constrained least squares estimation. The analytical solution is given for the general case and is demonstrated for three and four practices. Recent work (Athey and Stern, 2002; Bresnahan et al, 2002; Caroli and Van Reenen, 2001; Black and Lynch, 2001) has drawn conclusions on complementarity based on inadequate testing methods. With empirical studies of complementarity gaining prominence in a number of economics and management domains, the proposed framework should make adequate testing for complementarity more accessible for applied researchers. We also note that the proposed test is equivalently applicable for testing for superand submodularity of the objective function in organizationall design practices (e.g. Milgrom and Roberts, 1990).

Chapter 5 examines possible complementarities in cooperation strategies as they impact labor productivity growth for a large sample of innovating Dutch firms. We allow for an appropriate time lag with which the impact of $R \& D$ cooperation from previous period feeds through in productivity growth and apply a testing methodology developed in Chapter 4. The test indicates whether the impact of the adoption of one cooperative strategy significantly increases if another practice is adopted simultaneously. The empirical results on complementarities are mixed. Complementarity is found for joint cooperation strategies with competitors and customers, and with customers and universities. This may be related to the role of customer cooperation in facilitating commercialization and quicker diffusion of product innovations that are due to competitor and university cooperation. At the same time, a number of instances were found where the combination of cooperation strategies led to underperformance: supplier cooperation combined with either 
university or competitor cooperation, and competitor cooperation combined with university cooperation. The former result may be explained from diverging objectives of different collaborative efforts: supplier cooperation tends to focus more often on cost reduction and incremental and process innovations. This innovation strategy may be more difficult to combine with innovations efforts involving more radical and product innovations associated with university and competitor collaboration, respectively. The combination of competitor and university collaboration may suffer from threats to appropriability of R\&D efforts when working simultaneously with a competitor and public institutions, as spillovers from university may leak to competitors not involved in the collaboration (Leyden and Link, 1999). All these impacts are found for small firms while no significant impact is found for larger firms.

The main insight of this part of the study lies in the significance of complementarity effect in R\&D cooperative strategies. Our findings confirm an overall positive impact of R\&D cooperation on labor productivity growth (Chapter 3 ), but with distinct differences in magnitude and significance of impacts depending on (combinations of) cooperation types. We conclude that firms combining innovation strategies can achieve higher (innovative) performance as compared to firms that rely on single innovation strategy. At the same time we note increased complexity associated with engagement in different strategies. This has a counterproductive, bounding effect, especially on small firms.

\section{Internal, external $R \& D$ and absorptive capacity}

Chapter 6 produces micro-level econometric evidence that there are substantial productivity gains that the firms can achieve by combining internal and external R\&D sourcing. The analysis is based on the results from a dynamic labor productivity model estimated with GMM and a newly developed bias-corrected technique using a panel of innovating Dutch firms. In a linear dynamic model, controlling for incoming spillovers and fixed effects, we find positive impacts of both types of R\&D and a negative interaction between them. The latter result confirms the conclusions in some earlier studies (e.g. Basant and Fikkert, 1996). Our main model in this chapter is a non-linear specification that takes into account a possibility of economies of scale and scope in R\&D. The results reveal complementarity (supermodularity) in combining internal and external $R \& D$, which appears consistent with the frequent joint adoption of internal and external R\&D strategies. The positive effect of combining both types of $R \& D$ is only evident, however, when a substantial internal R\&D is present. This finding supports the dual role played by internal $R \& D$ emphasized in recent macro-level research (e.g. Griffith et al. 2004). The first role of in-house research and development activity is in stimulating innovation and productivity. The second role, not less important according to the results obtained in this chapter, is its role as an absorptive capacity needed to derive benefits from the externally acquired R\&D. The estimates from 
quadratic specification reveal stronger declining returns to focused increases in either internal or external R\&D expenditures. Hence, combining internal and external R\&D tather than focusing on one type of R\&D can improve performance, despite the existence of a negative interaction between the two R\&D strategies in the linear model.

A major insight of this chapter is that internal R\&D in addition to being complementary to external $\mathrm{R} \& \mathrm{D}$, plays a strong absorptive capacity role. This finding corroborates results from earlier studies (Cohen and Levinthal, 1989; Griffith et al, 2004). The analysis suggests that in order to make correct inferences about complementarity a researcher should adopt a more general, non-linear specification of a model and apply an appropriate testing method. One explanation behind this insight is that quantities of interest, such as R\&D expenditures display both the economies of scale and scope.

\subsection{Limitations and future research}

The findings presented in this study go some way in explaining the more ambiguous results obtained in previous empirical work on the effects of cooperation on innovative sales and productivity, where single performance measures were used and no (variation in) lag structures could be examined because of the cross section nature of the data (e.g. Hestimati and Löof, 2002; Janz et al., 2003; Monjon and Waelbroeck, 2003). Since different R\&D strategies can impact performance with different lag structures, future research should further explore the inter-temporal structure of the impact of R\&D strategies on innovation output and firm performance. The results of our analysis in Chapter 5 also raise a number of questions, which suggest pertinent issues for further research. Given the mixed findings on the benefits of pursuing multiple cooperation strategies simultaneously and the suggestion that complexity issues play a role here, a natural extension of analysis is to examine the impact of different cooperation strategies when adopted sequentially. This will require the construction of panel data, utilizing data from more than two imnovation surveys.

The increasing availability of consecutive CIS surveys will allow for the construction of panel data sets to examine the effectiveness of various innovation strategies in more detail. Our examination of interaction among cooperative R\&D strategies is limited in a sense that we could not control for "intensity" of R\&D cooperation. We suspect, however, that like R\&D expenditures, R\&D collaboration also has a property of decreasing returns to scale, as well as scope. Unfortunately, limitations of the data did not allow us to explore this potentially interesting issue. "This data limitation has its repercussions for the results discussed in Chapter 5: they are ambivalent for larger firms. This may be due to our inability to measure actual importance of R\&D partnerships for large firms and would require better data, beyond that provided by CIS. Such data (e.g. MERIT/CATI databank), including 
the number and importance of R\&D links have been used, for example, in alliance literature. However, to date this literature did not differentiate between the types of R\&D cooperation, concentrating on horizontal links. Such measures as patents and patent citations could be used to measure the impact of R\&D collaborative agreements. Combining the insights and tools developed in this study with the analysis developed in alliance literature would seem a promising way forward beyond possibilities of CIS. In general, our empirical results support an 'increasing complexity' hypothesis and show a decreasing marginal impact of multiple cooperation strategies in particular when these imply multiple objectives, with the largest impacts seen for combinations of two types of R\&D partnerships.

Other extensions concern the analysis of potential differences in the performance effects of R\&D cooperation across industries, and the robustness of results for different performance measures other than labor productivity. Again, a problem that is not easily solved is the lack of an indicator of the scale or number of R\&D collaborations of each type in the European Community innovation survey data used here. To accurately examine the impact of $\mathbb{R} \& D$ cooperation for larger firms, information on the number and importance of such partnerships may be indispensable. Where possible, throughout our empirical analysis we tried to provide robustness checks of our models. Yet, little could be done with a fact that almost all models presented in this study are aggregated in a sense that they assumed constant parameter values across all industries. It can be argued this assumption is unrealistic with respect to some variables, such as with the rates of return on R\&D differing across industries. A further and a more refined analysis would re-estimate these models by the industry level allowing for such differences or at least utilizing some kind of taxonomy of the Dutch manufacturing. Some steps in this direction have been recently taken (e.g. Raymond et al., 2004). Unfortunately, we were not able to perform by-industry regressions because there are too few observations per two-digit industry in our sample.

Last but not least, empirical analysis in this area could greatly benefit from more theoretical work on combined R\&D cooperation strategies, and in particular the role of collaboration with other partners than competitors. As we have noted in the conclusions of Chapter 2, further empirical work in the area of cooperative R\&D would greatly benefit from an extension of theoretical models to other types of R\&D partnerships than horizontal cooperation.

Finally, we would like to emphasize that our models are estimated conditioned on firms being innovative. We have left out the issue of selectivity, while it could be argued to be important enough to be taken into account. We plan to address selectivity in the future research.

Despite the need for further extensions, we believe that the analysis presented in these essays serves as an intuitive and tractable approach to understanding firmlevel productivity as well as its relationship to R\&D innovation strategies and provides original answers to the many interesting research questions we raised in this book. 


\section{References}

Acs, Zoltan, David Audretsch, and Maryann Feldman, 1994, R\&D spillovers and recipient firm size, Review of Economics and Statistics, 76(2), 336-340.

Acs, Zoltan and Steven Isberg, 1991, Innovation, firm size and corporate finance: An initial inquiry. Economics Letters, 1991, 35(3), 323-26.

Adams, James, 1990, Fundamental stocks of knowledge and productivity growth. Journal of Political Economy 98(4), 673-702

Adams, James and Adam Jaffe, 1996, Bounding the effects of R\&D: an investigation using matched establishment-firm data. RAND Journal of Economics. 27(4), 700-21.

Aitken, Brian, Gordon Hanson and Ann. Harrison, 1997, Spillovers, foreign investment, and export behavior. American Economic Review, 43, 103-132.

Aitken, Brian and Ann Harrison, 1999, Do domestic firms benefit from direct foreign investment? Evidence from Venezuela. American Economic Review, $89(3), 605-618$.

Amir, Rabah, Igor Evstigneev and John Wooders, 2003, Noncooperative versus cooperative R\&D with endogenous spillover rates. Games and Economic Behavior 42, 184-207.

Anbarci, Nehat, Robert Lemke and Roy Santanu, 2002, Inter-firm complementarities in R\&D: a re-examination of the relative performance of joint ventures. International Joumal of Industrial Organization, 20, 191-213.

Arellano, Manuel and Olympia Bover, 1995, Another look at the instrumental variable estimation of error-components models. Joumal of Econometrics, 68, 29-51.

Arora, Ashish, 1996, Testing for complementarities in reduced-form regressions: a note. Economics Letters 50, 51-5.

Arora, Ashish and Alfonso Gambardella, 1990, Complementarity and external linkages: the strategies of the large firms in biotechnology. Jotrmal of Industrial Economics 38, 361-79.

Arora, Ashish and Alfonso Gambardella, 1994, Evaluating technological information and utilizing it: Scientific knowledge, technological capability and external linkages in biotechnology. Journal of Economic Behavior and Organisation, 24(1), 91-114.

Arora, Ashish, Andrea Fosfuri, and Alfonso Gambardella, 2001, Markets for Technology: the Economics of Innovation and Corporate Strategy. Cambridge: MIT Press.

Atallah, Gamal, 2002, Vertical R\&D spillovers, cooperation, market structure and innovation. Economics of Innovation and New Technology, 11(3), 179-209.

Atallah, Gamal, 2003, Information sharing and the stability of cooperation in research joint ventures. Economics of Innovation and New Technology, 12(6), $531-54$. 
Athey, Susan and Armin Schmutzler, 1995, Product and process flexibility in an innovative environment, RAND Journal of Economics, 26(4), 557-74.

Athey, Susan and Scott Stern, 1998, An empirical framework for testing theories about complementarity in organizational design. NBER working paper $\# 6600$.

Athey, Susan and Scott Stern, 2002, The impact of information technology on emergency health care outcomes. RAND Joumal of Economics 33(3), 399432.

Audretsch, David and Maryann Feldman, 1996, R\&D spillovers and the geography of innovation and production. American Economic Review 86(3), 630-640.

Audretsch, David, Albert Menkveld and Roy Thurik, 1996, The decision between internal and external R\&D. Journal of Institufional and Theoretical Economics, 152(3): 519-530.

Basant, Rakesh and Brian Flikkert, 1996, The effects of R\&D, foreign technology purchase and domestic and international spillovers on productivity on Indian firms. Review of Economics and Statistics, 78(2), 187-99.

Baum, J. A. C.; Calabrese, T., and Silverman, B. S., 2000, Don't go it alone: alliance network composition and startups" performance in Canadian biotechnology. Strategic Management Jotrmal, 21 (3), 267-294.

Baumol, William, John Panzar, and Robert Willig, 1988, Contestable Markets and the Theory of Industry Structure. Harcourt Brace Jovanovich.

Becker, Wolfgang and Jürgen Dietz, 2004, R\&D cooperation and innovation activities of firms - evidence for the German manufacturing industry. Research Policy, 33, 209-33.

Belderbos, René, Martin Carree, Bert Diederen, Boris Lokshin, Reinhilde Veugelers, 2003, Heterogeneity in R\&D cooperation strategies. CEPR Discussion paper 4021.

Belderbos, René, Martin Carree, Bert Diederen, Boris Lokshin, Reinhilde Veugelers, 2004a, Heterogeneity in R\&D cooperation strategies, International Journal of Industrial Organization, 8/9, 1237-64

Belderbos, R., M. Carree, B. Lokshin, 2004b, Cooperative R\&D and Firm Performance. Research Policy 33(10), $1477-92$

Belderbos, René, 2001, Overseas innovations by Japanese firms: An analysis of patent and subsidiary data. Research Policy, 30(2), 313-332.

Benfratello, Luigi and Alessandro Sembenelli, 2002, Research joint ventures and firm level performance. Research Policy, 31, 493-507.

Berman, Eli, Kevin Lang, Erez Siniver, 2003, Language-skill complementarity: returns to immigrant language acquisition. Labour Economics, 10(3), 265-90.

Bertschek, Irene, 1995, Product and Process Innovation as a Response to Increasing Imports and Foreign Direct Investment, Journal of Industrial Economics, 43, 4, 341-357.

Bertschek, Irene and Michael Lechner, 1998, Convenient estimators for the panel probit model. Joumal of Econometrics 87(2): 329-372. 
Bhagat, Sanjai and Iwo Welch, 1995, Corporate Research \& Development Investments: International Comparisons, Journal of Accounting and Economics, $19(2 / 3), 443-470$.

Black, Sandra and Lisa Lynch, 2001, How to compete: the impact of workplace practices and information technology on productivity. The Review of Economics and Statistics, 83(3), 434-445.

Blomstrom Magnus and Ari Kokko, 1998, Multinational corporations and spillovers, Journal of Economic Surveys, 12(3), 247-277.

Blonigen, Bruce and Christopher Taylor, 2000, R\&D intensity and acquisitions in high-technology industries: evidence from the US electronic and electrical equipment industries. The Journal of Industrial Economics, 48, 47-70.

Blundell, Richard and Stephen Bond, 2000, GMM estimation with persistent panel data: an application to production functions. Econometrics Reviews, 19(3), $321-340$.

Blundell, Richard and Stephen Bond, 1998, Initial conditions and moment restrictions in dynamic panel data models, Journal of Econometrics, 87, 115143.

Bönte, Werner, 2003, R\&D and productivity: internal ws. external R\&D - evidence from West German manufacturing industries. Economics of Innovation and New Technology, 12(4), 343-360.

Bolton, Patrick and Mathias Dewatripont, 1994, The firm as a communication network. Quarterly Joumal of Economics, 109(4), 809-39.

Bresnahan, Timothy, Erik Brynjolfsson, and Lorin M. Hit, 2002, Information Technology, Workplace Organization, and the Demand for Skilled Labor: Firm-Level Evidence, Quarterly Journal of Economics 1 17, 339-375.

Branstetter, Lee, 2000, Is foreign direct investment a channel of knowledge spillovers: evidence from japan's FDI in the United States, NBER working paper 8015 , NBER, Cambridge, MA.

Braga, Helson and Larry Willmore, 1991, Technological imports and technological effort: An analysis of their determinants in Brazilian firms. The Journal of Industrial Economics, 39(4), 421-432.

Branstetter, Lee, 2001, Are knowledge spillovers international or international in scope? Microeconometric evidence from US and Japan. Journal of International Economics, 53, 53-79.

Brouwer, Erik and Alfred Kleinknecht, 1999, Innovative Output, and a Firm's Propensity to Patent. An Exploration of CIS Micro Data. Research Policy, 28, $615-24$

Bun, Maurice and Martin Carree, 2005, Bias-corrected estimation in dynamic panell data models. Journal of Business and Economic Statistics, forthcoming.

Busom, Isabel, 2000, An empirical evaluation of R\&D subsidies, Economics of Innovation and New Technology, 9(2), 111-48. 
Cancral, Luis, 2000, $\mathbb{R}$ \&D cooperation and product market competition. International Jownal of Industrial Organization, $18,1033-47$.

Cappelari, Lorenzo and Stephen P. Jenkins (2003). Multivariate probit regression using simulated maximum likelihood. Stata Jommal, 3(3), $221-235$.

Caroli, Eva and John Van Reenen, 2001, Skill-biased organizational change? Evidence from a panel of British and French establishments. Quarterly Joumal of Economics $116,1449-1492$.

Cassiman, Bruno and Reinhilde Veugelers, 2002, R\&D cooperation and spillovers: some empirical evidence from Belgium. American Economic Review $92(4)$ : 1169.84

Cassiman, Bruno, D. Perez-Castrillo, Reinhilde Veugelers, 2002, Endogeneizing know-how flows through the nature of R\&D investments, International Journal of Industrial Organization, 20, 775-799

Cassiman, Bruno and Reinhilde Veugelers, 2002, Complementarity in the innovation strategy: internal R\&D and external technology sourcing, C.E.P.R. Discussion Papers, \#3284.

Cincera, Michele, Kempen Lieselot, van Pottelsberghe, Bruno Veugelers Reinhilde and Villegas Sanchez Carolina, 2004, Productivity Growth, R\&D, and the Role of International Collaborative Agreements: Some Evidence for Belgian Manufacturing companies, forthcoming in: Brussels Economic Review.

Chesbrough, Henry, 2003, The Era of Open Innovation. Sloan Management Review, $44(3), 35-41$.

Chiesa, Vittorio, Raffaella Manzini, and Emauele Pizzumo, 2004, The externalization of $R \& D$ activities and the growing market of product development services. R\&D Management, 34(1), 65-75.

Coe, David and Elhanan Helpman, 1995, International R\&D spillovers. European Economic Review, 39(5), 859-87.

Cockbum, Iain and Zvi Griliches, 1988, Industry effects and appropriability measures in the stock market's valuation of R\&D and patents. American Economic Review, 78(2), 419-23.

Cohen, Wesley, Richard Levin, and David Mowery, 1987, Firm size and R\&D intensity: a rewamination. Joumal of Indwstrial Economics 35: 543-565.

Cohen, Wesley and Richard Levin, 1989, Empirical studies of innovation and market structure, in Richard Schmalensee and Robert Willig, Handbook of Industrial Organization, Elsevier Science Publishers, Amsterdam, 1060-11.07.

Cohen, Wesley and Daniel Levinthal, 1989, Innovation and Learning: the two faces of R\&D. Economic Jownal 99(397): 569-96.

Cohen, Wesley and Steve Klepper, 1994, Firm size and the nature of innovation within industries: The case of process and product R\&D. Review of Economics and Statistics, 78, 232-243.

Cohen, Wesley and Steve Klepper, 1996, A Reprise of Size and R\&D. Economic Jownal, 106, 925-951. 
Cohen, Wesley, 1995, Empirical studies of innovative activity, in: Paul Stoneman. ed., Handbook of the Economics of Innovation and Technological Change, Blackwell Publishers, Oxford, 182-264.

Colombo, Massimo and Paola Garrone, 1996, Technological cooperative agreements and firm"s R\&D intensity: a note on causality relations. Research Policy 25: 923-932

Contractor, Farok and Peter Lorange, 2002, Cooperative Strategies and Alliances. Amsterdam, Elsevier.

Cowan, Robin and Jonard, Nicolas, 2001, Knowledge creation, knowledge diffusion and network structure, in: A. Kirman and J-B. Zimmermann (eds.), Economies with Heterogeneous Interacting Agents, Springer.

Crépon, Bruno, Duguet, Emmanuel and Jacques Mairesse, 1998, Research, innovation and productivity: an econometric analysis at the firm level. The Economics of Innovation and New Technology, 7:115-58.

Criscuolo, Chiara, and Jonathan Haskel, 2003, Innovation and productivity Growth in the UK: Evidence from CIS2 and CIS3, working paper, Centre for Research into Business Activity.

D'Aspremont, Claude and Alexis Jacquemin, 1988, Cooperative and noncooperative R\&D in duopoly with spillovers. American Economic Review 78(5), 1133-1137.

Das, T. and Bing-Sheng Teng, 2000, A resource-based theory of strategic alliances. Journal of Management 26(1), 31-61.

David, Paul, Bronwyn Hall, and Andrew Toole, 2000, Is public R\&D a complement or substitute for private R\&D? A Review of the Econometric Evidence. Research Policy, 29(4-5), 497-529.

De Bondt, Raymond, 1996, Spillovers and innovative activities. International Journal of Industrial Organization. 15, 1-28.

De Bondt, Raymond, P. Slaets, and Bruno Cassiman,1992, The degree of spillovers and the number of rivals for maximum effective $\mathbb{R} \& D$. International Jounal of Industrial Organization, 10, 35-54.

De Bondt, Raymond and Reinhilde Veugelers, 1991, Strategic investment with spillovers. European Joumal of Political Economy, 7:345-66

Deolalikar, Anil and Robert Evenson, 1989, Technology production and technology purchase in indian industry: an econometric analysis. Review of Economics and Statistics, 71(4), 687-93.

Dechenaux, Emmanuel, Brent Goldfarb, Scott Shane and Marie Thursby, 2003, Appropriability and the timing of innovation: Evidence from MIT inventions. NBER Working paper 9735.

Diewert, W., 1971, An application of the Sheppard duality theorem: a generalized Leontief production function, Journal of Political Economy, 79(3), 481-507. 
Dussauge, P., B. Garrette and W. Mitchell, 2002, The market-share impact of interpartner learning in alliances: Evidence from the global auto industry, in: F.J. Contractor and P. Lorange (eds.), Cooperative Strategies and Alliances, Amsterdam: Pergamon, pp.707-727.

Duysters, Geert and John Hagedoorn, 1996, Internationalization of corporate technology through strategic partnering: an empirical investigation. Research Policy, 25, 1-22.

Dyer, Jeffrey and Harbir Singh, 1998, The relational view: cooperative strategy and sources of interorganizational competitive advantage, Academy of Managewent Review, 23, 660-79.

Eaton, B. Curtis and Mukesh Eswaran, 1997, Technology trading coalitions in supergames, Rand Journal of Economics, 28(1), 135-149.

European Commission, 2005, New proposals for growth and jobs under the next financial framework 2007-13. EC-IP/05/389.

Faems, Dries, Bart Van Looy, and Koenraad Debackere, 2004, The role of InterOrganizational Collaboration within Innovation Strategies: Towards a Portfolio Approach, working paper, Katholieke Universiteit Leuven, forthcoming in: Journal of Product Innovation Management.

Fernandez-Bagues, Manuel, 2003, Complementarity in innovation strategies: evidence from pharmaceutical dynamic panel data. Paper presented at the $30^{\text {th }}$ EARIE conference in Helsinki.

Fontana, Roberto, Aldo Geuna, and Mireille Matt, 2004, Firm size and openness: the driving forces of university-industry collaboration. Paper presented at the EARIE 2004 conference, Berlin 2-5 September, 2004.

Fors, Gunnar, 1996, Utilization of R\&D results in the home and foreign plants of multinationals, Journal of Industrial Economics, 45(3), 341-358.

Fritsch, Michael and Rolf Lukas, 2001, Who cooperates on R\&D? Research Policy 30, 297-312.

Fuss, Melvyn, Daniel McFadden, and Yair Mundlak, 1978, A survey of functional forms in the economic analysis of production, in M. Fuss and D. McFadden (eds.), Production Economics: a dual approach to theary and applications, Vol. 1, Amsterdam: North-Holland, 219-268.

Gans, Joshua and Scott Stem, 2000, Incumbency and R\&D incentives: licencing the gale of creative destruction, Journal of Economics and Management Strategy, 9(4), 485-511.

Garcia-Quevedo, Jose, 2004, Do Public Subsidies Complement Business R\&D? A Meta-analysis of the Econometric Evidence. Kyklos, 57(1), 87-102.

Genz, A, 1993, Comparison of methods for the computation of multivariate normal Probabilities. Compuring Science and Statistics 25, 400-05.

Geroski, Paul, 1991, Innovation and the sectoral sources of UK productivity growth. The Economic Journal, 101, 1438-1451. 
Geroski, Paul, Steve Machin and John van Reenen, 1993, The profitability of innovating firms. Rand Joumal of Economics, 24(2), 198-211.

Geweke, John, Michael Keane, and David Runkle, 1997, Statistical inference in the multinomial multiperiod probit model. Joumal of Econometrics, 80, 125-165.

Globerman, Steven, 1979, Foreign Direct Investment and 'Spillover' Efficiency' Benefits in Canadian Manufacturing Industries. Canadian Journal of Economics, 12(1), 42-56.

Goto, Akira, Tadahisa Koga, Kazuyuki Suzuki, 2002, Determinants of Industrial R\&D in Japanese Manufacturing Industries. Economic Review (Keizai Kenkyu), 53(1), 18-23.

Granstrand, Ove, Pari Patel and Keith Pavitt, 1997, Multi-technology corporations: why they have "distributed" rather than "distinctive core" competences. California Management Review, 39(4), 8-25.

Granstrand, Ove, Erik Bohlin, C. Oskarson, N. Sjöberg, 1992b, External technology acquisition in large multitechnology corporations. $R \& D$ Management, 22(2), $111-113$.

Greene, William, 2004, Convenient estimators for the panel probit model. Empirical Economics, 29(1), 21-47

Griffith, Rachel, 1999, Using the ARD establishment level data to look at foreign ownership and productivity in the United Kingdom. Economic Journal, 109: 416-42.

Griffith, Rachel, Stephen Redding, and John van Reenen, 2003, R\&D and absorptive capacity: theory and empirical evidence. Scandinavian Journal of Economics, $105(1), 99-118$.

Griffith Rachel, Stephen Redding, Jolin Van Reenen, 2004, Mapping The Two Faces Of R\&D: Productivity Growth In A Panel Of OECD Industries. Review of Economics and Statistics, 86(4), 883-895.

Griliches, Zvi, and Jacques Mairesse, 1984, Productivity and R\&D at the firm level. In R\&D, Patents and Productivity. Z. Griliches (ed.). Chicago Press.

Griliches, Zvi, 1979, Issues in assessing the contribution of Research and Development to productivity growth. Bell Journal of Economics, 10, 92-116.

Griliches, Zvi and Frank Lichtenberg, 1984a, Inter-industry knowledge flows and productivity growth. Review of Economics and Statistics, 66, 324-329.

Griliches, Zvi and Frank Lichtenberg, 1984b, R\&D productivity growth at the industry level: is there still a relationship? In Z. Griliches (Ed.), R\&D. Patents, and Productivity, Chicago: NBER and University of Chicago Press, 1984.

Griliches, Zvi, 1995, Paul Stoneman (ed.), Handbook of the Economics of Innovation and Technological Change, Blackwell Publishers, Oxford.

Gouriéroux, Cristian, Alberto Holly, and Alain Monfort, 1982, Likelihood ratio test, Wald test, and Kuhn-Tucker test in linear models with inequality constraints on the regression parameters. Econometrica 50(1), 63-80. 
Guellec, Dominique and Bruno van Pottelsberghe de la Potterie, 2003, The impact of public R\&D expenditure on business R\&D. Economics of Innovation and New Technology, 12(3), 225-43.

Gulati, Ranjay, 1995, Social structure and alliance formation patterns: A longitudinal analysis. Administrative Science Quarterly, 40(4), 619-652.

Hagedoorn, John, 1993, Understanding the rational of strategic technology partnering: inter-organizational modes of cooperation and sectoral differences. Strategic Management Journal, 14(5), 371-85.

Hagedoorn, John, 2002, Inter-firm R\&D partnerships: an overview of major trends and patterns since 1960. Research Policy 31: 477-492.

Hagedoorn, John, Albert Link and Nicholas Vonortas, 2000, Research Partnerships. Research Policy 29 (4-5): 567-86

Hajivassiliou, Vassilis, Daniel McFadden, and Paul Ruud, ,1996, Simulation of multivariate normal rectangle probabilities and their derivatives: Theoretical and computational results. Journal of Econometrics 72: 85-134.

Hall, Bronwyn, Albert Link, and John Scott, 2003, Universities as Research Partners, Review of Economics and Statistics, 85(2), 485-491.

Hall, Bronwyn and Jacques Mairesse, 1995, Exploring the relationship between R\&D and productivity in French manufacturing firms. Journal of Econometrics, 65, 263-93.

Hall, Bronwyn and John van Reenen, 2000, How effective are fiscal incentives for R\&D? A review of the evidence. Research Policy, 29(4/5), 449-460.

Hanel, Petr and Alain St-Pierre, 2002, Effects of R\&D spillovers on the profitability of firms. Review of Industrial Organization, 20(4), 305-22.

Hamel, G., 1991, Competition for competence and inter-partner learning within international strategic alliances. Strategic Management Journal, 12, 83-103.

Harrigan, K., 1986, Strategic alliances and partner asymmetries. Management International Review, 28: 5 -72.

Harris, R. and C. Robinson, 2003, Foreign ownership and productivity in the United Kingdom estimates for the U.K. using ARD. Review of Industrial Organization 22: 207-23.

Henderson, Rebecca and Kim Clark, 1990, Arehitectural innovation: the reconfiguration of existing product technologies and the failure of established firms. Administration Science Quarterly, 35(1), 9-30.

Hennart, Jean-Francois, 1988, A transaction cost theory of equity joint ventures. Strategic Management Journal 9: 361-374.

den Hertog, Rene and Roy Thurik, 1993, Determinants of Internal and External R\&D: Some Dutch Evidence. De Economist, 1993, 141(2), 279-89.

Himmelberg, Charles and Bruce Petersen, 1994, R\&D and Internal Finance: A Panel Study of Small Firms in High-Tech Industries, Review of Economics and Siatistics, 76, 51 . 
Hines, James Jr., 1994, No Place Like Home: Tax Incentives and the Location of R\&D by American Multinationals, in: Poterba, James M., ed., Tax policy and the economy, Volume 8, Cambridge: MIT Press for the National Bureau of Economic Research,65-1.04.

Hines, James Jr., 1995, Taxes, Technology Transfer, and R\&D by Multinational Firms, in: M. Feldstein, J.R. Hines, R.G. Hubbard, eds., Taxing multinational corporations. National Bureau of Economic Research Project Report. Chicago and London: University of Chicago Press, 51-62.

Holemans, Benni and Leo Sleuwaegen, 1988, Innovation expenditures and the role of government in Belgium. Research Policy, 17, 375-79.

Holmstrom, Bengt and Paul Milgrom, The firm as an incentive system. American Economic Review, 84(4), 972-91

Howells, Jeremy, Andrew James, and Khaleel Malik, 2004, Sourcing external technological knowledge: a decision support framework for firms. International Journal of Technology Management, 2004, 27(2/3), 143-155.

Huergo, Elena and Jordi Jaumandreu, 2004, Firm's age, process innovation and productivity growth. International Journal of Industrial Organization, 22(8/9), 541-60.

Ichniowski, Casey, Kathryn Shaw, and Giovanna Prennushi, 1997, The effects of human resource management practices on productivity. American Economic Review 87, 291-313.

Inkman, J. and W. Pohlmeier, 1995, R\&D spillovers, technological distance and Innovation success, University of Konstanz, mimeograph.

Jaffe, Adam, 1986, Technological opportunity and spillovers of R\&D: evidence from firm's patents, profits, and market value. American Economic Review 76(5): 584-1001.

Janz, Norbert, Lööf, Hans and Bettina Peters, 2003, Firm level innovation and productivity - is there a common story across countries. ZEW working paper dp0326

Judson, Ruth and Ann Owen, 1999, Estimating dynamic panel data models: a guide for macroeconomists. Economic Letters, 65, 9-15.

Kaiser, Ulrich, 2002a, An empirical test of models explaining research expenditures and research cooperation: evidence for the German service sector. International Journal of Industrial Organization 20, 747-774.

Kaiser, Ulrich, 2002b, Measuring knowledge spillovers in manufacturing and services: an empirical assessment of alternative approaches. Research Policy, $31,125-44$.

Kamien, Morton, and Israel Zang, 2000, Meet me halfway: research joint ventures and absorptive capacity. International Journal of Industrial Organization 18, 995-1012.

Kamien, Morton, Eitan Muller, and Israel Zang, 1992, Research joint ventures and R\&D cartels. American Economic Review 82(5), 1293-1992. 
Katsoulacos, Kannis and David Ulph, 1998, Endogenous spillovers and the performance of research joint ventures. Journal of Industrial Economics 46 : $333-357$.

Katrak, Homi, 1985, Imported technology, enterprise size and R\&D in a newly industrializing country: the Indian experience. Oxford Bulletin of Economics Statistics, $47(3), 213-30$

Katrak, Hom, 1989, Imported technologies and R\&D in a newly industrializing country. Jowmal of Development Economics, 31(1), 123-40

Katz, Michae]. 1986, An analysis of cooperative research and development. The Rand Jownal of Economics 17, 527-543.

Kesteloot, Katrien and Reinhilde Veugelers, 1995, Stable R\&D cooperation with spillovers. Joumal of Economics and Management Strategy 4(4): 651-672.

Kitazawa, Y., 2001, Exponential regression of dynamic panel data models, Economics Lerters, 73, 7-13.

Klette, Tor J., and Frode Johansen, 1998, Accumulation of R\&D capital and dynamic firm performance: a not-so-fixed effect model. Annales d'Economie et de Statistique, 49/50, 389-419.

Klette, Tor, Jacob Møen and Zvi Griliches, 2000, Do subsidies to commercial R\&D reduce market failures? Microeconometric evaluation studies, Research Policy, 290( 4/5), 471-495.

Klette, Tor J., 1996, R\&D, scope economies and plant performance, The RAND Journal of Economics, 27(3), 502-522.

Kleinknecht, Alfred and Jeroen Reijnen, 1992, Why do firms cooperate on R\&D? An empirical study. Research Policy 21: 347-360.

Kline, Jude, 2000, Research joint ventures and the cost paradox, International Jounal of Industrial Organization, 18, 1049-65.

Klevorick, Alvin K., Richard C. Levin, Richard R. Nelson, Sidney G. Winter, 1995, On the sources and significance of interindustry differences in technological opportunities. Research Policy 24, 185-205.

Klomp, Lutk and George van Leewwen, 2001, Linking innovation and firm performance: a new approach. International Joumal of the Economics of Business, 8(3), 343-64.

Kodde, David and Franz Palm, 1986, Wald criteria for jointly testing equality and inequality restrictions. Econometrica 54(5), 1243-48.

Kogut, Bruce, 1988, Joint ventures: theoretical and empirical perspectives. Sitrategic Management Journal 9: 319-332.

Kudo, Akio, 1963, A multivariate analogue of the one-sided test. Biometrika 50 : $403-18$.

Kuemmerle, Walter, 1998, Optimal scale for research and development in foreign environments: An investigation into size and performance of research and development laboratories abroad. Research Policy, 27, 111-126. 
Kumar, Nagesh, 1987, Technology Imports and Local Research and Development in Indian Manufacturing; Developing Economies; 25(3), 220-33

Laursen, Keld and Ammon Salter, 2004, Open for innovation: the role of openness in explaining the innovation performance among UK manufacturing firms. Paper presented at the DRUID Summer Conference, 2004.

Leahy, Dermont and Peter Neary, 1997, Public policy towards R\&D in oligopolistic industries. American Economic Review 87(4), 642-662.

Leeuwen, George van, 2002, Linking innovation to productivity growth using two waves of CIS, CEREM working paper 0202.

Lee, Chang-Yang, 2003, A simple theory and evidence on the determinants of firm R\&D. Economics of Innovation and New Technology, 12(5), 385-395.

Leeuwen, George van, and Luuk Klomp, 2001, On the Contribution of Innovation to Multi-Factor Productivity Growth, Paper presented at the Eindhoven Centre for Innovation Studies (ECIS) conference, 20-23 September 2001.

Leiponen, Aija, 2001, Why do firms not collaborate? The role of competencies and technological regimes, in: A. Kleinknecht and P. Mohnen (eds.), Innovarion and Firm Performance: Econometric Exploration of Survey Data, Palgrave, pp. 253-277.

Leiponen, Aija, 2004, Skills and innovation, Working paper, Cornell University.

Levin, Richard and Peter Reiss, 1984, Tests of a Schumpeterian Model of R\&D and Market Structure, in: Zvi Griliches, ed., R\&D, Patents and Productivity, The University of Chicago Press, Chicago and London, 175-204.

Levy, David, 1990, Estimating the Impact of Government R\&D. Economics Letters. 32(2), 169-73.

Levy, Frank and Richard Murnane, 1996, With what skills are computers a complement? American Economic Review, 86(2), 258-62.

Leyden, Dennis Patrick and Albert Link, 1999. Federal laboratories as research partners, International Journal of Industrial Organization, 17, 575-92.

Lichtenberg, Frank and Donald Siegel, 1991, The Impact of R\&D Investment on Productivity - New Evidence Using Linked R\&D-LRD Data. Economic Inquiry, 29(2), 203-29.

Lichtenberg, Frank, 1987, The Effect of Government Funding on Private Industrial Research and Development: A Re-assessment. Journal of Industrial Economics, 36(1), 97-104.

Lin, Ping and Kamal Saggi, 2002, Product differentiation, process R\&D, and the nature of market competition, European Economic Review, 46, 201-11.

Lisbon Review, 2004, The assessment of policies and reforms in Europe, principle authors: Jennifer Blanke and Augusto Lopez-Claros.

Lokshin, Boris, René Belderbos and Martin Carree, 2004, Testing for complementarity and substitutability in case of multiple practices. METEOR memorandum RM04002, University of Maastricht. 
Löoff, Hans and Almas Heshmati, 2002, Knowledge capital and performance heterogeneity: a firm-level innovation study. International Joumal of Production Economics, $76(1), 61-85$.

Lobf, Hans, 2002, Essays in the economics of innovation. The knowledge production function: evidence from new micro data. Doctoral dissertation, Royal Institute of Technology, Stockholm, Sweden.

Love, James and Stephen Roper, 1999, The determinants of innovation: R\&D, technology transfer and networking effects. Review of Industrial Organization $15,43-64$.

Love, James and Stephen Roper, 2002, Internal vs. external R\&D: a study of R\&D choice with sample selection. International Journal of Economics and Business, 9(2), 239-55.

Lowe, Julian and Peter Taylor, 1998, R\&D and technology purchase through licence agreements: complementary strategies and complementary assets. R\&D Management, 28(4), 263-278.

Mairesse, Jacques, Bronwyn Hall and B. Mulkay, 1999, Firm-level investment in France and United States: an exploration of what we have learned in twenty years. Annales d'Économie et de la Statistique 55/56, 27-67.

Mairesse, Jacques and Mohammed Sassenou, 1991, R\&D and productivity: a survey of econometric studies at the firm level, NBER working paper No 3666, Cambridge, MA.

Mamuneas, Theofanis and Ishaq Nadiri, 1996, Public R\&D Policies and Cost Behavior of the US Manufacturing Industries. Journal of Public Economics, 63(1), 57-81.

Martin, Stephen, 1994, Private and social incentives to form $\mathbb{R} \& D$ joint ventures, Review of Industrial Organization, 9, 157-71

Martin, Stephen, 1995, R\&D joint ventures and tacit product market collusion, European Journal of Political Economy, 11, 733-41.

Martin, Stephen, 2002, Spillovers, appropriability, and R\&D, Journal of Economics, $75(1), 1-32$.

Mackinnon, James and Anthony Smith Jr., 1998, Approximate bias correction in econometrics, Joumal of Econometrics 85, 205-230.

Mackun, Paul and Alan MacPherson, 1997, Externally-assisted product innovation in the manufacturing sector: The role of location, in-house R\&D and outside technical support. Regional-Studies, 31(7), 659-668.

Milgrom, Paul and Joln Roberts, 1990, The economics of modern manufacturing: technology, strategy, and organization. American Economic Review 80, 51128.

Milgrom, Paul and John Roberts, 1995, Complementarities and fit: Strategy, structure and organizational change in manufacturing. Journal of Accounting and Economics 19, 179-208. 
Miotti, Luis and Fréderique Sachwald, 2003, Co-operative R\&D: why and with whom: and integrated framework of analysis, Research Policy, 32, 1481-99.

Miravete, Eugenio and Jose Pernias, 2004, Innovation Complimentarity and Scale of Production C.E.P.R. Discussion Papers, CEPR Discussion Papers: 4483

Mohnen, Pierre and Normand Lepine, 1991, R\&D, R\&D Spillovers and Payments for Technology: Canadian Evidence, Structural Change and Economic Dynamics, 2(1), 213-28.

Mohnen, Pierre and Lars-Hendrick Röller, 2005, Complementarities in innovation policy. European Economic Review, forthcoming.

Mohnen, Pierre and Cathy Hoareau, 2003, What type of enterprises forges close links with universities and government labs? Managerial decision economics $24,133-45$.

Monjon, Stéphanie and Patrick Waelbroeck, 2003, Assessing Spillovers from Universities to Firms: Evidence from French firm-level data, International Journal of Industrial Organization, 21 (9), 1255-1270.

Mora-Valentin, Eva, Angeles Montoro-Sanchez and Luis Guerras-Martin, 2004, Determining factors in the success of $R \& D$ cooperative agreements between firms and research organizations, Research Policy 33, 17-40.

Nakamura, Masao, 2003, Research alliances and collaborations: Introduction to the special issue, Managerial and Decision Economics, March-May 2003, 24 (23), pp. 47-49

Narula, Rajneesh, 2001, Choosing between internal and non-internal R\&D activities: some technological and economic factors. Technology Amalysis and Strategic Management, 13(3), 365-387.

Narula, Rajneesh, 2002, R\&D collaboration by SMEs: Some analytical issues and evidence, in F.J. Contractor and P. Lorange (eds.), Cooperative Strategies and Alliances, pp. 543-566, Pergamon, Amsterdam.

National Science Foundation, 2002, Research and development in industry, NSF02312, project officer, and principle author Raymond Wolfe (Arlington, VA).

Nooteboom, B. 1999. Inter-firm alliances - analysis and design. London, Routledge.

Ocasio, William, 1997, Towards an attention-based view of the firm. Sirategic Management Journal 18: 187-206

OECD, 1992, Technology and the economy. OECD, Paris

OECD, 2002, Science, technology and industry outlook. OECD, Paris

Pakes, Ariel and Mark Schankerman, 1984, An Exploration into the Determinants of R\&D Intensity, in: Zvi Griliches, ed., R\&D, Patents, and Productivity, The University of Chicago Press, Chicago and London, 209-232.

Panagopoulos, Andreas, 2003, Understanding when universities and firms form RIVs: The importance of intellectual property protection. International Journal of Industrial Organization, 21(9), 1411-33.

Pavitt, Keith, 1984, Sectoral patterns of technical change: Towards a taxonomy and a theory, Research Policy $13(6), 343-373$ 
Pfaffermayr, Michael, 1999, Ownership advantages, foreign production and productivity: evidence from Austrian manufacturing firms. Review of Industrial Organization. 15(4), 379-96.

Piga, Caludio, and Marco Vivarelli, 2004, Internal and external R\&D: a sample selection approach. Oxford Bulletin of Economics and Statistics, 66(4), 457482.

Pisano, Garry, 1990, The R\&D boundaries of the firm: an empirical analysis. Administrative Science Quarterly, 35, 153-177.

Poyago-Theotoky, Joanna, 1995, Equilibrium and optimal size of a research joint venture in an oligopoly with spillovers. Journal of Industrial Economics, $43(2), 209-26$.

Rahm, Dianne, Kirkland, John and Bozeman, Barry, 2000, University-industry $R \& D$ collaboration in the United States, the United Kingdom, and Japan, vol. 1. Dordrecht; Boston and London: Kluwer Academic.

Raymond, Wladimir, Pierre Mohnen, Franz Palm, and Sybram Schim van der Loeff, 2004, An empirically-based taxonomy of Dutch manufacturing: innovation policy implications. METEOR working paper series, University of Maastricht

Robson, Martin, 1993, Federal funding and the level of private expenditures on basic research. Southern Economic Joumal, 60, 63-71.

Röller, Lars-Hendrik, Milikel Tombak and Ralph Siebert, 1997, Why firms form Research Joint Ventures: theory and evidence. CEPR Discussion Paper H1654.

Rosenkrantz, Stephanie, 2003, Simultaneous choice of process and product innovation when consumers have a preference for product variety, Journal of Economic Behavior and Organization, 50, 183-201.

Sakakibara, Mariko, 1997, Heterogeneity of firm capabilities and cooperative research and development: An empirical examination of motives. Strategic Management Journal 18, 134-164.

Saviotti, Pier Paolo, 1998, On the dynamics of appropriability, of tacit and of codified knowledge. Research Policy, 26(7-8), 843-56.

Scherer, Frederic, 1982, Inter-industry flows and productivity growth. Review of Ecomomics and Statistics, 64(4), 627-34.

Schmookler, 1966, Invention and economic growth. Cambridge MA: Harvard University Press.

Shapiro, Alexander, 1985, Asymptotic distribution of test statistics in the analysis of moment structures under inequality consraints. Biometrika $72(1), 133-44$.

Shapiro, Alexander, 1987, A conjecture related to chi-bar-squared distributions. American Mathematical Monthly 94, 46-48.

Siegel, Donald, Paul Westland and Mike Wright, 2003, Assessing the impact of university science parks on research productivity: exploratory firm-level evidence from the United Kingdom. International Journal of Industrial Organization 21, 1357-1369. 
Spence, Michael, 1984, Cost reduction, competition and industry performance. Econometrica 52(1): 101-121.

Steurs, Geert, 1995, Inter-industry R\&D spillovers: what difference do they make? International Joumal of Industrial Organization 13:249-276.

Sun, H-J., 1988, A General reduction method for n-variate normal orthant probability. Communication in Statistical-Theoretical Methods 17(11): 39133921.

Suzuki, Kazuyuki, 1993, R\&D Spillovers and Technology Transfer Among and Within Vertical Keiretsu Groups: Evidence from the Japanese Electrical Machinery Industry, International Journal of Industrial Organization, 11, 573-591.

Suzumura, Kotaro, 1992, Cooperative and noncooperative $\mathbb{R} \& D$ in oligopoly with spillovers. American Economic Review. 82(5): 1307-1320.

Teece, David, 1980, The diffusion of an administrative innovation. Management Science, 26: 464-70.

Tether, Bruce, 2002, Who co-operates for innovation, and why: an empirical analysis. Research Policy 31, 947-967.

Toivanen Otto and Petri Niininen, 2000, Investment, R\&D subsidies and credit constraints, WP-246, Helsinki School of Economics.

Topkis, Donald, 1998. Supermodularity and Complimentarity. Princeton University Press.

Tyler, Beverly and H. Kevin Steensma, 1995, Evaluating technological collaborative opportunities: a cognitive modeling perspective. Sirategic Management Journal 16, 43-70.

Train, Kenneth, 2002, Discrete choice methods with simulation. Cambridge University Press.

Vanhaverbeke, W.P.M., Duysters, G.M. \& Beerkens, B.E., 2002, Technology capability building through networking strategies within high-tech industries. In: Academy of Management best paper proceedings. Denver, Colorado: Academy of Management.

Verspagen, Bart, 1999, Large firms and knowledge flows in the Dutch R\&D system: A case study of philips electronics. Technology Analysis and Sirategic Management, 11(2), 211-33.

Veugelers, Reinhilde, 1997, Internal R\&D Expenditures and External Technology Sourcing. Research Policy 26(3), 303-15.

Veugelers, Reinhilde and Bruno Cassiman, 1999, Make and buy in innovation strategies: evidence from Belgian manufacturing firms. Research Policy, 28, 63-80.

Veugelers, Reinhilde and Bruno Cassiman, 2003, R\&D Cooperation between Firms and Universities, some empirical evidence from Belgian Manufacturing, Onderzoeksrapport 0325, DTEW, KULeuven and CEPR Discussion paper 2157 , London 
Vivero, Rafael, 2004, The Impact of Process Innovations on Firm's Productivity Growth: The Case of Spain. Applied Economics, 34, 1007-16.

Vonortas, Nicolas, 1994, Inter-firm cooperation with imperfectly appropriable research. International Journal of Industrial Organization 12, 413-435

Von Hippel, 1988, The Sources of Imnovation. New York: Oxford University Press.

Wallsten, Scott, 2000, The Effects of Govemment-Industry R\&D Programs on Private R\&D: The Case of the Small Business Innovation Research Program. RAND Joumal of Economics, 31(1), 82-100.

ter Weel, Bas, 2002, The computerization of the labor market. Doctoral thesis, University of Maastricht.

Wolak, Frank, 1989, Testing inequality constraints in linear econometric models. Journal of Econometrics 41, 205-35.

Wolak, Frank, 1991, The local nature of hypothesis tests involving inequality constraints in nonlinear models. Econometrica 59, 981-95.

Wu, Changqi and John Wei, 1998, Cooperative R\&D and the value of the firm, Review of Industrial Organization, 13, 425-446. 


\section{Nederlandse samenvatting (Summary in Dutch)}

\section{Onderzoek en Ontwikkeling: intern, extern en in samenwerkingsverband en gevolgen voor bedrijfsprestaties.}

\section{Inleiding}

Het economische fenomeen van korte tot middellange termijn samenwerking in O\&O (Onderzoek en Ontwikkeling) is de laatste tijd steeds belangrijker geworden. Een aantal factoren, zoals hoge vaste aanvangskosten voor onderzoek en ontwikkeling, en risico's gerelateerd aan vercommercialisering van innovaties, hebben bijgedragen aan deze trend. Tegelijkertijd is er wederzijds begrip onder economen en politici, weergegeven in de Lissabon agenda, dat het delen van kennis het creëren van nieuw kenniskapitaal kan versnellen. Dit delen van kennis door coöperatieve O\&O overeenkomsten is in een versnelling geraakt door de recente verschuivingen in de markt, zoals in zake toenemende technische complexiteit, het korter worden van de vernieuwingscycli en afnemende transactiekosten van verworven technologie van buiten het bedrijf. Met als resultaat dat de bedrijven niet langer alleen vertrouwen op eigen interne $O \& O$ activiteiten om zo hun technische concurrentie positie te kunnen handhaven.

Dit proefschrift heeft tot doel om een beter begrip te krijgen van het fenomeen van samenwerking in $O \& O$, contractuele en interne $O \& O$ en de invloed daarvan op de productiviteit van het bedrijf en innovatieve prestaties van bedrijven. De doelstelling van dit onderzoek was drieledig. Het eerste doel betrof het beantwoorden van de vraag wat bedrijven stimuleert zich bezig te houden met diverse soorten $O \& O$ samenwerkingsovereenkomsten. Het tweede doel was vast te stellen welk effect zo'n samenwerking heeft op de productiviteit en innovatie bij bedrijven, gemeten als groei in de verkoop met betrekking tot introductic van nieuwe producten op de markt. Het derde doel was de complementariteit te onderzoeken tussen interne, externe en collectieve O\&O strategieën .

Determinanten van samenwerking bij $O \& O$ en de effecten op bedriffsresultaten

Ten einde de onderzoeksdoelen te bereiken, is gekozen dit proefschrift te laten bestaan uit vijf empirische verhandelingen. Hoofdstuk 2 concentreert zich vooral op de determinanten van samenwerking op het gebied van $O \& O$, hierbij onderscheid makend tussen de verschillende types: verticalle (leveranciers, klanten), horizontale (concurrenten) en institutionele (universiteiten en onderzoekslaboratoria) $0 \& 0$ sa- 
menwerking. Er is een omvangrijke set van determinanten geanalyseerd en daarbij is speciaal aandacht geschonken aan verschillende overvloei-effecten, een centraal thema in de industriêle organisatie literatuur op het gebied van samenwerking in O\&O. Eén van onze belangrijkste bevindingen is dat samenwerking met een partner beduidend waarschijnlijker is als de kennis van buitenaf afkomstig van dat type partner belangrijk is voor het innovatieproces wan het bedrijf. Samen met bet resultaat dat enkele andersoortige overvloei-effecten niet significant zijn in ons model, zou dit er op duiden dat facilitering van de instroom van kennis uit specifieke bronnen samenwerking bij $O \& O$ aantrekkelijker kan maken voor bedrijven. Een andere bevinding in hoofdstuk 2 is dat kennis die overvloeit vanuit universiteiten en onderzoeksinstituten samenwerking van alle soorten bevordert. Dit wijst erop dat deze kennis van nature generieker is en dat het de technologische mogelijkheden en algemene effectiviteit verbetert van de $O \& O$ activiteiten en $O \& O$ samenwerkingsstrategieén van bedrijven.

Hoofdstuk 3 onderzoekt de effecten van samenwerking op het gebied van O\&O op de productiviteit en innovativiteit van bedrijven. De analyse onderscheidt, net zoals in hoofdstuk 2, verschillende soorten O\&O partners en bekijkt twee prestatiematen: arbeidsproductiviteit en productiviteit in zake verkoop van nieuwe producten voor de markt. De resultaten bevestigen een duidelijke heterogeniteit in de beweegredenen en doelen van $0 \& 0$ samenwerkingsverbanden. Samenwerking tussen concurrent en leverancier is gericht op vernieuwingen die de productiviteit van bedrijven verbeteren, terwijl samenwerking met universiteiten en ook weer tussen concurrenten belangrijk is bij het creëren en op de markt brengen van meer radicale innovaties, die de verkoop van producten op gang brengen die nieuw voor de markt zijn en derhalve de groei van bedrijven bevorderen. De bevindingen uit hoofdstuk 3 leveren enige ondersteuning voor de gedachte dat samenwerkende bedrijven zich over het algemeen bezighouden met innovatieve activiteiten op een hoger niveau. Dit gaat onmiskenbaar op voor bedrijven die samenwerken met universiteiten (bijvoorbeeld om toegang te krijgen tot fundamenteel onderzoek) en concurrenten (om O\&O mogelijk te maken voor risicovolle projecten), maar niet voor bedrijven die zich bezighouden met 'verticale samenwerking' met leveranciers en klanten. Als de laatstgenoemde vorm van samenwerking zich ook gedeeltelijk richt op meer "radicale' vernieuwingen, dan is er geen bewijs in onze analyses, dat deze pogingen een positief effect hebben op het op de markt brengen van nieuwe producten. Dit sluit niet uit dat een minderheid van zulke samenwerkingsvormen, bijvoorbeeld 'coproducentschap' tussen bedrijven en belangrijke leveranciers, wat meer fundamentele en radicale inspanningen in zake vernieuwend onderzoek met zich meebrengen.

Het belangrijkste inzicht uit de analyse, beschreven in de hoofdstukken 2 en 3 , is dat samenwerking op het gebied en O\&O niet als een totalverzameling moet worden gezien, maar eerder dat horizontale, verticale en institutionele koppelingen allemaal verschillende motieven hebben en wisselend bijdragen aan de productiviteit. $\mathrm{Zij}$ hebben echter gemeenschappelijk dat de neiging tot 
samenwerking voor een belangrijk deel bepaald wordt door overvloeiende kennis. De resultaten van het onderzoek hebben ook belangrije consequenties voor beleid. De resultaten uit hoofdstuk 2 geven aan dat bevordering van het uitwisselen en delen van informatie, samen met de meer traditionele 080 subsidies, bijdragen tot een effectief instrument voor een beleid dat tot doel heeft O\&O samenwerkingsverbanden te bevorderen. Daarbij zou het stimuleren van samenwerking in O\&O een positief effect kunnen hebben op innovatieve output en productiviteit. Volgens deze studie zou een beleid van bevordering van $0 \& 0$ privaat/publieke samenwerking, bijvoorbeeld met universiteiten en onderzoeksinstituten, leiden tot een toename van de innovatieve output.

\section{Complementariteiten bij interne, externe O\&O en O\&O in samenwerkings- verbanden}

Een aanzienlijk deel van dit proefschrift is gewijd aan de analyse van complementariteit in O\&O innovatiestrategieèn. Dit aspect is mogelijk belangrijk, ondat in het geval van meerkeuze-beslissingsvariabelen (bijvoorbeeld verschillende samenwerkingsverbanden), deze allemaal complementair moeten zijn om de zekerheid te hebben dat toenamen daarin wederzijds aanvullend zijn. In hoofdstuk 4 hebben we een test ontwikkeld ten aanzien van complementariteit en substitutie gebruikmakend van een outputfunctie benadering waarin meerdere inputs zijn opgenomen. In de test procedure wordt gebruik gemaakt wan kleinste kwadraten met ongelijkheidrestricties. De analytische oplossing wordt voor het algemene geval gegeven en er wordt een voorbeeld gegeven voor het geval van drie en vier inputs.

Hoofdstuk 5 bestudeert de mogelijke complementariteiten in samenwerkingsstrategieën, zo zjj invloed hebben op de groei van arbeidsproductiviteit binnen een grote steekproef van innovatieve Nederlandse bedrijven. We passen een passende tijdsvertraging toe, waarbinnen het effect van $0 \& O$ samenwerking van eerdere perioden leidt tot productiviteitsgroei en we gebruiken de in hoofdstuk 4 ontwikkelde testmethode. De empirische resultaten in zake complementariteiten zijn niet eenduidig. Complementariteit wordt zowel voor samenwerkingsstrategieern met concurrenten en klanten gevonden als met klanten en universiteiten. Dit zou kunnen worden gerelateerd aan de rol van samenwerking met klanten bij het faciliteren van commercialisatie en snellere verspreiding van productvernieuwing die is toe te schrijven aan de samenwerking met concurrenten of universiteiten. Tegelijkertijd werd een asntal gevallen gevonden waar de combinatie van samenwerkingsstrategieën heeft geleid tot mindere prestaties: samenwerking met leveranciers gecombineerd met samenwerking met universiteiten of met concurrenten of samenwerkingsverbanden met concurrenten gecombineerd met samenwerking met universiteiten. De eerstgenoemde resultaten kunnen worden verklaard uit uiteenlopende doelstellingen van samenwerkingsverbanden: samenwerkende leveranciers neigen zich meer te focussen op kostenbesparingen, stapsgewijze innovatie en procesinno- 
waties. Deze yernieuwingsstrategie zou misschien moeilijker te combineren zijn met pogingen tot vernieuwing die meer radicale pogingen met zich meebrengen en productwernieuwingen die geassocieerd kunnen worden met samenwerking met universiteit en concurrent. De combinatie van samenwerking tussen concurrent en universiteit kan te lijden hebben van bedreigingen in zake de mate waarin $O \& O$ resultaten kunnen worden toegeëigend, als kennis vanuit de universiteit misschien lekt naar concurrenten die niet betrokken zjjn bij de samenwerking. Al deze effecten worden gevonden voor kleine bedrijwen, terwijl geen significant effect wordt gevonden voor grotere bedrijven.

Het belangrijkste inzicht uit dit deel van het onderzoek ligt in de betekenis van het effect van complementariteit binnen O\&O samenwerkingsstrategieën. Onze bevindingen bevestigen een positieve impact van $O \& O$ samenwerking op de groei van arbeidsproductiviteit (hoofdstuk 3), maar met duidelijke verschillen in belangrijkheid en significantie van invloeden, afhankelijk van (combinaties van) verschillende types samenwerkingsverbanden. Wij concluderen dat bedrijven die innovatiestrategieën combineren een hoger (vernieuwend) prestatieniveau bereiken dan vergelijkbare bedrijven die vertrouwen op een enkele innovatiestrategie. Tegelijkertijd hebben we een toenemende complexiteit opgemerkt ten aanzien van betrokkenheid in verschillende strategieën. Dit heeft een contraproductief (beperkend) effect, speciaal bij kleine bedrijven.

\section{Interne, externe $O \& O$ en absorptie-capaciteit}

Hoofdstuk 6 levert op microniveau econometrisch bewijs dat er een substantiële productiviteitswinst is, die bedrijven kunnen bereiken door interne en externe $O \& O$ bronnen te combineren. De analyse is gebaseerd op de resultaten van een dynamisch arbeidsproductiviteitmodel, geschat met GMM en een recent ontwikkelde onzuiverheidgecorrigeerde schattingstechniek, waarbij gebruik gemaakt wordt van een panel van innovatieve Nederlandse bedrijven. Ons belangrijkste model in dit hoofdstuk is een niet-lineaire specificatie, die rekening houdt met een mogelijkheid van schaalvoordelen en voordelen in het samen uitvoeren van verschillende activiteiten in O\&O. De resultaten wijzen op complementariteit (supermodulariteit) bij de combinatie van interne en externe $0 \& 0$, het geen verenigbaar is met de veelvuldige gezamenlijke toepassing van interne en externe $O \& O$ strategieën. Het positieve effect van een combinatie van beide types $O \& O$ is echter slechts aanwezig wanneer er substantieel interne $O \& O$ aanwezig is. Deze bevindingen onderschrijven de dubbelrol die gespeeld wordt door interne $\mathrm{O} \& \mathrm{O}$, benadrukt in recent onderzoek op macroniveau. De eerste rol van onderzoek en ontwikkelingsactiviteiten binnen het bedrijf zelf is in het stimuleren van vernieuwing en productiviteit. De tweede rol, niet minder belangrijk volgens de in dit hoofdstuk verkregen resultaten, is de rol als absorptiecapaciteit, nodig om voordeel te halen uit de extern verkregen O\&O. De schattin- 
gen van kwadratische specificaties wijzen op sterker afnemende meeropbrengsten in uitgaven apart voor interne dan wel externe O\&O.

Derhalve, kan het combineren van interne en externe $O \& O$ eerder de resultaten verbeteren dan het focussen op maar één type $0 \& 0$, ondanks het bestaan van een negatieve interactie tussen de twee $O \& O$ strategieèn in het lineaire model.

Een belangrijke conclusie uit dit hoofdstuk is dat interne $0 \& O$ zowel aanvullend is op externe $O \& O$, als de absorptiecapaciteit van het bedrijf vergroot.

De analyse suggereert dat een onderzoeker, om correcte gevolgtrekkingen te maken omtrent complementariteit, gebruik moet maken van een meer algemene, niet-lineaire, specificatie van een model en een geschikte testmethode dient toe te passen. Een verklaring hiervoor is dat uitgaven voor $O \& O$ zowel schaalvoordelen als voordelen in het gelijktijdig uitvoeren van verschillende activiteiten met zich mee kunnen brengen. 


\section{Curriculum Vitae}

Boris Lokshin was born on 10 February 1975 in Kharkiv, Ukraine. He did his undergraduate studies (receiving BA cum laude) at Kharkiv National University and St. Norbert College, Wisconsin, USA. In 2002 he received an MA degree in economics from. University of Indiana, USA after which he joined the Strategy research group at the Faculty of Economics and Business Administration, University of Maastricht as a $\mathrm{PhD}$ candidate. Boris has published two articles, originating from the present study, in international refereed journals and several working papers in METEOR research series. He also presented his work on numerous occasions to conferences. 